\title{
Total Synthesis of (-)-Dictyostatin
}

Gregory W. O’Neil and Andrew J. Phillips*

Department of Chemistry and Biochemistry, University of Colorado, Boulder, CO 80309-0215

\section{SUPPORTING INFORMATION}

\section{General Experimental Procedures.}

${ }^{1} \mathrm{H}$ and ${ }^{13} \mathrm{C}$ NMR spectra were recorded at $25{ }^{\circ} \mathrm{C}$ on Varian Inova spectrometers at the indicated frequencies using $\mathrm{CDCl}_{3}$ as the solvent unless otherwise indicated. Inverse detect spectra were obtained with a Varian 3mm PFG indirect detect probe with jnxh $=8.3 \mathrm{~Hz}$ and ${ }^{1} \mathrm{~J}_{\mathrm{CH}}=130 \mathrm{~Hz}$. Coupling constants are reported in hertz, Hz. All non-aqueous reactions were run in flame-dried glassware under a dry $\mathrm{N}_{2}$ atmosphere. Toluene, THF, $\mathrm{CH}_{2} \mathrm{Cl}_{2}$, and $\mathrm{Et}_{2} \mathrm{O}$ were obtained from Aldrich (Pure-Pac) and further dried by passage through activated alumina as described by Bergman and Grubbs. ${ }^{1}$ All flash chromatography was performed with normal phase silica gel (Sorbent Technologies, 32-63 $\mu \mathrm{m}$ particle size, $60 \AA$ pore size), following the general protocol of Still. ${ }^{2}$

\section{Diisopropyl-\{1-[2-(4-methoxy-benzyloxy)-1-methyl-ethyl]-allyloxy\}-prop-1-ynyl-silane, 6}

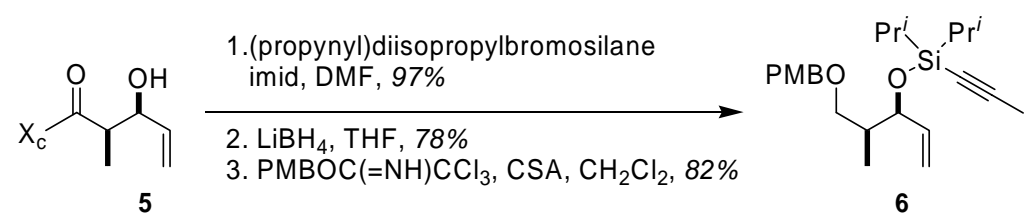

To a stirred solution of oxazolidinone 5 (5.00 g, $17.30 \mathrm{mmol}, 1.0 \mathrm{eq})$ in DMF (35 mL) was added imidazole (2.94 g, $43.35 \mathrm{mmol}, 2.5 \mathrm{eq}$ ) and bromo(diisopropyl)propynyl silane (4.84 g, $20.76 \mathrm{mmol}, 1.2$ eq) and the reaction was warmed to rt. The reaction was stirred for $1 \mathrm{~h}$ and was then diluted with water $(100 \mathrm{~mL})$ and $\mathrm{Et}_{2} \mathrm{O}(100 \mathrm{~mL})$. The organic phase was dried over $\mathrm{MgSO}_{4}$, filtered, and concentrated in vacuo. The crude product was purified by flash chromatography ( $25 \% \mathrm{Et}_{2} \mathrm{O} / \mathrm{hexanes}$ ) to yield the intermediate silyl ether (7.40 g, 97\%) as an oil.

${ }^{1} \mathbf{H}$ NMR (500 MHz, $\left.\mathrm{CDCl}_{3}\right): \delta 7.36(\mathrm{t}, J=7 \mathrm{~Hz}, 2 \mathrm{H}), 7.30(\mathrm{~m}, 1 \mathrm{H}), 7.25(\mathrm{~d}, J=7 \mathrm{~Hz}, 2 \mathrm{H}), 5.93$ (m, $1 \mathrm{H}), 5.25$ (dt, $J=1.5,17 \mathrm{~Hz}, 1 \mathrm{H}), 5.15$ (dt, $J=1,10.5 \mathrm{~Hz}, 1 \mathrm{H}), 4.63$ (m, 1H), 4.17 (m, 3H), 4.03 (m, 1H), 3.32 (dd, $J=3,13.5 \mathrm{~Hz}, 1 \mathrm{H}$ ), 2.80 (dd, $J=9.5,13 \mathrm{~Hz}, 1 \mathrm{H}$ ), 1.92 (s, 3H), 1.27 (d, $J=7 \mathrm{~Hz}, 3 \mathrm{H}$ ), 1.01-1.08 (m, 12H), 0.96 (m, 2H); ${ }^{13} \mathrm{C}$ NMR (100 MHz, $\left.\mathrm{CDCl}_{3}\right): \delta$ 174.77, 153.45, 139.03, 135.70, 129.71 (2C), 129.16 (2C), 127.53, 116.19, 105.31, 78.95, 76.38, 66.18, 55.96, 44.46, 38.01, 17.54, $17.43,17.21,17.04,13.92,13.35,12.67,5.01$.

To a stirred solution of the intermediate silyl ether $(5.00 \mathrm{~g}, 11.30 \mathrm{mmol}, 1.0 \mathrm{eq})$ in $\mathrm{THF}(68 \mathrm{~mL})$ at $0{ }^{\circ} \mathrm{C}$ was added a 1M solution of $\mathrm{LiBH}_{4}$ in THF (45.20 mL, $\left.4.0 \mathrm{eq}\right)$. The reaction was stirred for $6 \mathrm{~h}$ and was then quenched with saturated $\mathrm{NH}_{4} \mathrm{Cl}$. The organic phase was separated and then washed with water and saturated aqueous $\mathrm{NaCl}$, dried over $\mathrm{MgSO}_{4}$, and concentrated in vacuo. The crude product was purified

\footnotetext{
${ }^{1}$ a) Alaimo, P. J.; Peters, D.W.; Arnold, J.; Bergman, R.G. J. Chem. Educ. 200178 64. b) Pangborn, A. B.; Giardello, M. A.; Grubbs, R. H.; Rosen, R.K.; Timmers, F. J. Organometallics 1996, 15, 151.

${ }^{2}$ Still, W.C.; Kahn, M.; Mitra, A. J. Org. Chem. 1978, 43, 2923.
} 
by flash chromatography (10\% EtOAc/hexanes) to yield the intermediate alcohol $(2.40 \mathrm{~g}, 78 \%)$ as an oil.

${ }^{1}$ H NMR (400 MHz, $\left.\mathrm{CDCl}_{3}\right): \delta 5.87(\mathrm{~m}, 1 \mathrm{H}), 5.24(\mathrm{dt}, J=2,17.2 \mathrm{~Hz}, 1 \mathrm{H}), 5.17(\mathrm{dt}, J=1.6,10.4 \mathrm{~Hz}$, 1H), $4.52(\mathrm{~m}, 1 \mathrm{H}), 3.66(\mathrm{t}, J=10.8 \mathrm{~Hz}, 1 \mathrm{H}), 3.47(\mathrm{~m}, 1 \mathrm{H}), 2.85(\mathrm{~b}, 1 \mathrm{H}), 1.96(\mathrm{~m}, 1 \mathrm{H}), 1.94(\mathrm{~s}, 3 \mathrm{H}), 1.00$ - $1.07(\mathrm{~m}, 12 \mathrm{H}), 0.91(\mathrm{~m}, 2 \mathrm{H}), 0.77(\mathrm{~d}, J=6.8 \mathrm{~Hz}, 3 \mathrm{H}) ;{ }^{13} \mathbf{C}$ NMR $\left(400 \mathrm{MHz}, \mathrm{CDCl}_{3}\right): 138.53,115.46$, 105.55, 79.18, 75.84, 65.16, 41.29, 17.57, 17.40, 17.34 (2C), 13.86, 13.17, 11.09, 4.97.

To a stirred solution of the intermediate alcohol (2.40 g, $8.80 \mathrm{mmol}, 1.0 \mathrm{eq})$ in $\mathrm{CH}_{2} \mathrm{Cl}_{2}$ (35 mL) was added PMB-trichloroacetimidate $(2.24 \mathrm{~g}, 7.92 \mathrm{mmol}, 0.9 \mathrm{eq})$ and the solution was cooled to $-10{ }^{\circ} \mathrm{C}$. CSA $(0.184 \mathrm{~g}, 0.792 \mathrm{mmol}, 0.1 \mathrm{eq})$ was then added and the reaction warmed to rt. The reaction was stirred for $10 \mathrm{~h}$ and was then quenched with saturated $\mathrm{NaHCO}_{3}$, the layers were separated, and the organic layer was dried over $\mathrm{MgSO}_{4}$, filtered, and concentrated in vacuo. The crude product was purified by flash chromatography ( $10 \% \mathrm{Et}_{2} \mathrm{O} /$ hexanes) to yield $\mathbf{6}(2.80 \mathrm{~g}, 82 \%)$ as an oil.

${ }^{1}$ H NMR (500 MHz, CDCl $\left.)_{3}\right): \delta 7.31$ (d, $\left.J=9 \mathrm{~Hz}, 2 \mathrm{H}\right), 6.90(\mathrm{~d}, J=8.5 \mathrm{~Hz}, 2 \mathrm{H}), 5.84(\mathrm{~m}, 1 \mathrm{H}), 5.22$ (dt, $J=1.5,17.5 \mathrm{~Hz}, 1 \mathrm{H}), 5.11(\mathrm{dt}, J=1.8,10.5 \mathrm{~Hz}, 1 \mathrm{H}), 4.51$ (d, $J=11.5 \mathrm{~Hz}, 1 \mathrm{H}), 4.46$ (m, 1H), 4.42 (d, $J$ $=11.5 \mathrm{~Hz}, 1 \mathrm{H}), 3.83(\mathrm{~s}, 3 \mathrm{H}), 3.61(\mathrm{dd}, J=6,9 \mathrm{~Hz}, 1 \mathrm{H}), 3.28(\mathrm{dd}, J=7.5,9 \mathrm{~Hz}, 1 \mathrm{H}), 1.96(\mathrm{~m}, 1 \mathrm{H})$, $1.904(\mathrm{~s}, 1 \mathrm{H}), 1.0-1.1(\mathrm{~m}, 14 \mathrm{H}), 0.95$ (d, $J=7 \mathrm{~Hz}, 3 \mathrm{H}) ;{ }^{13} \mathbf{C}$ NMR $\left(100 \mathrm{MHz}, \mathrm{CDCl}_{3}\right): \delta 159.24,139.69$, 131.21, 129.38 (2C), 114.81, 113.91 (2C), 104.64, 79.44, 79.54, 72.84, 72.66, 55.50, 40.30, 17.68, 17.57, 17.49, 13.89, 13.40, 12.09, 5.02 (2C); [ $\alpha]_{\mathbf{D}}-17.7$ (c 0.5, $\mathrm{CHCl}_{3}$ ); IR (thin film): 2989, 2120, 1247, 1066, 985, $911 \mathrm{~cm}^{-1}$; HRMS (ESI): calculated for $\mathrm{C}_{23} \mathrm{H}_{36} \mathrm{O}_{3} \mathrm{SiNa}^{+} 411.2325$, found 411.2323 .

3-Ethylidene-2,2-diisopropyl-5-[2-(4-methoxy-benzyloxy)-1-methyl-ethyl]-4-methyl$[1,2]$ oxasilolane, 7

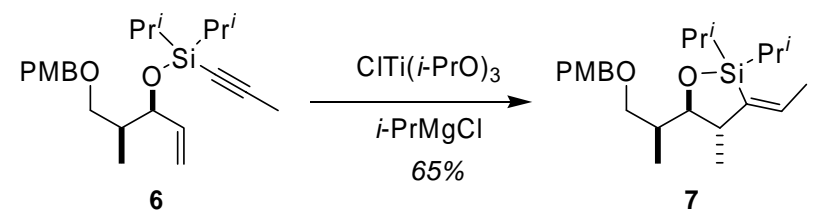

To a solution of $\mathrm{Ti}(\mathrm{i}-\mathrm{PrO})_{3} \mathrm{Cl}(0.503 \mathrm{~g}, 1.93 \mathrm{mmol}, 3.0 \mathrm{eq})$ in $\mathrm{Et}_{2} \mathrm{O}(6.40 \mathrm{~mL})$ at $-40{ }^{\circ} \mathrm{C}$ was added (siloxy)enyne 6 ( $0.25 \mathrm{~g}, 0.64 \mathrm{mmol}, 1.0 \mathrm{eq})$ and a $2 \mathrm{M}$ solution of $i$-PrMgCl $(1.93 \mathrm{~mL}, 3.86 \mathrm{mmol}, 6.0$ eq) via syringe pump over $2 \mathrm{~h}$. The reaction was stirred an additional $6 \mathrm{~h}$, quenched with saturated $\mathrm{NH}_{4} \mathrm{Cl}(25 \mathrm{~mL})$, and stirred with EtOAc $(50 \mathrm{~mL})$ for $1 \mathrm{~h}$. The mixture was filtered through Celite, the layers were separated, and the organic phase dried over $\mathrm{MgSO}_{4}$, filtered, and concentrated in vacuo. The crude product was purified by flash chromatography $\left(40 \% \mathrm{CH}_{2} \mathrm{Cl}_{2} /\right.$ hexanes $)$ to yield siloxane 7 $(0.162 \mathrm{~g}, 65 \%)$ as an oil.

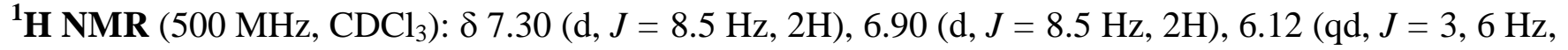
1H), 4.75 (m, 1H), 4.48 (m, 1H), 3.83 (s, 3H), 3.59 (dd, $J=7.5,9 \mathrm{~Hz}, 1 \mathrm{H}), 3.55$ (dd, $J=2,10 \mathrm{~Hz}, 1 \mathrm{H}$ ), 3.43 (dd, $J=6.5,8.5 \mathrm{~Hz}, 1 \mathrm{H}), 2.30(\mathrm{~m}, 1 \mathrm{H}), 2.00(\mathrm{~m}, 1 \mathrm{H}), 1.80$ (dd, $J=2.5,6.5 \mathrm{~Hz}, 3 \mathrm{H}), 1.07-1.16$ (m, 5H), 1.03 (d, $J=7 \mathrm{~Hz}, 6 \mathrm{H}), 0.99$ (d, $J=6.5 \mathrm{~Hz}, 6 \mathrm{H}), 0.91$ (d, $J=6.5 \mathrm{~Hz}, 3 \mathrm{H}) ;{ }^{13} \mathbf{C}$ NMR $(100 \mathrm{MHz}$, $\mathrm{CDCl}_{3}$ ): $\delta 159.21,142.83,131.82,131.27,129.36$ (2C), 113.92, 83.24, 74.30, 73.01, 55.49, 42.24,

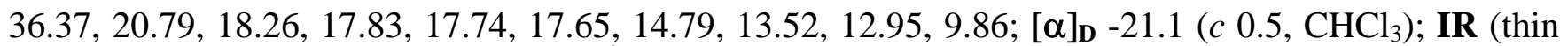
film): 2948, 1610, 1508, 1037, $832 \mathrm{~cm}^{-1}$; HRMS (ESI) calculated for $\mathrm{C}_{23} \mathrm{H}_{38} \mathrm{O}_{3} \mathrm{SiNa}^{+}$413.2482, found 413.2488. 


\section{Acrylic acid 1-[2-(4-methoxy-benzyloxy)-1-methyl-ethyl]-2-methyl-pent-3-enyl ester, 8}

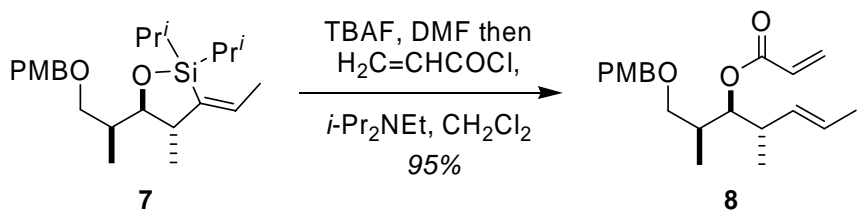

To a stirred solution of siloxane $7(0.162 \mathrm{~g}, 0.416 \mathrm{mmol}, 1.0 \mathrm{eq})$ in DMF (2.10 mL) was added $\mathrm{TBAF} \cdot \mathrm{H}_{2} \mathrm{O}(0.33 \mathrm{~g}, 1.25 \mathrm{mmol}, 3.0 \mathrm{eq})$ and the reaction was heated to $75^{\circ} \mathrm{C}$ for $6 \mathrm{~h}$. The reaction was cooled to rt and diluted with $\mathrm{Et}_{2} \mathrm{O}$ and water. The organic phase was separated, dried over $\mathrm{MgSO}_{4}$, filtered through a plug of silica with EtOAc, and concentrated in vacuo. This material was used directly in the next step.

${ }^{1} \mathbf{H}$ NMR (500 MHz, $\left.\mathrm{CDCl}_{3}\right): \delta 7.28(\mathrm{~d}, J=8 \mathrm{~Hz}, 2 \mathrm{H}), 6.90(\mathrm{~d}, J=8.5 \mathrm{~Hz}, 2 \mathrm{H}), 5.57(\mathrm{~m}, 1 \mathrm{H}), 5.38$ (ddd, $J=1.5,8.5,15$ Hz, 1H), 4.47 (m, 2H), 3.83 (s, 3H), 3.56 (dd, $J=6,9$ Hz, 1H), 3.46 (m, $2 \mathrm{H}$ ), 2.22 (m, 1H), $1.98(\mathrm{~m}, 1 \mathrm{H}), 1.72$ (dd, $J=1.5,6 \mathrm{~Hz}, 3 \mathrm{H}), 0.95$ (d, $J=7 \mathrm{~Hz}, 3 \mathrm{H}) ;{ }^{13} \mathbf{C}$ NMR $(100 \mathrm{MHz}$, $\left.\mathrm{CDCl}_{3}\right): \delta 159.35,134.63,130.73,129.43$ (2C), 126.89, 113.97 (2C), 75.82, 74.72, 73.19, 55.45, 41.15, 35.16, 18.31, 17.30, 10.02 .

To a stirred mixture of the intermediate alcohol in $\mathrm{CH}_{2} \mathrm{Cl}_{2}(2.10 \mathrm{~mL})$ at $0^{\circ} \mathrm{C}$ was added $i-\mathrm{Pr}_{2} \mathrm{NEt}(0.108$ g, $0.832 \mathrm{mmol}, 2.0 \mathrm{eq}$ ), DMAP (0.001 g, $0.042 \mathrm{mmol}, 0.1 \mathrm{eq}$ ) and acryloyl chloride (0.056 g, 0.624 mmol, $1.5 \mathrm{eq})$ and the reaction was warmed to rt. The reaction was stirred for $6 \mathrm{~h}$ and was then quenched with saturated aq. $\mathrm{NaHCO}_{3}$. The layers were separated and the organic phase was dried over $\mathrm{MgSO}_{4}$, filtered, and concentrated in vacuo. The crude product was purified by flash chromatography to yield 8 (0.131 g, 95\% over 2 steps) as an oil.

${ }^{1}$ H NMR (400 MHz, $\mathrm{CDCl}_{3}$ ): $\delta 7.25$ (d, $\left.J=8.4,2 \mathrm{H}\right), 6.87$ (d, $\left.J=8.8 \mathrm{~Hz}, 2 \mathrm{H}\right), 6.36$ (dd, $J=2,17.2 \mathrm{~Hz}$, 1H), 6.09 (dd, $J=10,17.2 \mathrm{~Hz}, 1 \mathrm{H}$ ), 5.79 (dd, $J=1.2,10.4 \mathrm{~Hz}, 1 \mathrm{H}$ ), 5.33 (m, 2H), 4.97 (dd, $J=4.8,7.2$ Hz, 1H), 4.41 (d, $J=11.6 \mathrm{~Hz}, 1 \mathrm{H}), 4.36$ (d, $J=11.6 \mathrm{~Hz}, 1 \mathrm{H}), 3.80$ (s, 3H), 3.31 (dd, $J=6,8.8 \mathrm{~Hz}, 1 \mathrm{H})$, 3.24 (dd, $J=6.8,8.8 \mathrm{~Hz}, 1 \mathrm{H}), 2.38(\mathrm{~m} 1 \mathrm{H}), 2.09(\mathrm{~m}, 1 \mathrm{H}), 1.59$ (d, $J=6 \mathrm{~Hz}, 3 \mathrm{H}), 0.95$ (d, $J=5.2 \mathrm{~Hz}$, $3 \mathrm{H}), 0.93(\mathrm{~d}, J=5.2 \mathrm{~Hz}, 3 \mathrm{H}) ;{ }^{13} \mathrm{C}$ NMR (100 MHz, $\left.\mathrm{CDCl}_{3}\right): \delta 166.08,159.31,132.91,130.80,130.39$, 129.51 (2C), 129.04, 126.17, 113.94 (2C), 77.43, 73.07, 72.77, 55.50, 39.71, 35.34, 18.13, 17.82, 11.89; $[\alpha]_{\mathbf{D}}-4.5$ (c 0.5, $\mathrm{CHCl}_{3}$ ); IR (thin film): 2990, 2930, 2810, 1715, 1634, 1527, 1262, 974, $905 \mathrm{~cm}^{-1}$; HRMS (ESI) calculated for $\mathrm{C}_{20} \mathrm{H}_{28} \mathrm{O}_{4} \mathrm{Na}^{+} 355.1879$, found 355.1890.

\section{1-(4-Methoxy-benzyloxy)-2,4-dimethyl-octa-5,7-dien-3-ol, 9}
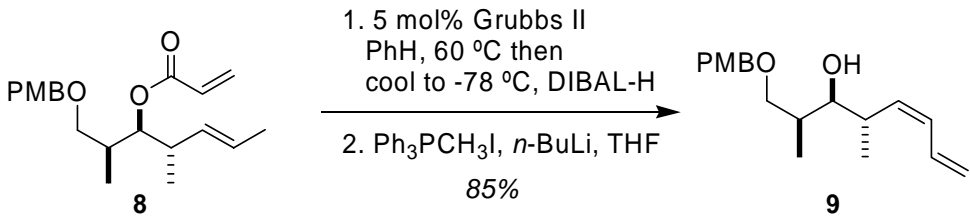

To a stirred solution of the diene $8(0.131 \mathrm{~g}, 0.395 \mathrm{mmol}, 1.0 \mathrm{eq})$ in toluene $(8.00 \mathrm{~mL})$ was added Grubbs 2nd generation catalyst $(0.0335 \mathrm{~g}, 0.0395 \mathrm{mmol}, 0.1 \mathrm{eq})$ and the reaction was warmed to $60{ }^{\circ} \mathrm{C}$. The reaction was stirred for $3 \mathrm{~h}$ and was then cooled to $-78{ }^{\circ} \mathrm{C}$ and a $1 \mathrm{M}$ solution of DIBAL-H in toluene $(0.395 \mathrm{~mL}, 0.395 \mathrm{mmol}, 1.0 \mathrm{eq})$ was added over $30 \mathrm{~min}$ via syringe pump. The reaction was stirred an additional $15 \mathrm{~min}$, then quenched with saturated $\mathrm{Na}_{2} \mathrm{SO}_{4}(25 \mathrm{~mL})$. The mixture was stirred with EtOAc (50 mL) $1 \mathrm{~h}$, and was then filtered through Celite, and the layers were separated. The 
organic phase was dried over $\mathrm{MgSO}_{4}$, filtered, and concentrated in vacuo. The crude material was used 4 without further purification.

${ }^{1} \mathbf{H}$ NMR (500 MHz, $\left.\mathrm{CDCl}_{3}\right): \delta 7.26(\mathrm{~d}, J=8.5 \mathrm{~Hz}, 2 \mathrm{H}), 6.86(\mathrm{~d}, J=8.5 \mathrm{~Hz}, 2 \mathrm{H}), 6.67(\mathrm{dt}, J=10.5$, $16.5 \mathrm{~Hz}, 1 \mathrm{H}), 6.04$ (t, $J=11 \mathrm{~Hz}, 1 \mathrm{H}), 5.55$ (t, $J=10 \mathrm{~Hz}, 1 \mathrm{H}) 5.22$ (d, $J=17 \mathrm{~Hz}, 1 \mathrm{H}), 5.12$ (d, $J=10.5$ Hz, 1H), 4.58 (d, $J=11 \mathrm{~Hz}, 1 \mathrm{H}), 4.46$ (d, $J=11 \mathrm{~Hz}, 1 \mathrm{H}), 3.80$ (s, 3H), 3.61 (dd, $J=7,11 \mathrm{~Hz}, 1 \mathrm{H}), 3.53$ (dd, $J=5,10.5 \mathrm{~Hz}, 1 \mathrm{H}), 3.41$ (dd, $J=4,6 \mathrm{~Hz}, 1 \mathrm{H}$ ), 3.00 (dt, $J=6,10 \mathrm{~Hz}, 1 \mathrm{H}), 1.97$ (m, $1 \mathrm{H}$ ), 1.03 (d, $J$ $=6.5 \mathrm{~Hz}, 3 \mathrm{H}), 0.88(\mathrm{~d}, J=7 \mathrm{~Hz}, 3 \mathrm{H})$.

To a stirred solution of methyltriphenylphosphonium bromide $(0.423 \mathrm{~g}, 1.185 \mathrm{mmol}, 3.0 \mathrm{eq})$ in THF $(3.00 \mathrm{~mL})$ at $0{ }^{\circ} \mathrm{C}$ was added a $1.6 \mathrm{M}$ solution of butyllithium in hexanes $(0.74 \mathrm{~mL}, 1.185 \mathrm{mmol}, 3.0 \mathrm{eq})$ and the solution was stirred for $5 \mathrm{~min}$. The solution was then cooled to $-78{ }^{\circ} \mathrm{C}$ and the intermediate lactol was added as a solution in THF $(0.21 \mathrm{~mL})$. The reaction mixture was warmed to $0{ }^{\circ} \mathrm{C}$ for $1 \mathrm{~h}$ and was then quenched with $1 / 2$ saturated $\mathrm{NH}_{4} \mathrm{Cl}(25 \mathrm{~mL})$. The mixture was extracted with EtOAc $(3 \times 25$ $\mathrm{mL}$ ), and the combined organic extracts dried over $\mathrm{MgSO}_{4}$, filtered, and concentrated in vacuo. The crude product was purified by flash chromatography (25\% EtOAc/hexanes) to yield 9 (0.098 g, 85\% over 3 steps) as an oil.

${ }^{1} \mathbf{H}$ NMR (500 MHz, $\mathrm{CDCl}_{3}$ ): $\delta 7.28$ (d, $\left.J=8.5 \mathrm{~Hz}, 2 \mathrm{H}\right), 6.90(\mathrm{~d}, J=8.5 \mathrm{~Hz}, 2 \mathrm{H}), 6.65$ (dt, $J=10.5,17$ $\mathrm{Hz}, 1 \mathrm{H}), 6.14$ (t, $J=11 \mathrm{~Hz}, 1 \mathrm{H}), 5.40$ (t, $J=10.5 \mathrm{~Hz}, 1 \mathrm{H}), 5.25$ (d, $J=17 \mathrm{~Hz}, 1 \mathrm{H}), 5.15$ (d, $J=10 \mathrm{~Hz}$, $1 \mathrm{H}), 4.48$ (d, $J=11.5 \mathrm{~Hz}, 1 \mathrm{H}), 4.45$ (d, $J=11.5 \mathrm{~Hz}, 1 \mathrm{H}), 3.83$ (s, 3H), 3.52-3.58 (m, 2H), 3.49 (dd, $J=$ 5, $9 \mathrm{~Hz}, 1 \mathrm{H}), 2.80(\mathrm{~m}, 1 \mathrm{H}), 2.00(\mathrm{~m}, 1 \mathrm{H}), 0.99(\mathrm{~d}, J=7 \mathrm{~Hz}, 3 \mathrm{H}), 0.97$ (d, $J=7 \mathrm{~Hz}, 3 \mathrm{H}) ;{ }^{13} \mathbf{C}$ NMR $(100$ $\mathrm{MHz}, \mathrm{CDCl}_{3}$ ): 159.39, 135.68, 132.48, 130.59, 129.50 (3C), 118.28, 113.99 (2C), 76.55, 74.64, 73.22, 55.51, 36.06, 35.30, 17.49, 10.18; $[\alpha]_{\mathbf{D}}-18.8$ (c 0.5, $\mathrm{CHCl}_{3}$ ); IR (thin film): 2989, 2853, 2721, 1613, 1524, 1253, $1037 \mathrm{~cm}^{-1}$; HRMS (ESI) calculated for $\mathrm{C}_{18} \mathrm{H}_{26} \mathrm{O}_{3} \mathrm{Na}^{+}$313.1774, found 313.1774.

\section{2-(4-Methoxy-phenyl)-5-methyl-4-(1-methyl-penta-2,4-dienyl)-[1,3]dioxane, 10}

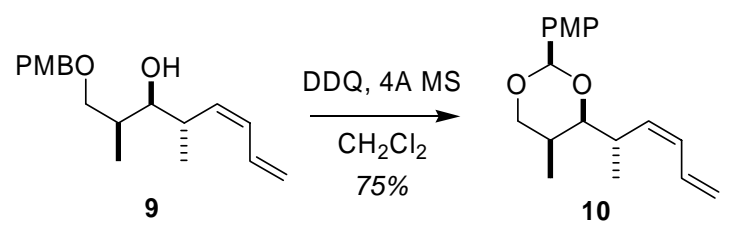

To a stirred solution of diene alcohol 9 (98 mg, $0.336 \mathrm{mmol}, 1.0 \mathrm{eq})$ in $\mathrm{CH}_{2} \mathrm{Cl}_{2}(3.40 \mathrm{~mL})$ at $0{ }^{\circ}$ over freshly activated 4 Á MS was added DDQ (76 mg, $0.336 \mathrm{mmol}, 1.0 \mathrm{eq})$. The reaction was stirred for 30 min and was then quenched with $\mathrm{pH}=7$ buffer $(25 \mathrm{~mL})$. The mixture was extracted with $\mathrm{CH}_{2} \mathrm{Cl}_{2}(3 \mathrm{x}$ $25 \mathrm{~mL}$ ), and the combined organic extracts were dried with $\mathrm{MgSO}_{4}$, filtered, and concentrated in vacuo. The crude product was purified by flash chromatography (25\% Et $2 \mathrm{O} /$ hexanes) to provide 10 (73 mg, 78 $\%)$ as an oil.

${ }^{1}$ H NMR (500 MHz, $\left.\mathrm{CDCl}_{3}\right): \delta 7.40(\mathrm{~d}, J=9 \mathrm{~Hz}, 2 \mathrm{H}), 6.87(\mathrm{~d}, J=9 \mathrm{~Hz}, 2 \mathrm{H}), 6.70(\mathrm{dt}, J=10.8,16.5$ $\mathrm{Hz}, 1 \mathrm{H}), 6.07$ (t, $J=11 \mathrm{~Hz}, 1 \mathrm{H}), 5.45$ (s, 1H), 5.39 (t, $J=10 \mathrm{~Hz}, 1 \mathrm{H}), 5.21$ (d, $J=17 \mathrm{~Hz}, 1 \mathrm{H}), 5.12$ (d, $J=10 \mathrm{~Hz}, 1 \mathrm{H}), 4.07$ (m, 2H), 3.81 (s, 3H), 3.61 (dd, $J=2,9 \mathrm{~Hz}, 2 \mathrm{H}), 2.90$ (m, 1H), 1.73 (m, $1 \mathrm{H}), 1.22$ (d, $J=7 \mathrm{~Hz}, 3 \mathrm{H}), 0.99$ (d, $J=6.5 \mathrm{~Hz}, 3 \mathrm{H}) ;{ }^{13} \mathrm{C}$ NMR (100 MHz, $\left.\mathrm{CDCl}_{3}\right):$ 159.87, 135.97, 133.27, 129.86, 127.43 (2C), 117.26, 113.61, 101.51, 83.56, 74.08, 55.50, 34.33, 30.25, 29.94, 16.24, 11.33; $[\alpha]_{\mathbf{D}}-28.4$ (c 0.5, $\left.\mathrm{CHCl}_{3}\right)$; IR (thin film): 2955, 2927, 2853, 1617, 1518, 1459, 1382, 1157, $1101 \mathrm{~cm}^{-1}$; HRMS (ESI) calculated for $\mathrm{C}_{18} \mathrm{H}_{24} \mathrm{O}_{3} \mathrm{Na}^{+} 311.1617$, found 311.1613. 
[4-(4-Methoxy-benzyloxy)-3,5-dimethyl-2-oxo-nona-6,8-dienyl]-phosphonic-acid dimethyl ester, 4

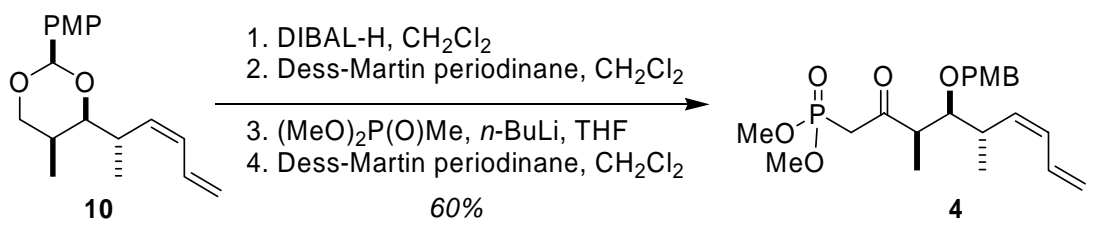

To a solution of PMP-acetal 10 (0.073 g, $0.252 \mathrm{mmol}, 1.0 \mathrm{eq})$ in $\mathrm{CH}_{2} \mathrm{Cl}_{2}(2.50 \mathrm{~mL})$ at $0{ }^{\circ} \mathrm{C}$ was added DIBAL-H (0.1075 g, $0.756 \mathrm{mmol}, 3.0 \mathrm{eq})$. The reaction was stirred $3 \mathrm{~h}$ and was then quenched with saturated $\mathrm{Na}_{2} \mathrm{SO}_{4}(25 \mathrm{~mL})$. EtOAc $(50 \mathrm{~mL})$ was then added and the mixture stirred for $1 \mathrm{~h}$, then filtered through Celite, and the layers were separated. The organic phase was dried over $\mathrm{MgSO}_{4}$, filtered, and concentrated in vacuo. The crude product was used without further purification.

${ }^{1} \mathbf{H}$ NMR (500 MHz, $\left.\mathrm{CDCl}_{3}\right): \delta 7.25$ (d, $\left.J=9 \mathrm{~Hz}, 2 \mathrm{H}\right), 6.85(\mathrm{~d}, J=8.5 \mathrm{~Hz}, 2 \mathrm{H}), 6.66(\mathrm{dt}, J=10.5,17$ Hz, 1H), 6.03 (t, $J=11 \mathrm{~Hz}, 1 \mathrm{H}), 5.54$ (t, $J=10.5 \mathrm{~Hz}, 1 \mathrm{H}), 5.21$ (d, $J=17.5 \mathrm{~Hz}, 1 \mathrm{H}), 5.11(\mathrm{t}, J=10 \mathrm{~Hz}$, $1 \mathrm{H}), 4.57$ (d, $J=10.5 \mathrm{~Hz}, 1 \mathrm{H}), 4.45$ (d, $J=10.5 \mathrm{~Hz}, 1 \mathrm{H}), 3.79$ (s, 3H), 3.60 (dd, $J=7,10.5 \mathrm{~Hz}, 1 \mathrm{H}$ ), 3.53 (dd, $J=5,10.5 \mathrm{~Hz}, 1 \mathrm{H}), 3.40$ (dd, $J=4,5.5 \mathrm{~Hz}, 1 \mathrm{H}), 2.99$ (dt, $J=7,10, \mathrm{~Hz}, 1 \mathrm{H}), 1.96$ (m, $1 \mathrm{H}$ ), 1.02 (d, $J=7 \mathrm{~Hz}, 3 \mathrm{H}), 0.95$ (d, $J=7 \mathrm{~Hz}, 3 \mathrm{H})$.

To a solution of the intermediate alcohol in $\mathrm{CH}_{2} \mathrm{Cl}_{2}(2.50 \mathrm{~mL})$ at $0{ }^{\circ} \mathrm{C}$ was added Dess-Martin periodinane ( $0.16 \mathrm{~g}, 0.378 \mathrm{mmol}, 1.5 \mathrm{eq})$. The solution was stirred for $45 \mathrm{~min}$ and was then quenched with $\mathrm{Na}_{2} \mathrm{SO}_{3}$-doped saturated $\mathrm{NaHCO}_{3}$ solution. The mixture was stirred vigorously for 30 min (until the organic layer was clear) and then the two layers were separated. The organic phase was washed with water, dried over $\mathrm{MgSO}_{4}$, filtered, and concentrated to yield the intermediate aldehyde as a pale yellow oil that was used immediately in the next step.

${ }^{1} \mathbf{H}$ NMR $\left(500 \mathrm{MHz}, \mathrm{CDCl}_{3}\right): \delta 9.72(\mathrm{~d}, J=1 \mathrm{~Hz}, 1 \mathrm{H}), 7.25(\mathrm{~d}, J=8.5 \mathrm{~Hz}, 2 \mathrm{H}), 6.88(\mathrm{~d}, J=6.5 \mathrm{~Hz}$, 2H), 6.58 (dt, $J=10.5,17 \mathrm{~Hz}, 1 \mathrm{H}), 6.07$ (t, $J=11 \mathrm{~Hz}, 1 \mathrm{H}), 5.47$ (t, $J=10 \mathrm{~Hz}, 1 \mathrm{H}), 5.24(\mathrm{~d}, J=16.5 \mathrm{~Hz}$, $1 \mathrm{H}), 5.15$ (d, $J=10 \mathrm{~Hz}, 1 \mathrm{H}), 4.50(\mathrm{~m}, 2 \mathrm{H}), 3.83$ (s, 3H), 3.73 (t, $J=5 \mathrm{~Hz}, 1 \mathrm{H}), 2.99$ (m, $1 \mathrm{H}), 2.62$ (m, 1H), 1.19 (d, $J=7 \mathrm{~Hz}, 3 \mathrm{H}), 1.09$ (d, $J=7 \mathrm{~Hz}, 3 \mathrm{H})$.

To a solution of (dimethyl)methylphosphonate (94 mg, $0.756 \mathrm{mmol}, 3.0 \mathrm{eq})$ in THF $(1.50 \mathrm{~mL})$ at $-78{ }^{\circ} \mathrm{C}$ was added a $1.6 \mathrm{M}$ solution of butyllithium in hexanes $(470 \mu \mathrm{L}, 0.756 \mathrm{mmol}, 3.0 \mathrm{eq})$. The reaction was stirred for $30 \mathrm{~min}$ and then the aldehyde obtained above was added as a solution in THF $(0.50 \mathrm{~mL})$. The reaction mixture was stirred for $30 \mathrm{~min}$, warmed to $0{ }^{\circ} \mathrm{C}$ for $15 \mathrm{~min}$, and was then quenched with saturated $\mathrm{NH}_{4} \mathrm{Cl}$ solution. The mixture was extracted with EtOAc and the combined organic extracts dried over $\mathrm{MgSO}_{4}$, filtered, and concentrated in vacuo to yield the intermediate $\beta$-hydroxy phosphonate. This material was dissolved in $\mathrm{CH}_{2} \mathrm{Cl}_{2}(2.50 \mathrm{~mL})$, cooled to $0{ }^{\circ} \mathrm{C}$ and Dess-Martin periodinane $(0.16 \mathrm{~g}$, $0.378 \mathrm{mmol}, 1.5 \mathrm{eq}$ ) was added. The reaction was warmed to rt, stirred for $1 \mathrm{~h}$ and was then quenched with $\mathrm{Na}_{2} \mathrm{SO}_{3}$-doped saturated $\mathrm{NaHCO}_{3}$ solution $(25 \mathrm{~mL})$ and EtOAc $(25 \mathrm{~mL})$. The mixture was stirred vigorously for $30 \mathrm{~min}$ (until the organic layer was clear) and then the two layers were separated. The organic phase was dried over $\mathrm{MgSO}_{4}$, filtered, and concentrated in vacuo. The crude product was purified by flash chromatography (50-100\% EtOAc/hexanes) to yield $\beta$-ketophosphonate 4 (62 mg, 60 $\%$ over 4 steps).

${ }^{1} \mathbf{H}$ NMR (500 MHz, $\left.\mathrm{CDCl}_{3}\right): \delta 7.28$ (d, $\left.J=8.5 \mathrm{~Hz}, 2 \mathrm{H}\right), 6.89(\mathrm{~d}, J=8.5 \mathrm{~Hz}, 2 \mathrm{H}), 6.52(\mathrm{dt}, J=10.5$, $16.5 \mathrm{~Hz}, 1 \mathrm{H}), 6.04$ (t, $J=11 \mathrm{~Hz}, 1 \mathrm{H}), 5.53$ (t, $J=10.5 \mathrm{~Hz}, 1 \mathrm{H}), 5.23$ (d, $J=16.5 \mathrm{~Hz}, 1 \mathrm{H}), 5.14(\mathrm{~d}, J=$ $10 \mathrm{~Hz}, 1 \mathrm{H}), 4.58$ (d, $J=10.5 \mathrm{~Hz}, 1 \mathrm{H}), 4.54$ (d, $J=11 \mathrm{~Hz}, 1 \mathrm{H}), 3.82$ (s, 3H), 3.79 (d, $J=10 \mathrm{~Hz}, 3 \mathrm{H})$, 
3.76 (d, $J=10 \mathrm{~Hz}, 3 \mathrm{H}$ ), 3.60 (dd, $J=4,6.5 \mathrm{~Hz}, 1 \mathrm{H}$ ), 3.33 (dd, $J=14,22 \mathrm{~Hz}, 1 \mathrm{H}$ ), 2.94-3.04 (m, 2H), $2.83(\mathrm{~m}, 1 \mathrm{H}), 1.22$ (d, $J=7 \mathrm{~Hz}, 3 \mathrm{H}), 1.09(\mathrm{~d}, J=7 \mathrm{~Hz}, 3 \mathrm{H}) ;{ }^{13} \mathbf{C}$ NMR $\left(100 \mathrm{MHz}, \mathrm{CDCl}_{3}\right) \delta 205.04$, 159.43, 133.74, 132.28, 130.63, 130.15, 129.73 (2C), 118.43, 113.93 (2C), 83.80, 74.53, 55.50, 53.26 (d, $J=6.1 \mathrm{~Hz}, 1 \mathrm{C}$ ), 53.07 (d, $J=6.7 \mathrm{~Hz}, 1 \mathrm{C}$ ), 50.81, 41.17 (d, $J=129.25 \mathrm{~Hz}, 1 \mathrm{C}$ ), 36.01, 19.22, 13.02; $[\alpha]_{\mathbf{D}}-3.8$ (c 0.5, $\mathrm{CHCl}_{3}$ ); IR (thin film): 2959, 1711, 1574, $1248 \mathrm{~cm}^{-1}$; HRMS (ESI) calculated for $\mathrm{C}_{21} \mathrm{H}_{31} \mathrm{O}_{6} \mathrm{PNa}^{+}$433.1750, found 433.1756 .

\section{Ethynyl-diisopropyl-[5-(4-methoxy-benzyloxy)-2,4-dimethyl-1-vinyl-pentyloxy]-silane, 12}

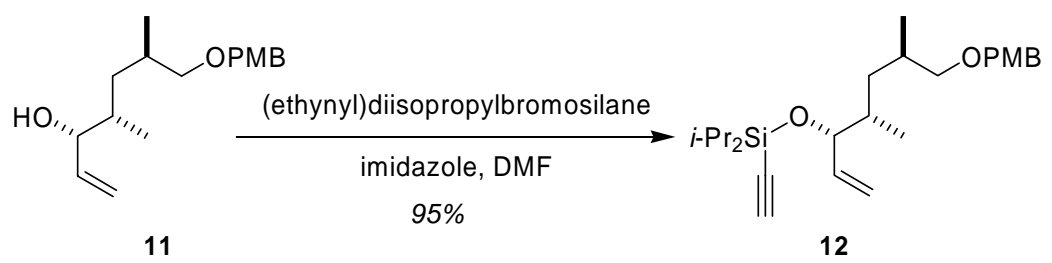

To a stirred solution of allylic alcohol $11(5.00 \mathrm{~g}, 17.96 \mathrm{mmol}, 1 \mathrm{eq})$ in DMF $(72.00 \mathrm{~mL})$ at $0{ }^{\circ} \mathrm{C}$ was added imidazole (2.445 g, $35.92 \mathrm{mmol}, 2.0 \mathrm{eq)}$ ) then bromo(diisopropyl)ethynyl silane (4.74 g, 21.552 mmol, $1.2 \mathrm{eq}$ ) and the reaction mixture was allowed to warm to rt. The mixture was stirred for $6 \mathrm{~h}$ then poured into a separatory funnel containing $\mathrm{Et}_{2} \mathrm{O}(150 \mathrm{~mL})$ and water $(150 \mathrm{~mL})$. The layers were separated and the organic phase dried with $\mathrm{MgSO}_{4}$, filtered and concentrated in vacuo. The crude product was purified by flash chromatography ( $5 \% \mathrm{Et}_{2} \mathrm{O} /$ hexanes) to yield 12 (7.35 g, 95\%) as a clear oil.

${ }^{1} \mathbf{H}$ NMR (500 MHz, CDCl $): \delta 7.30$ (d, $\left.J=8.5 \mathrm{~Hz}, 2 \mathrm{H}\right), 6.91$ (d, $\left.J=9 \mathrm{~Hz}, 2 \mathrm{H}\right), 5.84(\mathrm{~m}, 1 \mathrm{H}), 5.21$ (dt, $J=1.5,17 \mathrm{~Hz}, 1 \mathrm{H}), 5.14(\mathrm{dt}, J=1.5,10 \mathrm{~Hz}, 1 \mathrm{H}), 4.48(\mathrm{~d}, J=11.5 \mathrm{~Hz}, 1 \mathrm{H}), 4.44(\mathrm{~d}, J=12 \mathrm{~Hz}, 1 \mathrm{H})$, 4.42 (m, 1H), 3.84 (s, 3H), 4.43 (dd, $J=5,9.5 \mathrm{~Hz}, 1 \mathrm{H}), 3.25$ (t, $J=8.5 \mathrm{~Hz}, 1 \mathrm{H}), 2.41$ (s, 1H), 1.94 (m, 1H), 1.76 (m, 1H), 1.58 (m, 1H), 1.07-1.12 (m, 14H), 1.03 (m, 1H), 1.01 (d, $J=6.5 \mathrm{~Hz}, 3 \mathrm{H}), 0.92$ (d, $J$ $=7 \mathrm{~Hz}, 3 \mathrm{H}) ;{ }^{13} \mathrm{C}$ NMR (100 MHz, $\left.\mathrm{CDCl}_{3}\right): \delta$ 159.22, 139.20, 131.22, 129.29 (2C), 115.43, 113.90 (2C), 94.91, 85.62, 78.86, 75.68, 72.81, 55.46, 37.15, 36.66, 31.21, 18.98, 17.56, 17.45, 17.36, 17.33, 15.74, 13.71, 13.17; [ $\alpha]_{\mathbf{D}}-5.2$ (c 0.5, $\mathrm{CHCl}_{3}$ ); IR (thin film): 2989, 2857, 2127, 1608, 1513, 1098, 987, $912 \mathrm{~cm}^{-1}$; HRMS (ESI) calculated for $\mathrm{C}_{25} \mathrm{H}_{40} \mathrm{O}_{3} \mathrm{SiNa}^{+}$439.2638, found 439.2654 .

\section{2,2-Diisopropyl-5-[4-(4-methoxy-benzyloxy)-1,3-dimethyl-butyl]-4-methyl-3-methylene-} [1,2]oxasilolane, 13

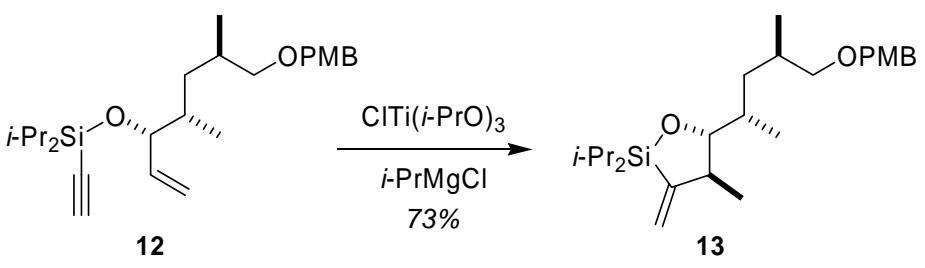

To a stirred solution of $\mathrm{Ti}(\mathrm{i}-\mathrm{PrO}){ }_{3} \mathrm{Cl}(0.495 \mathrm{~g}, 1.8 \mathrm{mmol}, 3.0 \mathrm{eq})$ in $\mathrm{Et}_{2} \mathrm{O}(5.80 \mathrm{~mL})$ at $-40{ }^{\circ} \mathrm{C}$ was added (siloxy)enyne $12(0.25 \mathrm{~g}, 0.6 \mathrm{mmol}, 1.0 \mathrm{eq})$ followed by the slow addition of a $2 \mathrm{M}$ solution of $i$-PrMgCl $(1.8 \mathrm{~mL}, 3.6 \mathrm{mmol}, 6.0 \mathrm{eq})$ over $2 \mathrm{~h}$. The reaction mixture was stirred for an additional $6 \mathrm{~h}$ and was then quenched with the addition of saturated $\mathrm{NH}_{4} \mathrm{Cl}(50 \mathrm{~mL})$ and EtOAc $(50 \mathrm{~mL})$. The resulting solution was stirred for $1 \mathrm{~h}$, filtered through Celite, and the layers were separated. The organic phase was dried with $\mathrm{MgSO}_{4}$, filtered, and concentrated in vacuo. The crude product was purified by flash chromatography (40\% $\mathrm{CH}_{2} \mathrm{Cl}_{2} /$ hexanes) to yield $\mathbf{1 3}(0.183 \mathrm{~g}, 73 \%$ ) as a clear oil. 
${ }^{1}$ H NMR (500 MHz, $\left.\mathrm{CDCl}_{3}\right): \delta 7.29$ (d, $\left.J=8.5 \mathrm{~Hz}, 2 \mathrm{H}\right), 6.90(\mathrm{~d}, J=8.5 \mathrm{~Hz}, 2 \mathrm{H}), 5.69(\mathrm{t}, J=2.5 \mathrm{~Hz}$, $1 \mathrm{H}), 5.47$ (t, $J=2.5 \mathrm{~Hz}, 1 \mathrm{H}), 4.47$ (d, $J=12 \mathrm{~Hz}, 1 \mathrm{H}), 4.44$ (d, $J=11.5 \mathrm{~Hz}, 1 \mathrm{H}), 3.83$ (s, $3 \mathrm{H}), 3.39$ (m, $1 \mathrm{H}), 3.37(\mathrm{~m}, 1 \mathrm{H}), 3.21(\mathrm{~m}, 1 \mathrm{H}), 2.35(\mathrm{~m}, 1 \mathrm{H}), 1.91(\mathrm{~m}, 1 \mathrm{H}), 1.76(\mathrm{~m}, 1 \mathrm{H}), 1.60(\mathrm{~m}, 1 \mathrm{H}), 1.18(\mathrm{~m}, 1 \mathrm{H})$, 1.01-1.10 (m, 14H), 1.0 (d, $J=6 \mathrm{~Hz}, 3 \mathrm{H}), 0.97$ (d, $J=6.5 \mathrm{~Hz}, 3 \mathrm{H}), 0.91(\mathrm{~d}, J=6.5 \mathrm{~Hz}, 3 \mathrm{H}) ;{ }^{13} \mathbf{C} \mathbf{N M R}$ (100 MHz, $\mathrm{CDCl}_{3}$ ): $\delta 159.21,153.02,131.20,129.31$ (2C), 121.00, 113.90 (2C), 85.81, 76.03, 72.68, 55.50, 43.09, 38.99, 32.68, 30.93, 18.12, 17.64, 17.56, 17.53, 17.31, 13.98, 13.38, 13.06, 12.51; $[\alpha]_{\mathbf{D}}$ 7.6 (c 0.5, $\mathrm{CHCl}_{3}$ ); IR (thin film): 2952, 2862, 1610, 1513, 1460, 1247, $852 \mathrm{~cm}^{-1}$; HRMS (ESI) calculated for $\mathrm{C}_{25} \mathrm{H}_{42} \mathrm{O}_{3} \mathrm{SiNa}^{+}$441.2795, found 441.2789.

8-(4-Methoxy-benzyloxy)-3,5,7-trimethyl-oct-1-en-4-ol, 2

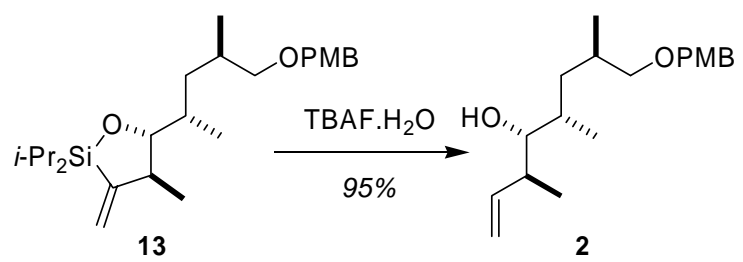

To a stirred solution of siloxane 13 (183 mg, $0.42 \mathrm{mmol}, 1.0 \mathrm{eq})$ in DMF (2.10 mL) was added TBAF $\cdot \mathrm{H}_{2} \mathrm{O}$ (332 mg, $1.27 \mathrm{mmol}, 3.0 \mathrm{eq}$ ) and the reaction mixture was heated to $65{ }^{\circ} \mathrm{C}$ for $6 \mathrm{~h}$. The reaction was then cooled to room temp and diluted with $\mathrm{H}_{2} \mathrm{O}(25 \mathrm{~mL})$ and $\mathrm{Et}_{2} \mathrm{O}(25 \mathrm{~mL})$. The organic phase was dried with $\mathrm{MgSO}_{4}$, filtered, and concentrated in vacuo. The crude product was purified by flash chromatography (25\% Et $2 \mathrm{O} /$ hexanes) to yield 2 (128 mg, 95\%) as an oil.

${ }^{1} \mathbf{H}$ NMR (400 MHz, $\mathrm{CDCl}_{3}$ ): $\delta 7.25$ (d, $\left.J=8.4 \mathrm{~Hz}, 2 \mathrm{H}\right), 6.87$ (d, $\left.J=8.8 \mathrm{~Hz}, 2 \mathrm{H}\right), 5.73$ (m, $\left.1 \mathrm{H}\right), 5.12$ (m, 2H), 4.44 (d, $J=11.6 \mathrm{~Hz}, 1 \mathrm{H}), 4.41$ (d, $J=12 \mathrm{~Hz}, 1 \mathrm{H}), 3.80$ (s, 3H), 3.31 (dd, $J=5.2,8.8 \mathrm{~Hz}, 1 \mathrm{H})$, 3.20 (dd $J=6.8,9.2 \mathrm{~Hz}, 1 \mathrm{H}), 3.18$ (t, $J=5.2 \mathrm{~Hz}, 1 \mathrm{H}), 2.27$ (m, $1 \mathrm{H}), 1.86(\mathrm{~m}, 1 \mathrm{H}), 1.75$ (m, $1 \mathrm{H}), 1.55$ (m, 1H), 1.06 (m, 1H), 0.96 (d, $J=6.8 \mathrm{~Hz}, 3 \mathrm{H}), 0.95$ (d, $J=6.8 \mathrm{~Hz}, 3 \mathrm{H}), 0.87(\mathrm{~d}, J=6.8 \mathrm{~Hz}, 3 \mathrm{H}) ;{ }^{13} \mathrm{C}$ NMR (100 MHz, $\mathrm{CDCl}_{3}$ ): $\delta$ 159.27, 142.03, 131.05, 129.36 (2C), 116.39, 113.93 (2C), 76.19, 75.91, 72.88, 55.48, 42.29, 38.57, 31.78, 30.89, 18.30, 16.78, 13.48; $[\alpha]_{\mathbf{D}}+2.7$ (c 0.5, $\left.\mathrm{CHCl}_{3}\right)$; IR (thin film): 3425, 2958, 1690, 1513, 1251, 1038, 994, $905 \mathrm{~cm}^{-1}$; HRMS (ESI) calculated for $\mathrm{C}_{19} \mathrm{H}_{30} \mathrm{O}_{3} \mathrm{Na}^{+}$ 329.2087, found 329.2096.

\section{3,5-Bis-(tert-butyl-dimethyl-silanyloxy)-2-methyl-hept-6-enoic acid 5-(4-methoxy-benzyloxy)-2,4- dimethyl-1-(1-methyl-allyl)-pentyl ester, 14}

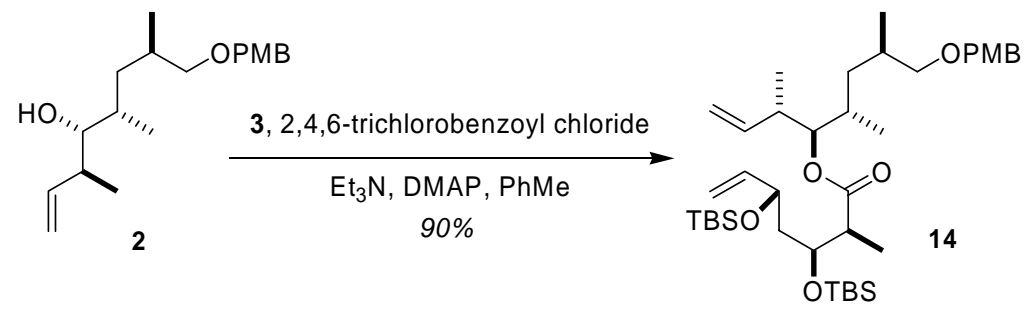

To a stirred solution of homoallylic alcohol 2 (125 mg, $0.408 \mathrm{mmol}, 1.0 \mathrm{eq}$ ) and acid 3 (164 mg, 0.408 mmol, $1.0 \mathrm{eq})$ in toluene $(40.80 \mathrm{~mL})$ at $-78{ }^{\circ} \mathrm{C}$ was added triethylamine $(682 \mu \mathrm{L}, 4.90 \mathrm{mmol}, 12.0 \mathrm{eq})$, DMAP (1.25 g, $10.2 \mathrm{mmol}, 25.0 \mathrm{eq}$ ), then 2,4,6-trichlorobenzoyl chloride (720 $\mu \mathrm{L}, 4.61 \mathrm{mmol}, 11.3$ eq) and the reaction mixture was allowed to warm to rt. The reaction was stirred for $8 \mathrm{~h}$ and was then quenched with saturated $\mathrm{NaHCO}_{3}$ solution and extracted with EtOAc (3x). The combined organic 
extracts were dried with $\mathrm{MgSO}_{4}$, filtered, and concentrated in vacuo. The crude product was purified by flash chromatography ( $10 \% \mathrm{Et}_{2} \mathrm{O} /$ hexanes) to yield $\mathbf{1 4}$ (253 mg, 90\%) as an oil.

${ }^{1}$ H NMR (500 MHz, CDCl $)$ ): $\delta 7.28$ (d, $\left.J=9 \mathrm{~Hz}, 2 \mathrm{H}\right), 6.90$ (d, $\left.J=6.5 \mathrm{~Hz}, 2 \mathrm{H}\right), 5.80(\mathrm{~m}, 1 \mathrm{H}), 5.72(\mathrm{~m}$, $1 \mathrm{H}), 5.13$ (d, $J=16.5 \mathrm{~Hz}, 1 \mathrm{H}), 4.98-5.06(\mathrm{~m}, 3 \mathrm{H}), 4.78$ (m, $1 \mathrm{H}), 4.45$ (d, $J=11.5 \mathrm{~Hz}, 1 \mathrm{H}), 4.41$ (d, $J=$ $11.5 \mathrm{~Hz}, 1 \mathrm{H}), 4.24$ (m, 1H), 4.19 (m, 1H), 3.83 (s, 3H), 3.34 (dd, $J=4.5,9 \mathrm{~Hz}, 1 \mathrm{H}), 3.16$ (dd, $J=7.5$, $9.5 \mathrm{~Hz}, 1 \mathrm{H}), 2.70(\mathrm{~m}, 1 \mathrm{H}), 2.48(\mathrm{~m}, 1 \mathrm{H}), 1.88(\mathrm{~m}, 2 \mathrm{H}), 1.78(\mathrm{~m}, 1 \mathrm{H}), 1.55(\mathrm{~m}, 1 \mathrm{H}), 1.37(\mathrm{~m}, 1 \mathrm{H}), 1.13$ (d, $J=7 \mathrm{~Hz}, 3 \mathrm{H}), 0.99$ (d, $J=6.5 \mathrm{~Hz}, 3 \mathrm{H}), 0.98(\mathrm{~m}, 1 \mathrm{H}), 0.97$ (d, $J=6.5 \mathrm{~Hz}, 3 \mathrm{H}), 0.91-0.93(\mathrm{~m}, 21 \mathrm{H})$, 0.13 (s, 3H), 0.11 (s, 3H), 0.09 (s, 3H), 0.06 (s, 3H); ${ }^{13}$ C NMR (100 MHz, $\left.\mathrm{CDCl}_{3}\right): \delta$ 173.42, 159.21, 142.66, 140.79, 131.14, 129.27 (2C), 115.38, 114.34, 113.89 (2C), 79.35, 75.50, 72.76, 72.27, 70.36, 55.47, 46.30, 42.83, 40.71, 38.28, 31.91, 30.84, 26.30 (3C), 26.15 (3C), 18.67, 18.40, 18.35, 17.64, 14.98, 11.45, -3.29, -4.06, -4.08, -4.12; [ $\alpha]_{\mathbf{D}}+2.3$; IR (thin film): 2956, 2930, 1733, 1249, 1091, 1040, 836, $775 \mathrm{~cm}^{-1}$; HRMS (ESI) calculated for $\mathrm{C}_{39} \mathrm{H}_{70} \mathrm{O}_{6} \mathrm{Si}_{2} \mathrm{Na}^{+} 713.4603$, found 713.4605 .

\section{4,6-Bis-(tert-butyl-dimethyl-silanyloxy)-10-[4-(4-methoxy-benzyloxy)-1,3-dimethyl-butyl]-3,9- dimethyl-3,4,5,6,9,10-hexahydro-oxecin-2-one, 15}

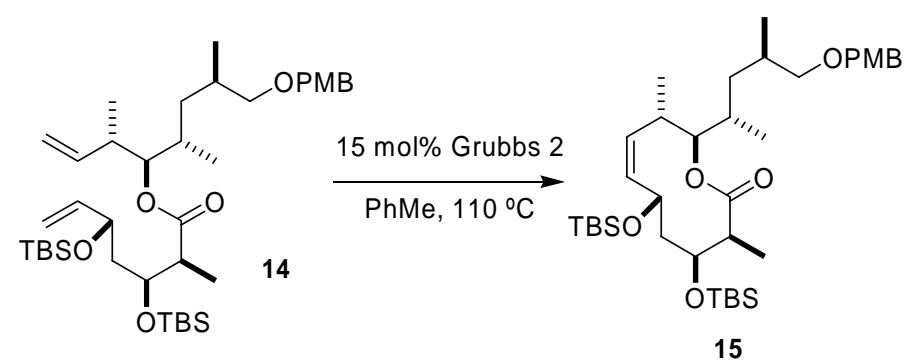

To a stirred solution of diene 14 (253 mg, $0.367 \mathrm{mmol}, 1.0 \mathrm{eq})$ in toluene $(18.35 \mathrm{~mL})$ at $110{ }^{\circ} \mathrm{C}$ was added Grubbs catalyst 2nd generation ( $47 \mathrm{mg}, 0.055 \mathrm{mmol}, 0.15 \mathrm{eq}$ ) in 3 equal batches over $18 \mathrm{~h}$. The reaction mixture was cooled to rt and concentrated in vacuo. The crude product was purified by flash chromatography (10\% Et $2 \mathrm{O} /$ hexanes) to yield $\mathbf{1 4}$ (192 mg, 76\%) as an oil.

${ }^{1}$ H NMR (500 MHz, $\left.\mathrm{CDCl}_{3}\right): \delta 7.25$ (d, $\left.J=8.5 \mathrm{~Hz}, 2 \mathrm{H}\right), 6.87(\mathrm{~d}, J=9 \mathrm{~Hz}, 2 \mathrm{H}), 5.41$ (t, $J=10.5 \mathrm{~Hz}$, $1 \mathrm{H}), 5.15$ (t, $J=9.75 \mathrm{~Hz}, 1 \mathrm{H}), 4.57-4.64(\mathrm{~m}, 2 \mathrm{H}), 4.41(\mathrm{~m}, 2 \mathrm{H}), 3.97(\mathrm{~m}, 1 \mathrm{H}), 3.81$ (s, 3H), 3.28 (dd, $J=6,9.5 \mathrm{~Hz}$ ), 3.21 (dd, $J=6,9 \mathrm{~Hz}, 1 \mathrm{H}), 2.62-2.72(\mathrm{~m}, 2 \mathrm{H}), 2.07$ (m, 1H), $1.99(\mathrm{~m}, 1 \mathrm{H}), 1.92(\mathrm{~m}, 1 \mathrm{H})$, 1.76 (m, 1H), 1.35 (m, 1H), 1.16 (d, $J=7 \mathrm{~Hz}, 3 \mathrm{H}), 1.02$ (m, 1H), 0.99 (d, $J=6.5 \mathrm{~Hz}, 3 \mathrm{H}), 0.97$ (d, $J=$ $7 \mathrm{~Hz}, 3 \mathrm{H}$ ), 0.92 (d, $J=6.5 \mathrm{~Hz}, 3 \mathrm{H}), 0.90$ (s, 9H), 0.89 (s, 9H), 0.11 (s, 3H), 0.10 (s, 3H), 0.09 (s, 3H), 0.05 (s, 3H); ${ }^{13} \mathrm{C}$ NMR (100 MHz, $\left.\mathrm{CDCl}_{3}\right): \delta$ 173.07, 159.21, 134.32, 133.31, 131.13, 129.22 (2C), 113.87 (2C), 77.31, 75.92, 72.56, 71.27, 64.23, 55.47, 48.75, 43.93, 38.82, 34.26, 30.28, 30.21, 26.04

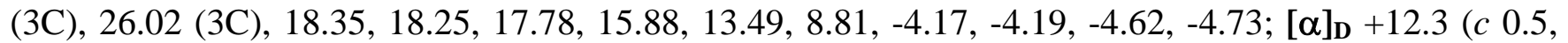
$\mathrm{CHCl}_{3}$ ); IR (thin film): 2955, 2930, 1727, 1250, 1082, 1042, 836, $775 \mathrm{~cm}^{-1}$; HRMS (ESI) calculated for $\mathrm{C}_{37} \mathrm{H}_{66} \mathrm{O}_{6} \mathrm{Si}_{2} \mathrm{Na}^{+} 685.4290$, found 642.4263 . 

tetramethyl-pentadeca-2,8-dienoic acid ethyl ester, 16

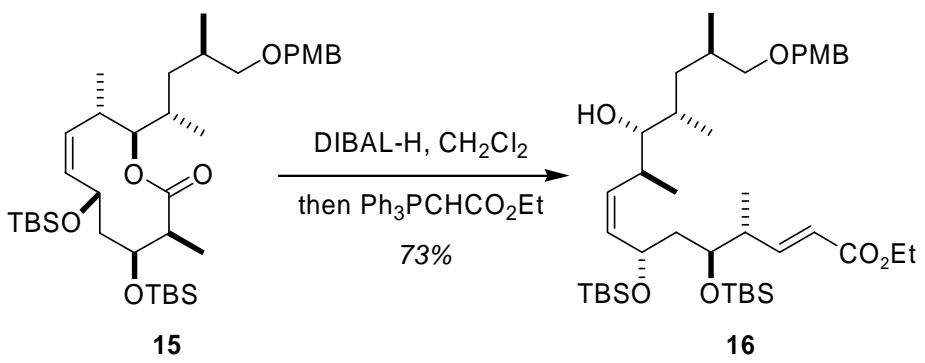

To a stirred solution of 15 (191 mg, $0.298 \mathrm{mmol})$ in toluene $(3.67 \mathrm{~mL})$ at $-100{ }^{\circ} \mathrm{C}$ was added DIBAL-H (67 $\mu \mathrm{L}, 0.367 \mathrm{mmol}, 1.2 \mathrm{eq})$ in $\mathrm{CH}_{2} \mathrm{Cl}_{2}(300 \mu \mathrm{L})$ over 30 minutes. The reaction was stirred for an additional 15 minutes, then quenched by pouring into a solution of saturated $\mathrm{Na}_{2} \mathrm{SO}_{4}(50 \mathrm{~mL})$. EtOAc $(50 \mathrm{~mL})$ was then added and the resulting solution stirred for 1h, filtered through Celite, and separated. The organic phase was dried with $\mathrm{MgSO}_{4}$, filtered, and concentrated in vacuo.

To a stirred solution of the intermediate hydroxy aldehyde in $\mathrm{CH}_{2} \mathrm{Cl}_{2}(1.835 \mathrm{~mL})$ at $0{ }^{\circ} \mathrm{C}$ was added (triphenyl- $\lambda^{5}$-phosphanylidene)acetic acid ethyl ester (384 mg, $1.1 \mathrm{mmol}, 3.0 \mathrm{eq}$ ) and the reaction mixture was allowed to warm to rt. The reaction was stirred for $2 \mathrm{~h}$ and concentrated in vacuo. The crude product was purified by flash chromatography (10\% EtOAc/hexanes) to yield 16 (148 mg, 73\% over 2 steps) as an oil.

${ }^{1} \mathbf{H}$ NMR (500 MHz, $\mathrm{CDCl}_{3}$ ): $\delta 7.28$ (d, $\left.J=9 \mathrm{~Hz}, 2 \mathrm{H}\right), 6.95$ (dd, $\left.J=7,16 \mathrm{~Hz}, 1 \mathrm{H}\right), 6.90(\mathrm{~d}, J=8.5 \mathrm{~Hz}$, 2H), 5.84 (dd, $J=1.5,16 \mathrm{~Hz}, 1 \mathrm{H}), 5.49$ (t, $J=10 \mathrm{~Hz}, 1 \mathrm{H}), 5.20$ (t $J=11 \mathrm{~Hz}, 1 \mathrm{H}), 4.56$ (td, $J=3,9$, Hz, 1H), 4.47 (d, $J=11.5 \mathrm{~Hz}, 1 \mathrm{H}), 4.43$ (d, $J=12 \mathrm{~Hz}, 1 \mathrm{H}), 4.21$ (q, $J=7 \mathrm{~Hz}, 2 \mathrm{H}), 3.98(\mathrm{~m}, 1 \mathrm{H}) 3.83$ (s, 3H), 3.33 (dd, $J=5.5,9$ Hz, 1H), 3.19-3.32 (m, 2H), $2.56(\mathrm{~m}, 2 \mathrm{H}), 1.88(\mathrm{~m}, 1 \mathrm{H}), 1.80(\mathrm{~m}, 1 \mathrm{H}), 1.51-$ $1.57(\mathrm{~m}, 2 \mathrm{H}), 1.44(\mathrm{~m}, 1 \mathrm{H}), 1.31$ (t, $J=7 \mathrm{~Hz}, 3 \mathrm{H}), 1.10(\mathrm{~m}, 1 \mathrm{H}), 1.05$ (d, $J=6.5 \mathrm{~Hz}, 3 \mathrm{H}), 0.96(\mathrm{~d}, J=$ $6.5 \mathrm{~Hz}, 3 \mathrm{H}), 0.88-0.93$ (m, 24H), 0.13 (s, 3H), 0.10 (s, 3H), 0.08 (s, 3H), $0.06(\mathrm{~s}, 3 \mathrm{H}) ;{ }^{13} \mathrm{C}$ NMR $(100$ $\left.\mathrm{MHz}, \mathrm{CDCl}_{3}\right): \delta 166.85,159.26,151.09,135.88,132.87,131.05,129.35$ (2C), 121.61, 113.92 (2C), 76.53, 76.04, 71.72, 66.29, 60.37, 55.49, 43.00, 42.84, 38.66, 36.73, 31.28, 30.85, 26.14 (3C), 26.04 (3C), 18.31, 18.29, 18.10, 16.93, 14.50, 13.71, 13.21, -2.98, -3.91, -4.13, -4.27; $[\alpha]_{\mathbf{D}}+15.84$ (c 0.5, $\mathrm{CHCl}_{3}$ ); IR (thin film): 2956, 2928, 2855, 1698, 1647, 1623, 1514, 1462, 1360, 1249, 1073, 835, 773 $\mathrm{cm}^{-1}$; HRMS (ESI) calculated for $\mathrm{C}_{41} \mathrm{H}_{74} \mathrm{O}_{7} \mathrm{Si}_{2} \mathrm{Na}^{+}$757.4865, found 757.4837.

\section{4,18,20,24-Tetrakis-(tert-butyl-dimethyl-silanyloxy)-6-(4-methoxy-benzyloxy)-5,7,11,13,15,21- hexamethyl-tetracosa-1,3,9,16,22-pentaen-8-one, 18}

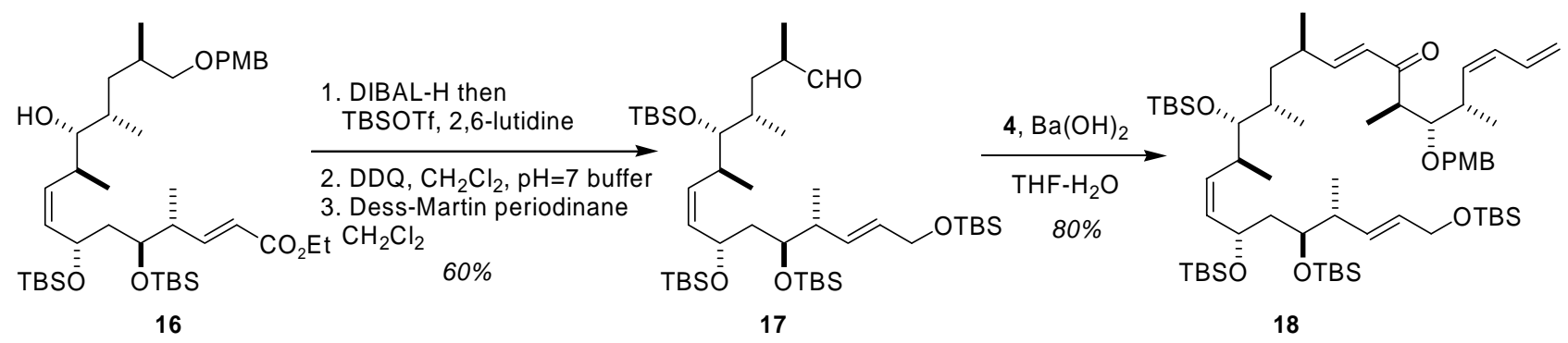

To a stirred solution of 16 (148 mg, $0.201 \mathrm{mmol}, 1.0 \mathrm{eq})$ in $\mathrm{CH}_{2} \mathrm{Cl}_{2}$ (2.00 mL) at $-78{ }^{\circ} \mathrm{C}$ was added DIBAL-H (118 $\mu \mathrm{L}, 0.644 \mathrm{mmol}, 3.2 \mathrm{eq})$ and the reaction mixture was warmed to $0{ }^{\circ} \mathrm{C}$ for $30 \mathrm{~min}$. The 
reaction was quenched by pouring into a saturated solution of $\mathrm{Na}_{2} \mathrm{SO}_{4}(25 \mathrm{~mL})$ and stirred with EtOAc $(25 \mathrm{~mL})$ for $45 \mathrm{~min}$, filtered through Celite, and separated. The organic phase was dried with $\mathrm{MgSO}_{4}$, filtered, and concentrated in vacuo. The crude diol was used directly in the next step.

${ }^{1}$ H NMR (500 MHz, CDCl $): \delta 7.28$ (d, $\left.J=9 \mathrm{~Hz}, 2 \mathrm{H}\right), 6.90(\mathrm{~d}, J=8 \mathrm{~Hz}, 2 \mathrm{H}), 5.55(\mathrm{~m}, 2 \mathrm{H}), 5.53(\mathrm{t}, J=$ $11 \mathrm{~Hz}, 1 \mathrm{H}), 5.18$ (t, $J=10.5 \mathrm{~Hz}, 1 \mathrm{H}), 4.57$ (td, $J=3,5.5 \mathrm{~Hz}, 1 \mathrm{H}), 4.45(\mathrm{~m}, 2 \mathrm{H}), 4.08(\mathrm{~m}, 2 \mathrm{H}), 3.91(\mathrm{~m}$, 1H), 3.83 (s, 3H), 3.32 (dd, $J=5.5,9 \mathrm{~Hz}, 1 \mathrm{H}), 3.19-3.24(\mathrm{~m}, 2 \mathrm{H}), 2.56(\mathrm{~m}, 1 \mathrm{H}), 2.38(\mathrm{~m}, 1 \mathrm{H}), 1.88(\mathrm{~m}$, 1H), 1.79 (m, 1H) 1.48 (m, 2H), 1.23 (d, $J=7 \mathrm{~Hz}, 3 \mathrm{H}), 1.00$ (d, $J=7 \mathrm{~Hz}, 3 \mathrm{H}), 0.88-0.98$ (m, 24H), 0.14 (s, 3H), 0.11 (s, 3H), $0.08 \mathrm{~s}, 6 \mathrm{H})$.

To a stirred solution of the intermediate diol in $\mathrm{CH}_{2} \mathrm{Cl}_{2}(2.00 \mathrm{~mL})$ at $0{ }^{\circ} \mathrm{C}$ was added 2,6-lutidine $(94 \mu \mathrm{L}$, $0.804 \mathrm{mmol}, 4.0 \mathrm{eq})$ and TBSOTf ( $138 \mu \mathrm{L}, 0.603 \mathrm{mmol}, 3.0 \mathrm{eq})$ and the reaction mixture was allowed to warm to rt. The reaction was stirred for $2.5 \mathrm{~h}$ and quenched with a saturated $\mathrm{NaHCO}_{3}$ solution. The mixture was extracted with $\mathrm{CH}_{2} \mathrm{Cl}_{2}$ and the combined organic extracts were dried with $\mathrm{MgSO}_{4}$, filtered, and concentrated in vacuo. The crude product was used directly in the next step.

${ }^{1}$ H NMR (400 MHz, CDCl $)$ ): $\delta 7.25$ (d, $\left.J=11 \mathrm{~Hz}, 2 \mathrm{H}\right), 6.86(\mathrm{~d}, J=11 \mathrm{~Hz}, 2 \mathrm{H}), 5.54(\mathrm{~m}, 2 \mathrm{H}), 5.38(\mathrm{t}, J$ $=13 \mathrm{~Hz}, 1 \mathrm{H}), 5.24(\mathrm{t}, J=10.5 \mathrm{~Hz}, 1 \mathrm{H}), 4.52(\mathrm{~m}, 1 \mathrm{H}), 4.40(\mathrm{~m}, 2 \mathrm{H}), 4.13(\mathrm{~m}, 2 \mathrm{H}), 3.89(\mathrm{dt}, J=3.5,10.5$ Hz, 1H), 3.80 (s, 3H), 3.36 (m, 1H), 3.32 (dd, $J=6.5,12 \mathrm{~Hz}, 1 \mathrm{H}) 3.08$ (t, $J=9.5 \mathrm{~Hz}, 1 \mathrm{H}), 2.56(\mathrm{~m}, 1 \mathrm{H})$, $2.37(\mathrm{~m}, 1 \mathrm{H}), 1.86(\mathrm{~m}, 1 \mathrm{H}), 1.73(\mathrm{~m}, 1 \mathrm{H}), 1.61(\mathrm{~m}, 1 \mathrm{H}), 1.51(\mathrm{~m}, 1 \mathrm{H}), 0.96(\mathrm{~d}, J=7 \mathrm{~Hz}, 3 \mathrm{H}), 0.83-0.93$ (m, 45H), 0.08 (s, 6H), 0.06 (s, 12H), 0.01 (s, 6H).

To a stirred biphasic solution of the intermediate obtained above in $\mathrm{CH}_{2} \mathrm{Cl}_{2}(7.73 \mathrm{~mL})$ and $\mathrm{pH}=7 \mathrm{Buffer}$ $\left(2.32 \mathrm{~mL}\right.$ ) at $0{ }^{\circ} \mathrm{C}$ was added DDQ (54 mg, $\left.0.241 \mathrm{mmol}, 1.2 \mathrm{eq}\right)$ and the reaction was allowed to warm to rt. The reaction was stirred for $1 \mathrm{~h}$ and the layers were then separated. The aqueous layer was extracted with $\mathrm{CH}_{2} \mathrm{Cl}_{2}(3 \times 10 \mathrm{~mL})$ and the combined organic extracts dried with $\mathrm{MgSO}_{4}$, filtered through a plug of silica with EtOAc, and concentrated in vacuo. The crude product was used without further purification.

${ }^{1}$ H NMR (400 MHz, $\left.\mathrm{CDCl}_{3}\right): \delta 5.55(\mathrm{~m}, 2 \mathrm{H}), 5.43(\mathrm{t}, J=12.5 \mathrm{~Hz}, 1 \mathrm{H}), 5.27(\mathrm{t}, J=10.5 \mathrm{~Hz}, 1 \mathrm{H}), 4.53$ (m, 1H), 4.14 (m, 2H), 3.91 (m, 1H), 3.54 (dd, $J=6.5,12 \mathrm{~Hz}, 1 \mathrm{H}), 3.37$ (t, $J=4 \mathrm{~Hz}, 1 \mathrm{H}), 3.32(\mathrm{~m}, 1 \mathrm{H})$, $2.58(\mathrm{~m}, 1 \mathrm{H}), 2.37(\mathrm{~m}, 1 \mathrm{H}), 1.65(\mathrm{~m}, 1 \mathrm{H}), 1.64(\mathrm{~m}, 1 \mathrm{H}), 1.43(\mathrm{~m}, 1 \mathrm{H}), 1.33(\mathrm{~m}, 1 \mathrm{H}), 0.97(\mathrm{~d}, J=7 \mathrm{~Hz}$, 3H), 0.94 (d, $J=7$ Hz, 3H), 0.82-0.92 (m, 42H), 0.09 (s, 6H), 0.06 (s, 6H), 0.04 (s, 6H), 0.03 (s, 6H).

To a solution of the intermediate alcohol in $\mathrm{CH}_{2} \mathrm{Cl}_{2}(2.00 \mathrm{~mL})$ at $0{ }^{\circ} \mathrm{C}$ was added Dess-Martin periodinane (128 mg, $0.302 \mathrm{mmol}, 1.5 \mathrm{eq}$ ) and the solution was allowed to warm to rt. The solution was stirred for $45 \mathrm{~min}$ and was then quenched with $\mathrm{Na}_{2} \mathrm{SO}_{3}$-doped saturated $\mathrm{NaHCO}_{3}$ solution. The mixture was stirred vigorously for $30 \mathrm{~min}$ (until the organic layer was clear) and then the two layers were separated. The organic phase was dried over $\mathrm{MgSO}_{4}$, filtered, and concentrated in vacuo. The crude product was purified by flash chromatography (10\% Et $2 \mathrm{O} /$ petroleum ether) to yield 17 (109 mg, 60\% 4steps) as an oil.

${ }^{1}$ H NMR (500 MHz, CDCl $): \delta 9.54(\mathrm{~d}, J=2.5 \mathrm{~Hz}, 1 \mathrm{H}), 5.57(\mathrm{~m}, 2 \mathrm{H}), 5.45$ (t, $\left.J=10.5 \mathrm{~Hz}, 1 \mathrm{H}\right), 5.30$ (dd, $J=9,11.5 \mathrm{~Hz}, 1 \mathrm{H}), 4.56(\mathrm{~m}, 1 \mathrm{H}), 4.16(\mathrm{~m}, 2 \mathrm{H}), 3.94(\mathrm{~m}, 1 \mathrm{H}), 3.43(\mathrm{t}, J=3.5 \mathrm{~Hz}, 1 \mathrm{H}), 2.63(\mathrm{~m}$, 1H), $2.40(\mathrm{~m}, 1 \mathrm{H}), 1.88(\mathrm{~m}, 1 \mathrm{H}), 1.75(\mathrm{~m}, 1 \mathrm{H}), 1.64(\mathrm{~m}, 1 \mathrm{H}), 1.54(\mathrm{~m}, 1 \mathrm{H}), 1.27(\mathrm{~m}, 2 \mathrm{H}), 1.25$ (d, $J=7$ Hz, 3H), 1.23 (d, $J=7.5 \mathrm{~Hz}, 3 \mathrm{H}$ ), 0.84-1.00 (m, 42H), 0.12 (s, 6H), 0.09 (s, 6H), 0.08 (s, 6H), 0.06 (s, $6 \mathrm{H})$. 
A solution of phosphonate 4 (32 mg, $0.078 \mathrm{mmol}, 1.0 \mathrm{eq})$ in dry THF (390 $\mu \mathrm{L}$ ) was added to a flask containing $\mathrm{Ba}(\mathrm{OH})_{2}{ }^{\bullet} 8 \mathrm{H}_{2} \mathrm{O}(20 \mathrm{mg}, 0.062 \mathrm{mmol}, 0.8 \mathrm{eq})$ previously heated to $120{ }^{\circ} \mathrm{C}$ for $1.5 \mathrm{~h}$ then cooled to rt. The reaction was stirred for $30 \mathrm{~min}$, then aldehyde 17 (50 mg, $0.062 \mathrm{mmol}, 0.8 \mathrm{eq}$ ) was added as a solution in 40:1 THF: $\mathrm{H}_{2} \mathrm{O}(390 \mu \mathrm{L})$, and the reaction was stirred for $6 \mathrm{~h}$. $\mathrm{CH}_{2} \mathrm{Cl}_{2}(50 \mathrm{~mL})$ and $\mathrm{MgSO}_{4}$ were then added to the reaction and the mixture was filtered through Celite and concentrated in vacuo. The crude product was purified by flash chromatography $\left(10 \% \mathrm{Et}_{2} \mathrm{O} /\right.$ petroleum ether) to yield $\mathbf{1 8}$ (54 $\mathrm{mg}, 80 \%$ ) as an oil.

${ }^{1}$ H NMR (400 MHz, $\left.\mathrm{CDCl}_{3}\right): \delta 7.27(\mathrm{~d}, J=9.6 \mathrm{~Hz}, 2 \mathrm{H}), 6.87(\mathrm{~d}, J=8.8 \mathrm{~Hz}, 2 \mathrm{H}), 6.66$ (dd, $J=8.4,16$ $\mathrm{Hz}, 1 \mathrm{H}), 6.39$ (dt, $J=10.8,16.8 \mathrm{~Hz}, 1 \mathrm{H}), 6.03(\mathrm{~d}, J=16.4 \mathrm{~Hz}, 1 \mathrm{H}), 6.01(\mathrm{t}, J=9.6 \mathrm{~Hz}, 1 \mathrm{H}), 5.54$ (d, $J$ $=2.8 \mathrm{~Hz}, 2 \mathrm{H}), 5.52(\mathrm{t}, J=10.4 \mathrm{~Hz}, 1 \mathrm{H}), 5.41(\mathrm{t}, J=10.8 \mathrm{~Hz}, 1 \mathrm{H}), 5.24(\mathrm{dd}, J=8.4,10.8 \mathrm{~Hz}, 1 \mathrm{H}), 5.14$ (dd, $J=2,16.8 \mathrm{~Hz}, 1 \mathrm{H}$ ), 5.00 (d, $J=10.4 \mathrm{~Hz}, 1 \mathrm{H}), 4.51-4.58$ (m, 3H), 4.13 (m, 2H), 3.91 (m, 1H), 3.80 (s, 3H), 3.68 (dd, $J=3.2,8.8 \mathrm{~Hz}, 1 \mathrm{H}), 3.35$ (t, $J=3.6 \mathrm{~Hz}, 1 \mathrm{H}), 2.90(\mathrm{~m}, 1 \mathrm{H}), 2.76(\mathrm{~m}, 1 \mathrm{H}), 2.58$ (m, $1 \mathrm{H}), 2.38(\mathrm{~m}, 1 \mathrm{H}), 2.28(\mathrm{~m}, 1 \mathrm{H}), 1.34-1.57(\mathrm{~m}, 5 \mathrm{H}), 1.08(\mathrm{~d}, J=6.8 \mathrm{~Hz}, 3 \mathrm{H}), 1.00(\mathrm{~d}, J=6.4 \mathrm{~Hz}, 3 \mathrm{H})$, 0.83-0.95 (m, 48H), -0.09 (s, 3H), -0.06 (s, 3H), -0.04 (s, 3H), -0.02 (s, 3H), -0.01 (s, 3H); ${ }^{13}$ C NMR (100 MHz, $\left.\mathrm{CDCl}_{3}\right): \delta$ 203.28, 159.37, 153.14, 134.19, 133.24, 133.06, 132.64, 131.03, 129.86, 129.61 (2C), 128.11, 117.60, 113.93 (2C), 84.45, 80.21, 75.65, 72.31, 66.64, 64.40, 55.50, 48.98, 42.38, 41.51, 39.31, 36.66, 36.10, 34.85, 34.71, 29.94, 26.40 (3C), 26.25 (3C), 26.17 (6C), 20.81, 20.03, 19.15, 18.66, $18.60,18.36,18.34,15.28,14.65,13.13,-2.71,-3.50,-3.53,-3.97,-4.04,-4.12,-4.80,-4.84 ;[\alpha]_{\mathbf{D}}-13.22$ (c 0.5, $\mathrm{CHCl}_{3}$ ); IR (thin film): 2956, 2927, 2856, 1720, 1513, 1463, 1249, 1180, 1089, 1038, 836, 774 $\mathrm{cm}^{-1}$; HRMS (ESI) calculated for $\mathrm{C}_{62} \mathrm{H}_{114} \mathrm{O}_{7} \mathrm{Si}_{4} \mathrm{Na}^{+} 1105.7533$, found 1105.7570 .

\section{4,18,20,24-Tetrakis-(tert-butyl-dimethyl-silanyloxy)-5,7,11,13,15,21-hexamethyl-tetracosa- 1,3,16,22-tetraene-6,8-diol, 19}

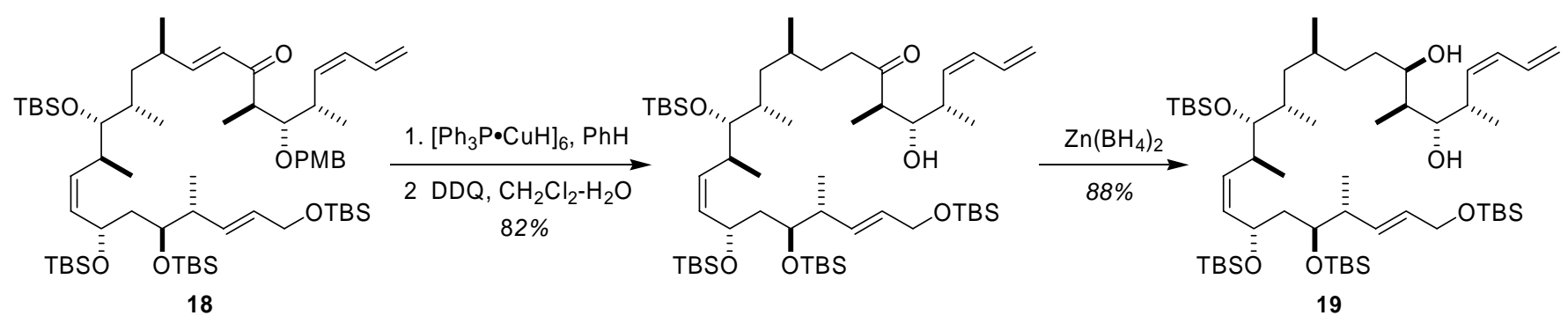

Enone 18 (23.4 mg, $0.022 \mathrm{mmol}, 1.0 \mathrm{eq})$ was added with degassed toluene to a flask containing $\left[\mathrm{Ph}_{3} \mathrm{P} \cdot \mathrm{CuH}\right]_{6}(21 \mathrm{mg}, 0.011 \mathrm{mmol}, 0.5 \mathrm{eq})$ at rt. The reaction was stirred for $8 \mathrm{~h}$, flushed through a plug of silica with EtOAc and concentrated in vacuo to yield the intermediate ketone as an oil.

${ }^{1}$ H NMR (500 MHz, $\mathrm{CDCl}_{3}$ ): $\delta 7.27$ (d, $\left.J=8.5 \mathrm{~Hz}, 2 \mathrm{H}\right), 6.88$ (d, $\left.J=9 \mathrm{~Hz}, 2 \mathrm{H}\right), 6.44$ (dt, $J=11,16.5$ $\mathrm{Hz}, 1 \mathrm{H}), 6.04$ (t, $J=11 \mathrm{~Hz}, 1 \mathrm{H}), 5.52-5.56(\mathrm{~m}, 3 \mathrm{H}), 5.40$ (t, $J=10.5 \mathrm{~Hz}, 1 \mathrm{H}), 5.26$ (dd, $J=8.5,11 \mathrm{~Hz}$, 1H), 5.19 (d, $J=16.5 \mathrm{~Hz}, 1 \mathrm{H}), 5.08$ (d, $J=10 \mathrm{~Hz}, 1 \mathrm{H}), 4.50-4.58(\mathrm{~m}, 3 \mathrm{H}), 4.136(\mathrm{~m}, 2 \mathrm{H}), 3.905$ (m, $1 \mathrm{H}), 3.81(\mathrm{~s}, 3 \mathrm{H}), 3.65$ (dd, $J=3,8 \mathrm{~Hz}, 1 \mathrm{H}), 3.37(\mathrm{~m}, 1 \mathrm{H}), 2.70-2.78(\mathrm{~m}, 3 \mathrm{H}), 2.58(\mathrm{~m}, 2 \mathrm{H}), 2.33-2.44$ (m, 3H), 1.62-1.72 (m, 2H), $1.46(\mathrm{~m}, 1 \mathrm{H}), 1.38(\mathrm{~m}, 2 \mathrm{H}), 1.28(\mathrm{~m}, 2 \mathrm{H}) 1.18(\mathrm{~d}, J=7 \mathrm{~Hz}, 3 \mathrm{H}), 1.11(\mathrm{~m}$, 1H), 1.09 (d, $J=7 \mathrm{~Hz}, 1 \mathrm{H}$ ), 0.97 (d, $J=7 \mathrm{~Hz}, 3 \mathrm{H}$ ), 0.95 (d, $J=7 \mathrm{~Hz}, 3 \mathrm{H}), 0.91$ (s, 18H), 0.90 (s, 9H), 0.87-0.88 (m, 12H), 0.85 (d, $J=7 \mathrm{~Hz}, 3 \mathrm{H}), 0.80$ (d, $J=6.5 \mathrm{~Hz}, 3 \mathrm{H}), 0.09$ (s, 3H), 0.07 (s, 6H), 0.05 (s, 6H), 0.04 (s, 6H). ${ }^{13} \mathrm{C}$ NMR (100 MHz, $\left.\mathrm{CDCl}_{3}\right): \delta 214.64,159.38,134.16,133.31,133.13,132.55$, 132.32, 130.97, 129.82, 129.57 (2C), 128.57, 118.03, 113.95 (2C), 84.07, 80.13, 75.59, 72.35, 66.69, 64.43, 55.50, 50.69, 42.36, 41.61, 41.40, 40.66, 36.43, 35.79, 35.26, 30.04, 29.94 (2C), 29.62, 26.48 
(3C), 26.25 (6C), 26.18 (3C), 20.52, 19.78, 19.08, 18.70, 18.66, 18.35, 15.47, 14.40, 13.27, -2.74, -3.25, -3.48, -3.98, -4.06, -4.10, -4.79, -4.84; $[\alpha]_{\mathbf{D}}+7.69$ (c 0.5, $\left.\mathrm{CHCl}_{3}\right) ;$ IR (thin film): 2929, 1709, 1613, 1513, 1249, $1037 \mathrm{~cm}^{-1}$; HRMS (ESI) calculated for $\mathrm{C}_{62} \mathrm{H}_{116} \mathrm{O}_{7} \mathrm{Si}_{4} \mathrm{Na}^{+}$1107.7690, found 1107.7676.

To a stirred solution of the intermediate ketone in $\mathrm{CH}_{2} \mathrm{Cl}_{2}(220 \mu \mathrm{L})$ at $0{ }^{\circ} \mathrm{C}$ was added DDQ (6 mg, $0.026 \mathrm{mmol}, 1.2 \mathrm{eq}$ ) and the solution was warmed to rt. The reaction was stirred $30 \mathrm{~min}$, then quenched with $\mathrm{pH}=7$ buffer $(10 \mathrm{~mL})$, and the aqueous layer extracted with $\mathrm{CH}_{2} \mathrm{Cl}_{2}(3 \times 10 \mathrm{~mL})$. The combined organic extracts were dried with $\mathrm{MgSO}_{4}$, filtered, and concentrated in vacuo. The crude product was purified by flash chromatography (5\% EtOAc/petroleum ether) to yield the intermediate hydroxyl ketone (17 mg, 82\% over 2 steps) as an oil.

${ }^{1} \mathbf{H}$ NMR (500 MHz, $\left.\mathrm{CDCl}_{3}\right): \delta 6.54(\mathrm{dt}, J=10.5,17 \mathrm{~Hz}, 1 \mathrm{H}), 6.10(\mathrm{t}, J=11 \mathrm{~Hz}, 1 \mathrm{H}), 5.52(\mathrm{~m}, 2 \mathrm{H})$, $5.37(\mathrm{t}, J=10 \mathrm{~Hz}, 1 \mathrm{H}), 5.25(\mathrm{~m}, 3 \mathrm{H}), 5.11(\mathrm{~d}, J=10 \mathrm{~Hz}, 1 \mathrm{H}), 4.50(\mathrm{t}, J=8 \mathrm{~Hz}, 1 \mathrm{H}), 4.11(\mathrm{~m}, 2 \mathrm{H}), 3.71$ (t, $J=5 \mathrm{~Hz}, 1 \mathrm{H}), 3.34(\mathrm{~m}, 2 \mathrm{H}), 2.73(\mathrm{~m}, 1 \mathrm{H}), 2.65(\mathrm{~m}, 1 \mathrm{H}), 2.55(\mathrm{~m}, 1 \mathrm{H}), 2.35(\mathrm{~m}, 2 \mathrm{H}), 1.65(\mathrm{~m}, 1 \mathrm{H})$, $1.38(\mathrm{~m}, 1 \mathrm{H}), 1.30(\mathrm{~m}, 2 \mathrm{H}), 1.23(\mathrm{~m}, 2 \mathrm{H}), 1.15(\mathrm{~m}, 2 \mathrm{H}), 1.10(\mathrm{~m}, 2 \mathrm{H}), 1.14$ (d, $J=7 \mathrm{~Hz}, 3 \mathrm{H}), 0.97$ (d, $J$ $=7 \mathrm{~Hz}, 3 \mathrm{H}), 0.94$ (d, $J=7 \mathrm{~Hz}, 3 \mathrm{H}), 0.92$ (d, $J=7 \mathrm{~Hz}, 3 \mathrm{H}), 0.88$ (m, $42 \mathrm{H}), 0.06$ (s, 3H), 0.04 (s, 9H), 0.02 (s, 9H), 0.01 (s, 3H).

To a stirred solution of the intermediate hydroxy ketone ( $8.5 \mathrm{mg}, 8.8 \mu \mathrm{mol}, 1.0 \mathrm{eq})$ in $\mathrm{Et}_{2} \mathrm{O}(150 \mu \mathrm{L})$ at $-40{ }^{\circ} \mathrm{C}$ was added a $0.28 \mathrm{M}$ solution of $\mathrm{Zn}\left(\mathrm{BH}_{4}\right)_{2}(126 \mu \mathrm{L}, 35.2 \mu \mathrm{mol}, 4.0 \mathrm{eq})$ dropwise over 5 min The solution was stirred for $30 \mathrm{~min}$, then quenched with saturated $\mathrm{NH}_{4} \mathrm{Cl}(10 \mathrm{~mL})$, and the aqueous phase extracted with EtOAc. The organic phase was dried with $\mathrm{MgSO}_{4}$, filtered, and concentrated in vacuo. The crude material was purified by flash chromatography (25\% Et ${ }_{2} \mathrm{O}$ /petroleum ether) to yield 19 (7 mg, $88 \%)$ as an oil.

${ }^{1} \mathbf{H}$ NMR (400 MHz, $\left.\mathrm{CDCl}_{3}\right): \delta 6.64(\mathrm{dt}, J=10.4,16 \mathrm{~Hz}, 1 \mathrm{H}), 6.20(\mathrm{t}, J=11.2 \mathrm{~Hz}, 1 \mathrm{H}), 5.54(\mathrm{~d}, J=$ $2.8 \mathrm{~Hz}, 2 \mathrm{H}), 5.40$ (t, $J=10.4 \mathrm{~Hz}, 1 \mathrm{H}), 5.17-5.29(\mathrm{~m}, 4 \mathrm{H}), 4.52$ (m 1H), 4.13 (m, 2H), 3.89 (m, $1 \mathrm{H}), 3.77$ (m, 1H), 3.45 (d, $J=10.8 \mathrm{~Hz}, 1 \mathrm{H}), 3.36(\mathrm{t}, J=3.6 \mathrm{~Hz}, 1 \mathrm{H}), 2.81(\mathrm{~m}, 1 \mathrm{H}), 2.58(\mathrm{~m}, 1 \mathrm{H}), 2.37(\mathrm{~m}, 1 \mathrm{H})$, 1.62-1.74 (m, 2H), 1.22-1.52 (m, 8H), 0.83-0.97 (m, 54H), 0.08 (s, 3H), 0.06 (s, 9H), 0.04 (s, 6H), 0.03 (s, 3H), 0.02 (s, 3H); ${ }^{13} \mathrm{C}$ NMR (100 MHz, $\left.\mathrm{CDCl}_{3}\right): \delta$ 134.63, 133.33, 132.51, 132.24 (2C), 129.53, 119.29, 80.96, 80.23, 77.45, 72.36, 66.71, 64.44, 42.36, 41.65, 41.39, 37.10, 36.60, 35.74, 35.39, 32.67, 30.55, 29.94, 26.49 (3C), 26.25 (3C), 26.18 (3C), 20.75, 19.81, 18.69 (2C), 18.36 (2C), 16.88, 15.63, 13.33, 4.35, -2.75, -3.28, -3.45, -3.98, -4.09 (2C), -4.79, -4.84; $[\alpha]_{\mathbf{D}}+7.7\left(c\right.$ 0.5, $\left.\mathrm{CHCl}_{3}\right)$; IR (thin film): 3425, 2959, 2928, 2855, 1513, 1460, 1250, 1180, 1089, 1037, $835 \mathrm{~cm}^{-1}$; HRMS (ESI) calculated for $\mathrm{C}_{54} \mathrm{H}_{110} \mathrm{O}_{6} \mathrm{Si}_{4} \mathrm{Na}^{+}$989.7271, found 989.7300 .

[Bis-(2,2,2-trifluoro-ethoxy)-phosphoryl]-acetic acid 3,9,13,15,19-pentakis-(tert-butyl-dimethylsilanyloxy)-2,6,8,10,16-pentamethyl-1-(1-methyl-penta-2,4-dienyl)-nonadeca-11,17-dienyl ester, 20

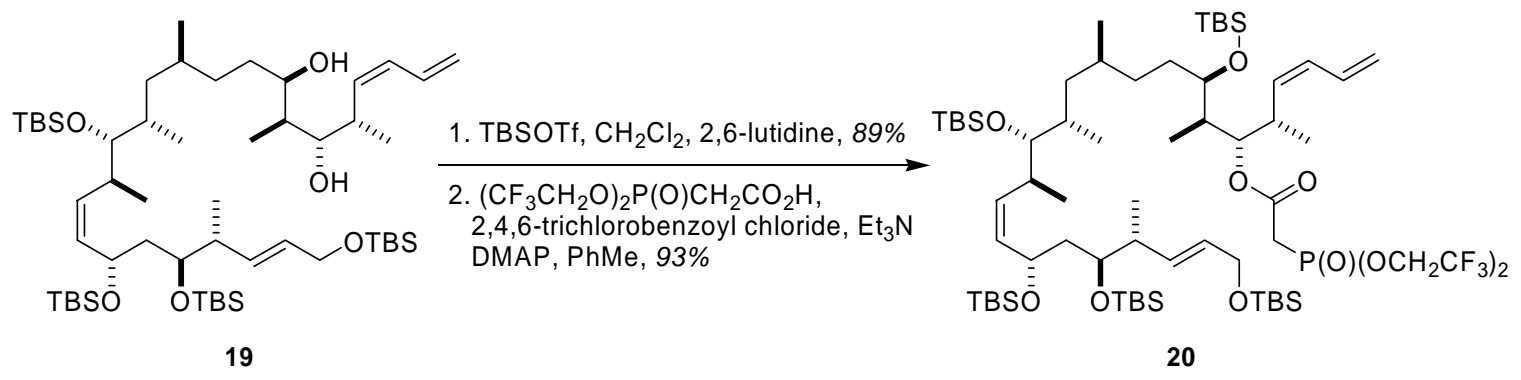


To a stirred solution of diol 19 (7.0 mg, $7.7 \mu \mathrm{mol}, 1.0 \mathrm{eq})$ in $\mathrm{CH}_{2} \mathrm{Cl}_{2}(150 \mu \mathrm{L})$ at $0{ }^{\circ} \mathrm{C}$ was added 2,6lutidine ( $2.7 \mu \mathrm{L}, 23.1 \mu \mathrm{mol}, 3.0 \mathrm{eq})$ and TBSOTf ( $3.5 \mu \mathrm{L}, 15.4 \mu \mathrm{mol}, 2.0$ eq). The reaction was stirred for $45 \mathrm{~min}$, quenched with saturated $\mathrm{NaHCO}_{3}$ solution $(10 \mathrm{~mL})$, and the aqueous phase was extracted with $\mathrm{CH}_{2} \mathrm{Cl}_{2}(3 \times 10 \mathrm{~mL})$. The combined organic extracts were dried over $\mathrm{MgSO}_{4}$, filtered through a plug of silica with EtOAc, and concentrated in vacuo. The crude product was used without further purification.

${ }^{1}$ H NMR (500 MHz, CDCl 3 ): $\delta 6.66(\mathrm{dt}, J=10.5,17 \mathrm{~Hz}, 1 \mathrm{H}), 6.12(\mathrm{t}, J=11 \mathrm{~Hz}, 1 \mathrm{H}), 5.57(\mathrm{~m}, 2 \mathrm{H})$, 5.43 (m, 2H), 5.27 (dd, $J=9,11.5 \mathrm{~Hz}, 1 \mathrm{H}), 5.24$ (d, $J=17.5 \mathrm{~Hz}, 1 \mathrm{H}), 5.14(J=10.5 \mathrm{~Hz}, 1 \mathrm{H}), 4.55$ (t, $J$ $=8.5 \mathrm{~Hz}, 1 \mathrm{H}), 4.16(\mathrm{~m}, 2 \mathrm{H}), 3.92(\mathrm{~m}, 1 \mathrm{H}), 3.79(\mathrm{~m}, 1 \mathrm{H}), 3.50(\mathrm{dd}, J=2.5,7.5 \mathrm{~Hz}, 1 \mathrm{H}), 3.39(\mathrm{t}, J=3$ $\mathrm{Hz}, 1 \mathrm{H}), 2.82(\mathrm{~m}, 1 \mathrm{H}), 2.60(\mathrm{~m}, 1 \mathrm{H}), 2.40(\mathrm{~m}, 2 \mathrm{H}), 1.73(\mathrm{~m}, 1 \mathrm{H}), 1.68(\mathrm{~m}, 1 \mathrm{H}), 1.60(\mathrm{~m}, 2 \mathrm{H}), 1.48(\mathrm{~m}$, 1H), 1.40 (m, 2H), $1.32(\mathrm{~m}, 1 \mathrm{H}), 1.25(\mathrm{~m}, 1 \mathrm{H}), 1.03(\mathrm{~m}, 1 \mathrm{H}), 0.99$ (d, $J=6.5 \mathrm{~Hz}, 3 \mathrm{H}), 0.97$ (d, $J=6.5$ $\mathrm{Hz}, 3 \mathrm{H}), 0.93$ (m, 51H), 0.87 (d, $J=6.5 \mathrm{~Hz}, 3 \mathrm{H}), 0.86$ (d, $J=7 \mathrm{~Hz}, 3 \mathrm{H}), 0.11$ (s, 6H), 0.10 (s, 6H), 0.09 (s, 6H), 0.06 (s, 6H), 0.04 (s, 6H).

To a stirred solution of the intermediate alcohol and bis(2,2,2-trifluoroethyl)phosphonoacetic acid (6.0 $\mathrm{mg}, 19.3 \mu \mathrm{mol}, 2.5 \mathrm{eq})$ in toluene $(770 \mu \mathrm{L})$ at $0{ }^{\circ} \mathrm{C}$ was added $\mathrm{Et}_{3} \mathrm{~N}(6.0 \mu \mathrm{L}, 43.1 \mu \mathrm{mol}, 5.6 \mathrm{eq})$, DMAP (8.0 mg, $64.7 \mu \mathrm{mol}, 8.4 \mathrm{eq}$ ), and 2,4,6-trichlorobenzoyl chloride ( $4.0 \mu \mathrm{L}, 26.9 \mu \mathrm{mol}$, 3.5eq) and the reaction was allowed to warm to rt. The reaction was stirred for $8 \mathrm{~h}$ and was then quenched with saturated $\mathrm{NaHCO}_{3}$ solution. The mixture was extracted with EtOAc and the combined extracts dried over $\mathrm{MgSO}_{4}$, filtered, and concentrated in vacuo. The crude product was purified by flash chromatography (25\% EtOAc/petroleum ether) to yield 20 (7.8 mg, 74\% over 2 steps).

${ }^{1}$ H NMR (500 MHz, CDCl $)$ ): $\delta 6.54(\mathrm{dt}, J=10.5,17 \mathrm{~Hz}, 1 \mathrm{H}), 6.03(\mathrm{t}, J=11 \mathrm{~Hz}, 1 \mathrm{H}), 5.54(\mathrm{~d}, J=3$ $\mathrm{Hz}, 2 \mathrm{H}), 5.36$ (t, $J=10 \mathrm{~Hz}, 1 \mathrm{H}), 5.21-5.38(\mathrm{~m}, 2 \mathrm{H}), 5.15$ (d, $J=10.5 \mathrm{~Hz}, 1 \mathrm{H}), 5.06$ (dd, $J=4.5,8 \mathrm{~Hz}$, 1H), 4.41-4.53 (m, 5H), 4.13 (m, 2H), $3.89(\mathrm{~m}, 1 \mathrm{H}), 3.59(\mathrm{~m}, 1 \mathrm{H}), 3.34(\mathrm{~m}, 1 \mathrm{H}), 3.19(\mathrm{~s}, 1 \mathrm{H}), 3.11$ (s, 1H), $3.02(\mathrm{~m}, 1 \mathrm{H}), 2.57(\mathrm{~m}, 1 \mathrm{H}), 2.37(\mathrm{~m}, 1 \mathrm{H}), 1.74(\mathrm{~m}, 1 \mathrm{H}), 1.62(\mathrm{~m}, 1 \mathrm{H}), 1.53(\mathrm{~m}, 1 \mathrm{H}), 1.16-1.48(\mathrm{~m}$, 9H), 0.97 (d, $J=7 \mathrm{~Hz}, 3 \mathrm{H}), 0.95$ (d, $J=6.5 \mathrm{~Hz}, 3 \mathrm{H}), 0.94$ (d, $J=7 \mathrm{~Hz}, 3 \mathrm{H}), 0.79-0.90(\mathrm{~m}, 54 \mathrm{H}), 0.08$ (s, 3H), 0.07 (s, 3H), 0.06 (s, 12H), 0.04 (s, 3H), 0.03 (s, 3H), 0.02 (s, 3H), 0.01 (s, 3H); ${ }^{13}$ C NMR (100 $\mathrm{MHz}, \mathrm{CDCl}_{3}$ ): $\delta$ 164.66, 133.32 (2C), 132.73, 132.42, 131.87, 130.34, 129.53, 126.273 (q, $J=270.5$ Hz, 2C), 118.72, 80.83, 79.98, 72.53 (2C), 66.69, 64.42, 62.80 (q, $J=38.3 \mathrm{~Hz}, 2 \mathrm{C}$ ), 42.37, 41.89, 41.65, 38.49, 35.97, 34.88, 34.75, 34.00, 33.44, 32.39, 31.33, 30.54, 29.94, 26.49 (5C), 26.17 (5C), 26.08 (5C), 20.40, 19.48, 18.70, 18.35 (2C), 17.96, 15.25, 13.32, 9.22, -2.76, -3.06, -3.38, -3.54, -3.99, -4.06, -4.11, 4.40, -4.80; [ $\alpha]_{\mathbf{D}}-28.4$ (c 0.5, $\mathrm{CHCl}_{3}$ ); IR (thin film): 3449, 2927, 1739, 1299, 1265, 1174, $1070 \mathrm{~cm}^{-1}$; HRMS (ESI) calculated for $\mathrm{C}_{66} \mathrm{H}_{129} \mathrm{~F}_{6} \mathrm{O}_{10} \mathrm{PSi}_{5} \mathrm{Na}^{+}$1389.7966, found 1389.7898 .

\section{8,10,14,20-Tetrakis-(tert-butyl-dimethyl-silanyloxy)-7,13,15,17,21-pentamethyl-22-(1-methyl- penta-2,4-dienyl)-oxacyclodocosa-3,5,11-trien-2-one, 21}

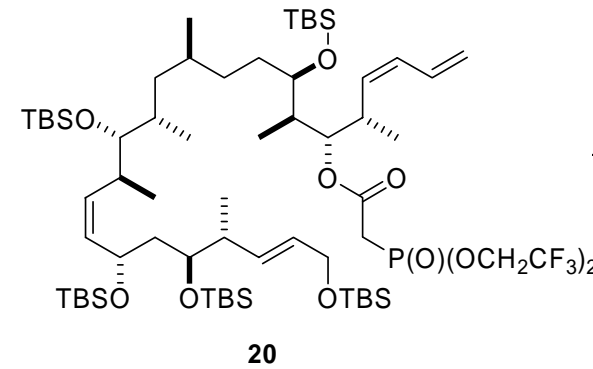

20

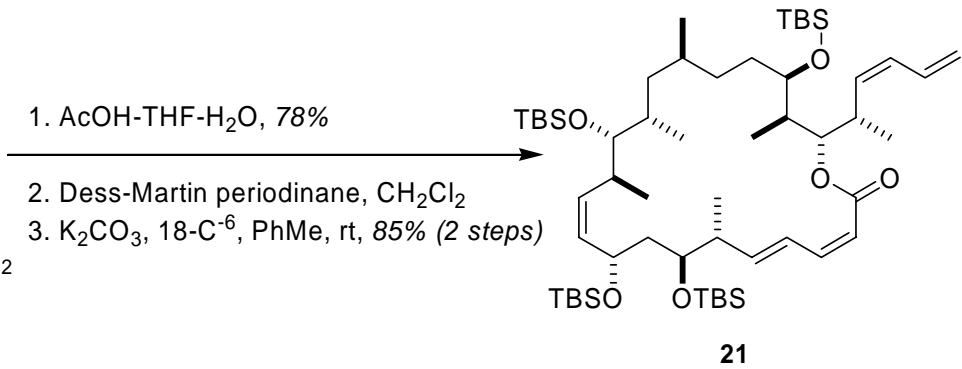

21 
Phosphonate 20 (7.8 mg, $5.7 \mu \mathrm{mol}, 1.0$ eq) was treated with a 3:1:1 AcOH:THF: $\mathrm{H}_{2} \mathrm{O}$ solution $(500 \mu \mathrm{L})$ at $0{ }^{\circ} \mathrm{C}$ and the solution was slowly warmed to rt. The reaction was stirred for $24 \mathrm{~h}$ and was then cooled to $0{ }^{\circ} \mathrm{C}$, diluted with EtOAc $(10 \mathrm{~mL})$ and quenched with saturated $\mathrm{NaHCO}_{3}$ solution $(10 \mathrm{~mL})$. The layers were separated and the aqueous phase extracted with EtOAc $(10 \mathrm{~mL})$. The combined organic extracts were dried over $\mathrm{MgSO}_{4}$, filtered, and concentrated in vacuo. The crude product was purified by flash chromatography (25\% EtOAc/hexanes) to yield the intermediate alcohol (5.6 mg, 60\%).

${ }^{1}$ H NMR (500 MHz, $\left.\mathrm{CDCl}_{3}\right): \delta 6.57(\mathrm{dt}, J=10.5,17 \mathrm{~Hz}, 1 \mathrm{H}), 6.06(\mathrm{t}, J=16.5 \mathrm{~Hz}, 1 \mathrm{H}), 5.66(\mathrm{~m}, 2 \mathrm{H})$, 5.39 (m, 2H), $5.28(\mathrm{~m}, 1 \mathrm{H}), 5.25$ (d, $J=17 \mathrm{~Hz}, 1 \mathrm{H}), 5.18(\mathrm{~d}, J=10.5 \mathrm{~Hz}, 1 \mathrm{H}), 5.09$ (dd, $J=4.5,7.5 \mathrm{~Hz}$, $1 \mathrm{H}), 4.54(\mathrm{~m}, 1 \mathrm{H}), 4.48(\mathrm{~m}, 4 \mathrm{H}), 3.93(\mathrm{~m}, 1 \mathrm{H}), 3.62(\mathrm{~m}, 1 \mathrm{H}), 3.35(\mathrm{~m}, 1 \mathrm{H}), 3.20(\mathrm{~s}, 1 \mathrm{H}), 3.16(\mathrm{~s}, 1 \mathrm{H})$, $3.05(\mathrm{~m}, 1 \mathrm{H}), 2.60(\mathrm{~m}, 1 \mathrm{H}), 2.40(\mathrm{~m}, 1 \mathrm{H}), 1.77(\mathrm{~m}, 1 \mathrm{H}), 1.65(\mathrm{~m}, 1 \mathrm{H}), 1.59(\mathrm{~m}, 1 \mathrm{H}), 1.47(\mathrm{~m}, 1 \mathrm{H}), 1.37$ (m, 2H), 1.28 (m, 4H), 1.01 (m, 1H), 1.00 (d, $J=7 \mathrm{~Hz}, 3 \mathrm{H}), 0.98$ (d, $J=7 \mathrm{~Hz}, 3 \mathrm{H}), 0.91$ (m, 36H), 0.87 (d, $J=7 \mathrm{~Hz}, 3 \mathrm{H}$ ), 0.86 (d, $J=7 \mathrm{~Hz}, 3 \mathrm{H}), 0.84$ (d, $J=7 \mathrm{~Hz}, 3 \mathrm{H}$ ), 0.83 (d, $J=6.5 \mathrm{~Hz}, 3 \mathrm{H}$ ), 0.12 (s, 3H), 0.11 (s, 3H), 0.11 (s, 3H), 0.09 (s, 3H), 0.07 (s, 3H), 0.06 (s, 6H), 0.05 (s, 3H)

To a stirred solution of the intermediate allylic alcohol (5.6 mg, $4.4 \mu \mathrm{mol}, 1.0 \mathrm{eq})$ in $\mathrm{CH}_{2} \mathrm{Cl}_{2}(90 \mu \mathrm{L}$ ) at 0 ${ }^{\circ} \mathrm{C}$ was added Dess-Martin periodinane ( $3.0 \mathrm{mg}, 6.6 \mu \mathrm{mol}, 1.5 \mathrm{eq}$ ) and the solution was allowed to warm to rt. The reaction was stirred for 45 min and was then quenched with $\mathrm{Na}_{2} \mathrm{SO}_{3}$-doped saturated $\mathrm{NaHCO}_{3}$ solution. The mixture was stirred vigorously for 15 min (until the organic layer was clear) and then the two layers were separated. The organic phase was dried over $\mathrm{MgSO}_{4}$, filtered, and concentrated in vacuo to yield the intermediate aldehyde which was used without purification.

${ }^{1}$ H NMR (500 MHz, CDCl $): \delta 9.50(\mathrm{~d}, J=8 \mathrm{~Hz}, 1 \mathrm{H}), 6.80(\mathrm{dd}, J=6.5,15.5 \mathrm{~Hz}, 1 \mathrm{H}), 6.55(\mathrm{dt}, J=$ 10.5, $16.5 \mathrm{~Hz}, 1 \mathrm{H}), 6.13$ (ddd, $J=1.5,8,15 \mathrm{~Hz}, 1 \mathrm{H}), 6.04$ (t, $J=10.5 \mathrm{~Hz}, 1 \mathrm{H}), 5.36$ (m, 2H), 5.23 (m, 2H), 5.16 (d, $J=10.5 \mathrm{~Hz}, 1 \mathrm{H}), 5.07$ (dd, $J=4,7 \mathrm{~Hz}, 1 \mathrm{H}), 4.53$ (m, 1H), 4.46 (m, 4H), 4.05 (m, 1H), $3.59(\mathrm{~m}, 1 \mathrm{H}), 3.33(\mathrm{~m}, 1 \mathrm{H}), 3.18(\mathrm{~s}, 1 \mathrm{H}), 3.14(\mathrm{~s}, 1 \mathrm{H}), 3.03(\mathrm{~m}, 1 \mathrm{H}), 2.66(\mathrm{~m}, 1 \mathrm{H}), 2.55(\mathrm{~m}, 1 \mathrm{H}), 1.75$ (m, 2H), $1.57(\mathrm{~m}, 2 \mathrm{H}), 1.48(\mathrm{~m}, 1 \mathrm{H}), 1.40(\mathrm{~m}, 1 \mathrm{H}) 1.33(\mathrm{~m}, 2 \mathrm{H}), 1.20(\mathrm{~m}, 3 \mathrm{H}), 1.08$ (d, $J=7 \mathrm{~Hz}, 3 \mathrm{H})$, 0.98 (d, $J=7 \mathrm{~Hz}, 3 \mathrm{H}), 0.89$ (m, 39H), 0.81 (d, $J=7 \mathrm{~Hz}, 3 \mathrm{H}), 0.81$ (d, $J=6 \mathrm{~Hz}, 3 \mathrm{H}), 0.12$ (s, 3H), 0.10 (s, 3H), 0.08 (s, 3H), 0.07 (s, 3H), 0.06 (s, 3H), 0.04 (s, 3H), 0.03 (s, 3H), 0.02 (s, 3H).

To a flask containing $\mathrm{K}_{2} \mathrm{CO}_{3}(4.0 \mathrm{mg}$, $26.4 \mu \mathrm{mol}$, $6.0 \mathrm{eq})$, briefly flame-dried under vacuum, was added a solution of the intermediate aldehyde and 18-crown-6 (14.0 mg, $52.8 \mu \mathrm{mol}, 12.0 \mathrm{eq})$ as a solution in toluene $(4.4 \mathrm{~mL})$ and the reaction was stirred for $6 \mathrm{~h}$. The reaction was diluted with EtOAc, washed with water, and the organic phase dried over $\mathrm{MgSO}_{4}$, filtered, and concentrated in vacuo. The crude product was purified by flash chromatography ( $5 \% \mathrm{Et}_{2} \mathrm{O} /$ hexanes) to yield 21 (3 mg, $74 \%$ of desired diastereoisomer over 2 steps).

${ }^{1}$ H NMR (500 MHz, CDCl $\left.)_{3}\right): \delta 7.02(\mathrm{~m}, 1 \mathrm{H}), 6.56-6.64(\mathrm{~m}, 2 \mathrm{H}), 6.09(\mathrm{t}, J=11 \mathrm{~Hz}, 1 \mathrm{H}), 6.06$ (dd, $J=$ 6, $15.5 \mathrm{~Hz}, 1 \mathrm{H}), 5.64(\mathrm{~d}, J=11.5 \mathrm{~Hz}, 1 \mathrm{H}), 5.63(\mathrm{~m}, 1 \mathrm{H}), 5.44(\mathrm{t}, J=10.5 \mathrm{~Hz}, 1 \mathrm{H}), 5.37$ (t, $J=8.5 \mathrm{~Hz}$, 1H), 5.24 (d, $J=10.5 \mathrm{~Hz}, 1 \mathrm{H}), 5.16$ (d, $J=10.5 \mathrm{~Hz}, 1 \mathrm{H}), 5.10(\mathrm{~m}, 1 \mathrm{H}), 4.57$ (t, $J=9 \mathrm{~Hz}), 4.07$ (m, 1H), $3.68(\mathrm{~m}, 1 \mathrm{H}), 3.23(\mathrm{~d}, J=6.5 \mathrm{~Hz}, 1 \mathrm{H}), 3.08(\mathrm{~m}, 1 \mathrm{H}), 2.63(\mathrm{~m}, 1 \mathrm{H}), 2.57(\mathrm{~m}, 2 \mathrm{H}), 1.86(\mathrm{~m}, 1 \mathrm{H}), 1.43-$ 1.56 (m, 5H), 1.31 (m, 4H), 1.06 (d, $J=6.5 \mathrm{~Hz}, 3 \mathrm{H}), 1.05$ (d, $J=7 \mathrm{~Hz}, 3 \mathrm{H}), 1.01$ (d, $J=7 \mathrm{~Hz}, 3 \mathrm{H})$, 0.99 (d, $J=7 \mathrm{~Hz}, 3 \mathrm{H}), 0.88-0.96$ (m, 36H), 0.82 (d, $J=6.5 \mathrm{~Hz}, 3 \mathrm{H}), 0.80$ (d, $J=6.5 \mathrm{~Hz}, 3 \mathrm{H}), 0.15$ (s, 3H), 0.12 (s, 3H), 0.109 (s, 3H), 0.09 (s, 3H), 0.08 (s, 3H), 0.07 (s, 3H); ${ }^{13}$ C NMR (100 MHz, $\mathrm{CDCl}_{3}$ ): $\delta$ 166.80, 143.17, 134.28, 132.66, 131.98, 130.07, 128.57, 128.22, 118.69, 118.42, 114.12, 81.14, 79.12, 77.45, 70.47, 66.64, 43.20, 41.54, 39.18, 35.32, 34.85, 34.66, 32.16, 30.49, 29.94 (2C), 29.60 (2C), 26.45 (3C), 26.27 (3C), 26.13 (3C), 26.06 (3C), 22.93, 20.50, 19.98, 18.73, 18.50, 18.38, 16.40, 14.37, 2.45, -3.25, -3.55, -3.72, -3.91 (2C), - 4.08 (2C); [ $\alpha]_{\mathbf{D}}-17.8$ (c 0.1, $\mathrm{CHCl}_{3}$ ); IR (thin film): 2955, 2929, 
2857, 1716, 1640, 1474, 1225, $1045 \mathrm{~cm}^{-1}$; HRMS (ESI) calculated for $\mathrm{C}_{56} \mathrm{H}_{108} \mathrm{O}_{6} \mathrm{Si}_{4} \mathrm{Na}^{+}{ }_{1011.7115,} 15$ found 1011.7131.

\section{Dictyostatin, 1}

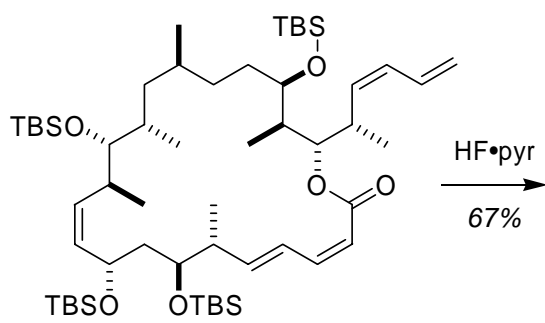

21

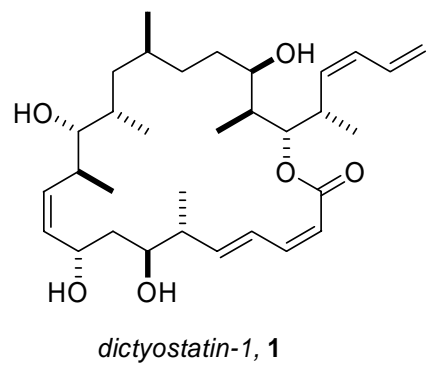

To a solution of macrolactone $21(3.0 \mathrm{mg}, 3 \mu \mathrm{mol}, 1.0 \mathrm{eq})$ in THF $(400 \mu \mathrm{L})$ at $0{ }^{\circ} \mathrm{C}$ was added HF•pyridine $(100 \mu \mathrm{L})$ dropwise over 2 min and the solution was allowed to slowly warm to rt. The reaction was stirred $40 \mathrm{~h}$ and was then cooled to $0{ }^{\circ} \mathrm{C}$, diluted with EtOAc $(2 \mathrm{~mL})$, and quenched with saturated $\mathrm{NaHCO}_{3}$ solution $(2 \mathrm{~mL})$. The layers were separated and the aqueous layer extracted with EtOAc $(3 \times 2 \mathrm{~mL})$. The combined organic extracts were dried over $\mathrm{MgSO}_{4}$, filtered, and concentrated in vacuo. The crude product was purified by flash chromatography $(50 \rightarrow 75 \rightarrow 100 \%$ EtOAc/hexanes) to yield 1 (1.1 mg, 67\%).

${ }^{1}$ H NMR (500 MHz, CD $\left.\mathrm{CD}_{3} \mathrm{OD}\right): \delta 7.18$ (dd, $\left.J=11.5,16 \mathrm{~Hz}, 1 \mathrm{H}\right), 6.68(\mathrm{dt}, J=10.5,16.5 \mathrm{~Hz}, 1 \mathrm{H}), 6.62$ (t, $J=11.5 \mathrm{~Hz}, 1 \mathrm{H}), 6.16(\mathrm{dd}, J=6.5,15.5 \mathrm{~Hz}, 1 \mathrm{H}), 6.03(\mathrm{t}, J=11 \mathrm{~Hz}, 1 \mathrm{H}), 5.53(\mathrm{~d}, J=11.5 \mathrm{~Hz}, 1 \mathrm{H})$, $5.52(\mathrm{t}, J=10.5 \mathrm{~Hz}, 1 \mathrm{H}), 5.38(\mathrm{dd}, J=8.5,11 \mathrm{~Hz}, 1 \mathrm{H}), 5.31(\mathrm{t}, J=11 \mathrm{~Hz}, 1 \mathrm{H}), 5.22(\mathrm{~d}, J=17.5 \mathrm{~Hz}$, 1H), 5.09-5.13 (m, 2H), $4.62(\mathrm{~m}, 1 \mathrm{H}), 4.03(\mathrm{dt}, J=3,11 \mathrm{~Hz}, 1 \mathrm{H}), 3.34(\mathrm{~m}, 1 \mathrm{H}), 3.13(\mathrm{dt}, J=7,10 \mathrm{~Hz}$, 1H), 3.07 (dd, $J=3,8 \mathrm{~Hz}, 1 \mathrm{H}), 2.73(\mathrm{~m}, 1 \mathrm{H}), 2.57(\mathrm{~m}, 1 \mathrm{H}), 1.82(\mathrm{~m}, 1 \mathrm{H}), 1.86(\mathrm{~m}, 1 \mathrm{H}), 1.60(\mathrm{~m}, 1 \mathrm{H})$, 1.58 (m, 1H), 1.55 (m, 1H), 1.47 (m, 1H), 1.40 (m, 1H), 1.22 (m, 1H), 1.12 (d, $J=7 \mathrm{~Hz}, 3 \mathrm{H}), 1.09$ (d, $J$ $=7 \mathrm{~Hz}, 3 \mathrm{H}), 1.07(\mathrm{~m}, 1 \mathrm{H}), 1.04(\mathrm{~d}, J=7 \mathrm{~Hz}, 3 \mathrm{H}), 0.98$ (d, $J=6.5 \mathrm{~Hz}, 3 \mathrm{H}), 0.92$ (d, $J=6.5 \mathrm{~Hz}, 3 \mathrm{H})$, 0.90 (d, $J=7 \mathrm{~Hz}, 3 \mathrm{H}), 0.88$ (m, 1H), 0.67 (m, 1H); ${ }^{13}$ C NMR (125 MHz, CD $\left.{ }_{3} \mathrm{OD}\right): \delta 168.10,146.24$, 144.74, 134.76, 134.36, 133.28, 131.12, 130.71, 128.38, 118.33, 117.83, 80.13, 78.39, 73.49, 70.16, 65.35, 43.84, 42.01, 40.60, 40.37, 36.36, 35.53, 35.12, 32.79, 32.46, 31.09, 21.58, 19.09, 17.85, 15.69, 13.53, 10.12; $[\alpha]_{\mathbf{D}}-22.00\left(\right.$ c $0.05 \mathrm{MeOH}$ ); HRMS (ESI) calculated for $\mathrm{C}_{32} \mathrm{H}_{52} \mathrm{O}_{6} \mathrm{H}^{+}$533.3836, found 533.3831 . 
Table. Comparison of data for synthetic and natural dictyostatin

\begin{tabular}{|c|c|c|c|c|}
\hline Entry & Natural $\left(\mathrm{CD}_{3} \mathrm{OD}\right)$ & & Synthetic $\left(\mathrm{CD}_{3} \mathrm{OD}\right)$ & \\
\hline & ${ }^{1} \mathrm{H} \delta$ (mult, $J$ ) & ${ }^{13} \mathrm{C} \delta$ & & ${ }^{13} \mathrm{C} \delta^{3}$ \\
\hline 1 & - & 168.10 & - & 168.10 \\
\hline 2 & $5.52(d, 11)$ & 118.03 & $5.53(\mathrm{~d}, 11.5)$ & 117.83 \\
\hline 3 & $6.62(\mathrm{t}, 11)$ & 144.89 & $6.62(\mathrm{t}, 11.5)$ & 144.74 \\
\hline 4 & $7.17(\mathrm{dd}, 11,16)$ & 128.58 & $7.18(\mathrm{dd}, 11.5,16)$ & 128.68 \\
\hline 5 & $6.14(\mathrm{dd}, 6.7,16)$ & 146.42 & $6.16(\mathrm{dd}, 6.5,15.5)$ & 146.28 \\
\hline 6 & 2.57 (brm) & 44.05 & $2.57(\mathrm{~m})$ & 43.99 \\
\hline 7 & $4.02(\mathrm{dt}, 3.1,10.7)$ & 70.37 & $4.03(\mathrm{dt}, 3,11)$ & 70.26 \\
\hline \multirow[t]{2}{*}{8} & $1.47(\mathrm{~m})$ & 40.59 & $1.47(\mathrm{~m})$ & 40.60 \\
\hline & $1.38(\mathrm{~m})$ & & $1.40(\mathrm{~m})$ & \\
\hline 9 & 4.62 (br dd, 4.8, 8.7) & 65.50 & $4.62(\mathrm{~m})$ & 65.35 \\
\hline 10 & 5.37 (br dd, 8.7, 11) & 134.89 & $5.38(\mathrm{dd}, 8.5,11)$ & 134.76 \\
\hline 11 & $5.52(\mathrm{br} \mathrm{t}, 11)$ & 131.32 & $5.52(\mathrm{t}, 10.5)$ & 131.03 \\
\hline 12 & $2.72(\mathrm{brm})$ & 35.74 & $2.73(\mathrm{~m})$ & 35.53 \\
\hline 13 & $3.06(\mathrm{dd}, 2.9,8.2)$ & 80.37 & $3.07(\mathrm{dd}, 3,8)$ & 80.35 \\
\hline 14 & $1.58(\mathrm{~m})$ & 35.32 & $1.60(\mathrm{~m})$ & 35.31 \\
\hline \multirow[t]{2}{*}{15} & $1.22(\mathrm{~m})$ & 42.26 & $1.22(\mathrm{~m})$ & 42.11 \\
\hline & $0.88(\mathrm{~m})$ & & $0.88(\mathrm{~m})$ & \\
\hline 16 & $1.50(\mathrm{~m})$ & 31.22 & $1.52(\mathrm{~m})$ & 31.09 \\
\hline \multirow[t]{2}{*}{17} & $1.56(\mathrm{~m})$ & 32.74 & $1.58(\mathrm{~m})$ & 32.73 \\
\hline & $0.68(\mathrm{~m})$ & & $0.67(\mathrm{~m})$ & \\
\hline \multirow[t]{2}{*}{18} & $1.82(\mathrm{~m})$ & 32.50 & $1.82(\mathrm{~m})$ & 32.46 \\
\hline & $1.08(\mathrm{~m})$ & & $1.07(\mathrm{~m})$ & \\
\hline 19 & $3.33(\mathrm{~m})$ & 73.72 & $3.34(\mathrm{~m})$ & 73.55 \\
\hline 20 & $1.86(\mathrm{~m})$ & 40.82 & $1.86(\mathrm{~m})$ & 40.70 \\
\hline 21 & $5.10(\mathrm{dd}, 5,7)$ & 78.63 & $5.09-5.13(\mathrm{~m}, 2 \mathrm{H})$ & 78.48 \\
\hline 22 & 5.11 (brd, 11) & 118.58 & & 118.59 \\
\hline 23 & $3.13(\mathrm{~m})$ & 35.82 & $3.13(\mathrm{dt}(7,10)$ & 36.36 \\
\hline 24 & $5.30(\mathrm{t}, 11)$ & 134.53 & $5.31(\mathrm{t}, 11)$ & 134.55 \\
\hline 25 & $6.02(\mathrm{t}, 11)$ & 131.22 & $6.03(\mathrm{t}, 11)$ & 131.12 \\
\hline \multirow[t]{2}{*}{26} & $6.67(\mathrm{dt}, 11,17)$ & 133.43 & $6.68(\mathrm{dt}, 10.5,16.5)$ & 133.28 \\
\hline & 5.21 (brd, 17) & & $5.22(\mathrm{~d}, 17.5)$ & \\
\hline 27 & $1.11(\mathrm{~d}, 7.0)$ & 13.75 & $1.12(\mathrm{~d}, 7)$ & 13.53 \\
\hline 28 & $1.09(\mathrm{~d}, 7.1)$ & 19.35 & $1.09(\mathrm{~d}, 6.5)$ & 19.12 \\
\hline 29 & $0.92(\mathrm{~d}, 6.4)$ & 15.97 & $0.92(\mathrm{~d}, 6.5)$ & 15.84 \\
\hline 30 & $0.89(\mathrm{~d}, 6.5)$ & 21.81 & $0.90(\mathrm{~d}, 7)$ & 21.58 \\
\hline 31 & $1.03(\mathrm{~d}, 6.8)$ & 10.39 & $1.04(\mathrm{~d}, 7)$ & 10.21 \\
\hline 32 & $0.98(\mathrm{~d}, 6.7)$ & 18.06 & $0.98(\mathrm{~d}, 6.5)$ & 17.95 \\
\hline
\end{tabular}

\footnotetext{
${ }^{3}$ Due to limited sample, this data was obtained by HSQC and HMBC experiments.
} 
Procedure for the Synthesis of Acid 3

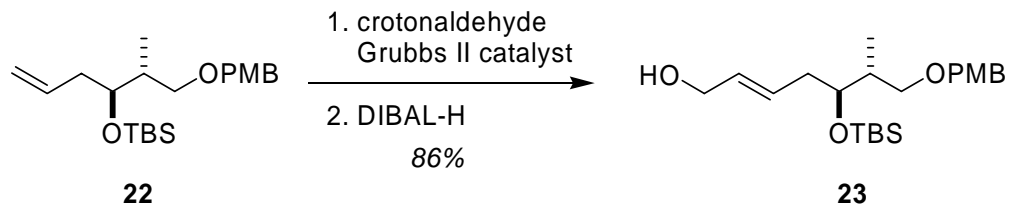

To a stirred solution of $\mathbf{2 2}^{4}$ (500 $\mathrm{mg}, 1.37 \mathrm{mmol}, 1.0 \mathrm{eq}$ ) in toluene $(13.7 \mathrm{~mL}$ ) was added crotonaldehyde (560 $\mu \mathrm{L}, 6.85 \mathrm{mmol}, 5.0$ eq) and Grubbs second generation catalyst (58 mg, $0.069 \mathrm{mmol}, 0.05 \mathrm{eq}$ ) and the reaction was heated to $60{ }^{\circ} \mathrm{C}$. After stirring for $3 \mathrm{~h}$, the reaction was cooled to $\mathrm{rt}$, and the volatiles were removed in vacuo. The residue was dissolved in $\mathrm{CH}_{2} \mathrm{Cl}_{2}(13.70 \mathrm{~mL})$ and cooled to $-78{ }^{\circ} \mathrm{C}$. DIBAL-H (300 $\mathrm{LL}, 1.64 \mathrm{mmol}, 1.2 \mathrm{eq})$, was added and the reaction was warmed to $0{ }^{\circ} \mathrm{C}$ and stirred for 15 min, before being quenched with saturated $\mathrm{Na}_{2} \mathrm{SO}_{4}(25 \mathrm{~mL})$. The mixture was stirred with EtOAc $(50 \mathrm{~mL})$ for $1 \mathrm{~h}$, and was then filtered through Celite, and the layers were separated. The organic phase was dried over $\mathrm{MgSO}_{4}$, filtered, and concentrated in vacuo. The crude product was purified by flash chromatography (25\% EtOAc/hexanes) to yield the allylic alcohol (460 mg, 86\%) as an oil.

${ }^{1}$ H NMR (400 MHz, $\mathrm{CDCl}_{3}$ ): $\delta 7.25$ (d, $\left.J=9.2 \mathrm{~Hz}, 2 \mathrm{H}\right), 6.87$ (d, $\left.J=8.8 \mathrm{~Hz}, 2 \mathrm{H}\right), 4.41$ (m, 2H), 4.09 (d, $J=5.6 \mathrm{~Hz}, 2 \mathrm{H}), 3.81(\mathrm{~s}, 3 \mathrm{H}), 3.70(\mathrm{~m}, 1 \mathrm{H}), 3.46(\mathrm{dd}, J=5.6,9.2 \mathrm{~Hz}, 1 \mathrm{H}), 3.26(\mathrm{dd}, J=6.8,8.8 \mathrm{~Hz}$, 1H), $2.18(\mathrm{~m}, 2 \mathrm{H}), 1.92(\mathrm{~m}, 1 \mathrm{H}), 0.91(\mathrm{~d}, J=7.2 \mathrm{~Hz}, 3 \mathrm{H}), 0.87(\mathrm{~m}, 9 \mathrm{H}), 0.02(\mathrm{~s}, 6 \mathrm{H}) ;{ }^{13} \mathbf{C}$ NMR $(100$ $\mathrm{MHz}, \mathrm{CDCl}_{3}$ ): $\delta$ 159.26, 131.37, 131.03, 130.00 (2C), 113.93 (2C), 73.55, 72.88, 72.32, 64.11, 55.51, 38.68, 36.71, 26.11 (3C), 18.34, 13.59, -4.01, -4.45.
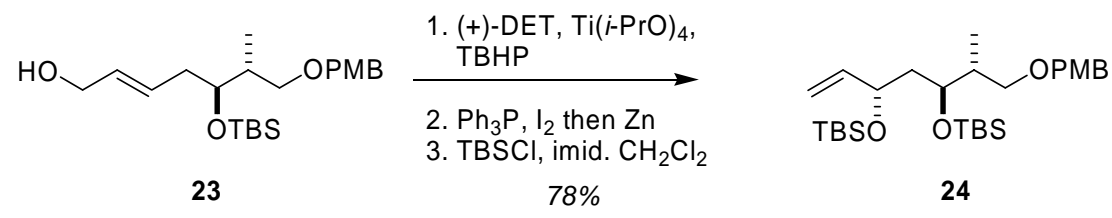

To a stirred solution of (+)-diethyltartrate ( $30 \mu \mathrm{l}, 0.175 \mathrm{mmol}, 0.15 \mathrm{eq})$ in $\mathrm{CH}_{2} \mathrm{Cl}_{2}(7.00 \mathrm{~mL})$ over freshly activated $4 \AA \hat{~ m o l e c u l a r ~ s i e v e s ~}(92 \mathrm{mg})$ at $0{ }^{\circ} \mathrm{C}$ was added $\mathrm{Ti}(\mathrm{i}-\mathrm{PrO})_{4}(45 \mu \mathrm{l}, 0.152 \mathrm{mmol}, 0.13$ eq) and the reaction was stirred for 5 min The reaction was then cooled to $-20^{\circ} \mathrm{C}$ and a $3.3 \mathrm{M}$ solution of tert-butyl hydrogen peroxide in toluene ( $636 \mu \mathrm{l}, 1.8 \mathrm{eq})$ was added. The reaction was stirred for $20 \mathrm{~min}$, and then the allylic alcohol $(0.46 \mathrm{~g}, 1.17 \mathrm{mmol}, 1.0 \mathrm{eq})$ was added as a solution in $\mathrm{CH}_{2} \mathrm{Cl}_{2}(1.75 \mathrm{~mL})$. The reaction was kept at this temperature for $15 \mathrm{~h}$, and then $\mathrm{H}_{2} \mathrm{O}(0.86 \mathrm{~mL})$ was added and the solution warmed to rt. The mixture was stirred for $45 \mathrm{~min}$, and then a $30 \%$ solution of $\mathrm{NaOH}$ in saturated $\mathrm{NaCl}$ $(0.17 \mathrm{~mL})$ was added. The reaction was stirred for $30 \mathrm{~min}$, and was then filtered through a plug of cotton and then filtered through Celite with $\mathrm{CH}_{2} \mathrm{Cl}_{2}$ and water. The layers were separated, and the organic phase was washed with saturated aqueous $\mathrm{NaCl}$, dried over $\mathrm{MgSO}_{4}$, and concentrated in vacuo. The product was used without further purification.

${ }^{1}$ H NMR (500 MHz, $\left.\mathrm{CDCl}_{3}\right): \delta 7.27(\mathrm{~d}, J=6.5 \mathrm{~Hz}, 2 \mathrm{H}), 6.90(\mathrm{~d}, J=8.5 \mathrm{~Hz}, 2 \mathrm{H}), 4.43(\mathrm{~m}, 2 \mathrm{H}), 4.01$ (m, 1H), 3.95 (ddd, $J=2.5,5.5,17.5 \mathrm{~Hz}, 1 \mathrm{H}), 3.83(\mathrm{~s}, 3 \mathrm{H}), 3.64$ (m, 1H), 3.38 (dd, $J=7,9.5 \mathrm{~Hz}, 1 \mathrm{H}$ ), 3.26 (dd, $J=6.5,9.5 \mathrm{~Hz}, 1 \mathrm{H}), 3.10(\mathrm{~m}, 1 \mathrm{H}), 2.95(\mathrm{~m}, 1 \mathrm{H}), 2.06(\mathrm{~m}, 1 \mathrm{H}), 1.71(\mathrm{~m}, 1 \mathrm{H}), 1.52(\mathrm{~m}, 1 \mathrm{H})$, $0.91(\mathrm{~m}, 12 \mathrm{H}), 0.10(\mathrm{~s}, 6 \mathrm{H})$.

\footnotetext{
${ }^{4}$ White, J. D.; Hong, J.; Robarge, L. D. J. Org. Chem. 1999, 64, 6206.
} 
To a stirred solution of the intermediate epoxy alcohol in THF $(4.00 \mathrm{~mL})$ and MeCN $(1.20 \mathrm{~mL})$ was added $\mathrm{PPh}_{3}(0.368 \mathrm{~g}, 1.40 \mathrm{mmol}, 1.2 \mathrm{eq})$ and imidazole $(0.096 \mathrm{~g}, 1.40 \mathrm{mmol}, 1.2 \mathrm{eq})$ and the solution was cooled to $0^{\circ} \mathrm{C}$. $\mathrm{I}_{2}(0.356 \mathrm{~g}, 1.40 \mathrm{mmol}, 1.2 \mathrm{eq})$ was then added as a solution in THF $(0.68 \mathrm{~mL})$ and the reaction was stirred for $45 \mathrm{~min}$ Activated zinc ${ }^{5}(0.459 \mathrm{~g}, 7.02 \mathrm{mmol}, 6.0 \mathrm{eq})$ was then added and the solution heated to reflux for $30 \mathrm{~min}$ The reaction was cooled to rt, water was added $(0.15 \mathrm{~mL})$ and the mixture was filtered through Celite and concentrated in vacuo. The crude product was purified by flash chromatography (10\% EtOAc/hexanes) to yield the allylic alcohol as an oil.

To a solution of the allylic alcohol (0.36 g, $0.913 \mathrm{mmol}, 1.0 \mathrm{eq})$ in $\mathrm{CH}_{2} \mathrm{Cl}_{2}(3.65 \mathrm{~mL})$ at $0{ }^{\circ} \mathrm{C}$ was added imidazole (0.155 g, $2.28 \mathrm{mmol}, 2.5 \mathrm{eq})$ and TBSCl $(0.165 \mathrm{~g}, 1.10 \mathrm{mmol}, 1.2 \mathrm{eq})$ and the reaction was warmed to rt. The reaction was stirred for 4 h, diluted with $\mathrm{Et}_{2} \mathrm{O}(25 \mathrm{~mL})$, washed with aq. $\mathrm{NH}_{4} \mathrm{Cl}(25$ $\mathrm{mL})$ and saturated aqueous $\mathrm{NaCl}(25 \mathrm{~mL})$, dried over $\mathrm{MgSO}_{4}$, filtered, and concentrated in vacuo to give 24 (464 mg, 78\% over 3 steps). The intermediate silyl ether could be used without further purification.

${ }^{1} \mathbf{H}$ NMR (500 MHz, $\left.\mathrm{CDCl}_{3}\right): \delta 7.28$ (d, $\left.J=6.5 \mathrm{~Hz}, 2 \mathrm{H}\right), 6.90$ (d, $\left.J=8.5 \mathrm{~Hz}, 2 \mathrm{H}\right), 5.82$ (m, $\left.1 \mathrm{H}\right), 5.13$ (d, $J=17 \mathrm{~Hz}, 1 \mathrm{H}), 5.04$ (d, $J=10 \mathrm{~Hz}, 1 \mathrm{H}), 4.44$ (m, 2H), 4.20 (m, 1H), 3.91 (m, 1H), 3.83 (s, $3 \mathrm{H}), 3.46$ (dd, $J=6,9.5 \mathrm{~Hz}, 1 \mathrm{H}), 3.22$ (dd, $J=7.5,9.5 \mathrm{~Hz}, 1 \mathrm{H}), 2.01$ (m, 1H), 1.66 (m, 1H), 1.48 (m, $1 \mathrm{H}), 0.92$ (d, $J=7 \mathrm{~Hz}, 3 \mathrm{H}), 0.90$ (s, 9H), 0.89 (s, 9H), 0.13 (s, 3H), 0.09 (s, 3H), 0.07 (s, 6H).

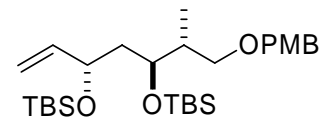

24

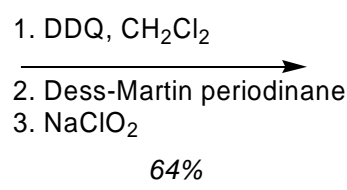

$64 \%$

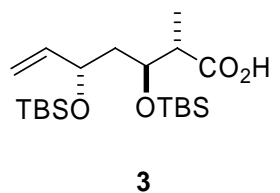

3

To a stirred solution of 24 (464 mg, $0.91 \mathrm{mmcol})$ in $\mathrm{CH}_{2} \mathrm{Cl}_{2}(9 \mathrm{~mL})$ at $0{ }^{\circ} \mathrm{C}$ was added DDQ $(0.249 \mathrm{~g}$, $1.10 \mathrm{mmol}, 1.2 \mathrm{eq})$. The reaction was stirred for $15 \mathrm{~min}$ and was then quenched with $\mathrm{pH}=7 \mathrm{buffer}$ (25 $\mathrm{mL})$. The mixture was extracted with $\mathrm{CH}_{2} \mathrm{Cl}_{2}(3 \times 25 \mathrm{~mL})$, and the combined organic extracts were dried with $\mathrm{MgSO}_{4}$, filtered, and concentrated in vacuo. The crude product was purified by flash chromatography (25\% Et $\mathrm{E}_{2} \mathrm{O} /$ hexanes) to provide the intermediate alcohol.

To a stirred solution of the intermediate alcohol in $\mathrm{CH}_{2} \mathrm{Cl}_{2}(7 \mathrm{~mL})$ at $0{ }^{\circ} \mathrm{C}$ was added Dess-Martin periodinane ( $0.372 \mathrm{~g}, 0.88 \mathrm{mmol}, 1.2 \mathrm{eq})$ and the reaction was warmed to rt. The reaction was stirred for $45 \mathrm{~min}$ and was then quenched with $\mathrm{Na}_{2} \mathrm{SO}_{3}$-doped saturated $\mathrm{NaHCO}_{3}$ solution $(25 \mathrm{~mL}$ ) and EtOAc $(25 \mathrm{~mL})$. The mixture was stirred vigorously $30 \mathrm{~min}$ (until the organic layer was clear) and then the two layers were separated. The organic phase was dried over $\mathrm{MgSO}_{4}$, filtered, and concentrated in vacuo to provide the crude aldehyde, which was used immediately without further purification.

To a stirred solution of the intermediate aldehyde in THF (11.68 mL) and $\mathrm{H}_{2} \mathrm{O}(2.92 \mathrm{~mL})$ at rt. was added a 2M solution of 2-methyl-2-butene in THF (1.53 mL, $3.07 \mathrm{mmol}, 4.2 \mathrm{eq})$ and $\mathrm{KH}_{2} \mathrm{PO}_{4}(0.140 \mathrm{~g}$, $0.80 \mathrm{mmol}, 1.1 \mathrm{eq})$. The reaction was stirred for $5 \mathrm{~min}$, and then $\mathrm{NaClO}_{2}(0.198 \mathrm{~g}, 2.19 \mathrm{mmol}, 3.0 \mathrm{eq})$ was added and the reaction was stirred for $2.5 \mathrm{~h}$. The reaction was quenched with aq. $\mathrm{NH}_{4} \mathrm{Cl}(25 \mathrm{~mL})$ and the mixture extracted with EtOAc $(2 \times 25 \mathrm{~mL})$. The combined organic extracts were dried over $\mathrm{MgSO}_{4}$, filtered, and concentrated in vacuo. The crude product was purified by flash chromatography (25\% EtOAc/hexanes) to yield 3 (0.250 g, 64\% over 3 steps) as an oil.

\footnotetext{
${ }^{5}$ Activated by washing with $2 \% \mathrm{HCl}$, distilled water, $95 \% \mathrm{EtOH}$, and finally $\mathrm{Et}_{2} \mathrm{O}$.
} 
${ }^{1} \mathbf{H}$ NMR (500 MHz, $\left.\mathrm{CDCl}_{3}\right): \delta 5.79(\mathrm{~m}, 1 \mathrm{H}), 5.17(\mathrm{~d}, J=17 \mathrm{~Hz}, 1 \mathrm{H}), 5.10(\mathrm{~d}, J=10 \mathrm{~Hz}, 1 \mathrm{H}), 4.20$ (dd, $J=7,13 \mathrm{~Hz}, 1 \mathrm{H}), 4.01$ (m, 1H), 2.75 (qd, $J=3,7 \mathrm{~Hz}, 1 \mathrm{H}), 1.83(\mathrm{~m}, 1 \mathrm{H}), 1.71$ (dt, $J=6.5,14 \mathrm{~Hz}, 1 \mathrm{H})$, 1.23 (d, $J=7$ Hz, 3H), 0.94 (s, 9H), 0.91 (s, 9H), 0.17 (s, 3H), 0.14 (s, 3H), 0.09 (s, 3H), 0.06 (s, 3H); ${ }^{13} \mathrm{C}$ NMR (400 MHz, $\mathrm{CDCl}_{3}$ ): $\delta$ 177.17, 141.46, 115.18, 71.93, 71.78, 45.50, 43.92, 26.08 (3C), 25.96 (3C), 18.36, 18.18, 13.95, -3.67, -4.00, -4.43, -4.49; [ $\alpha]_{\mathbf{D}}+28.4\left(c 0.5 \mathrm{CHCl}_{3}\right)$; IR (thin film): 1714, 1320, 1249, 1060, 957, $911 \mathrm{~cm}^{-1}$; HRMS (ESI) calculated for $\mathrm{C}_{20} \mathrm{H}_{42} \mathrm{O}_{4} \mathrm{Si}_{2} \mathrm{Na}^{+}$425.2513, found 425.2503. 


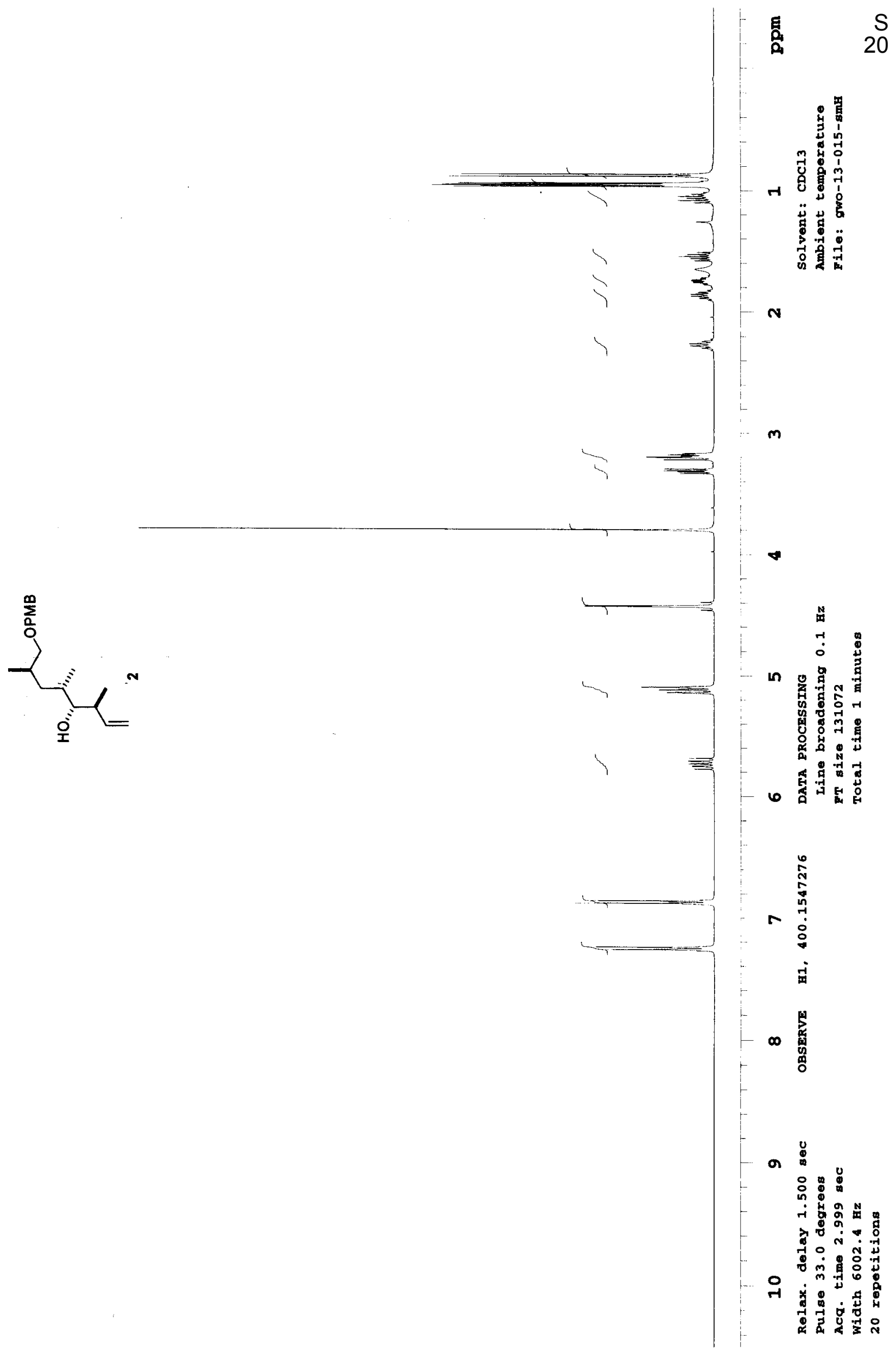




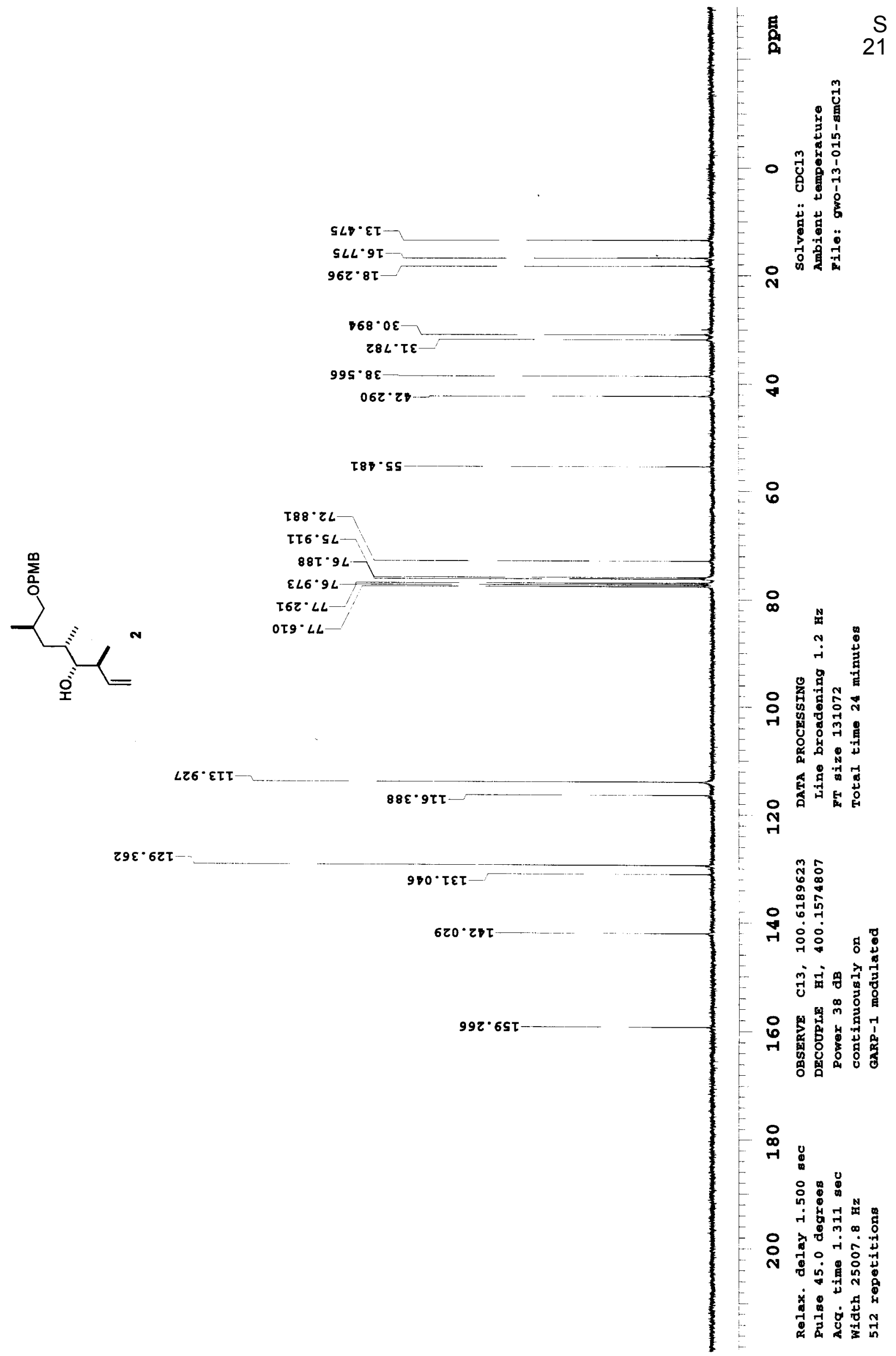




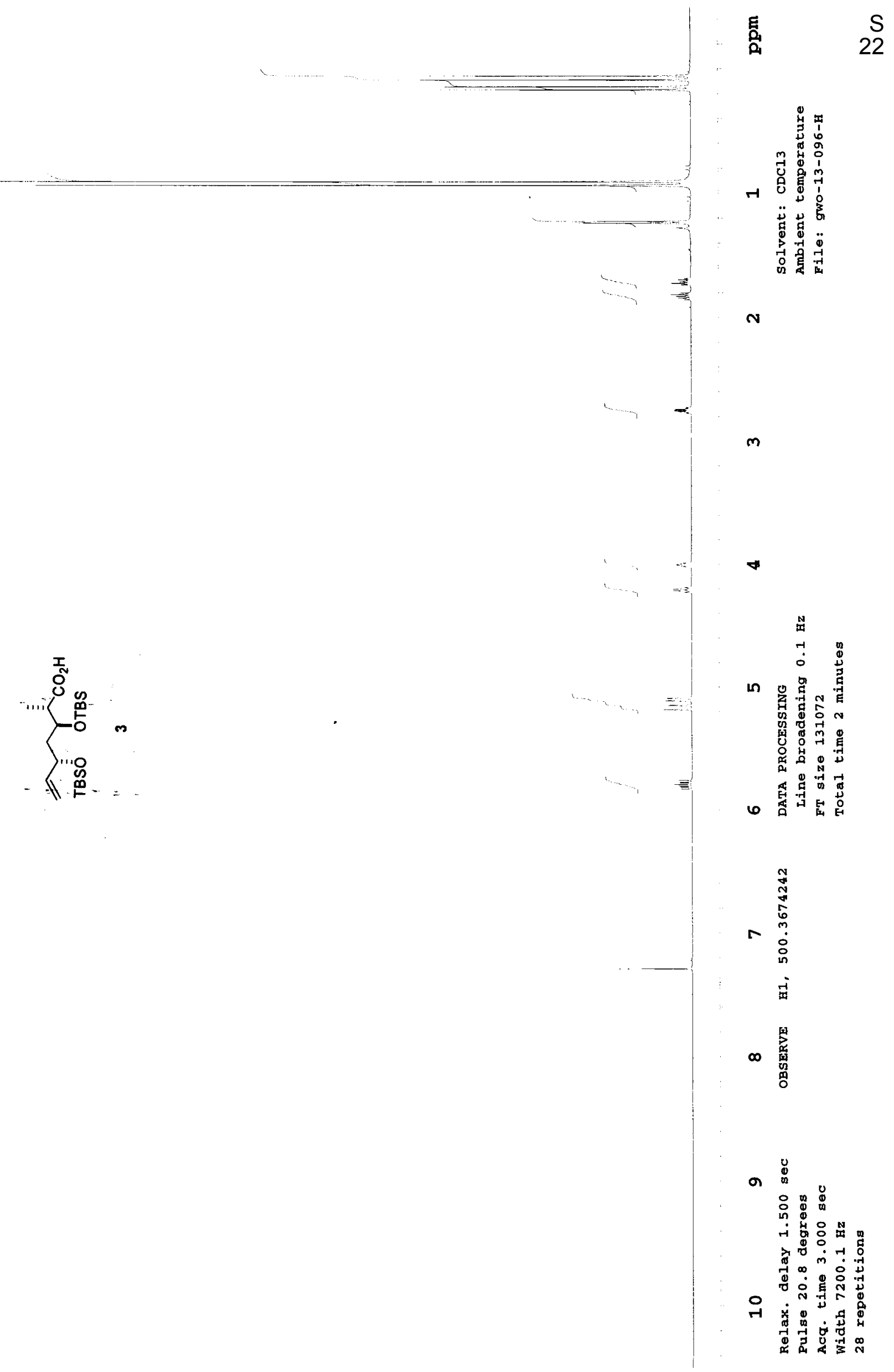




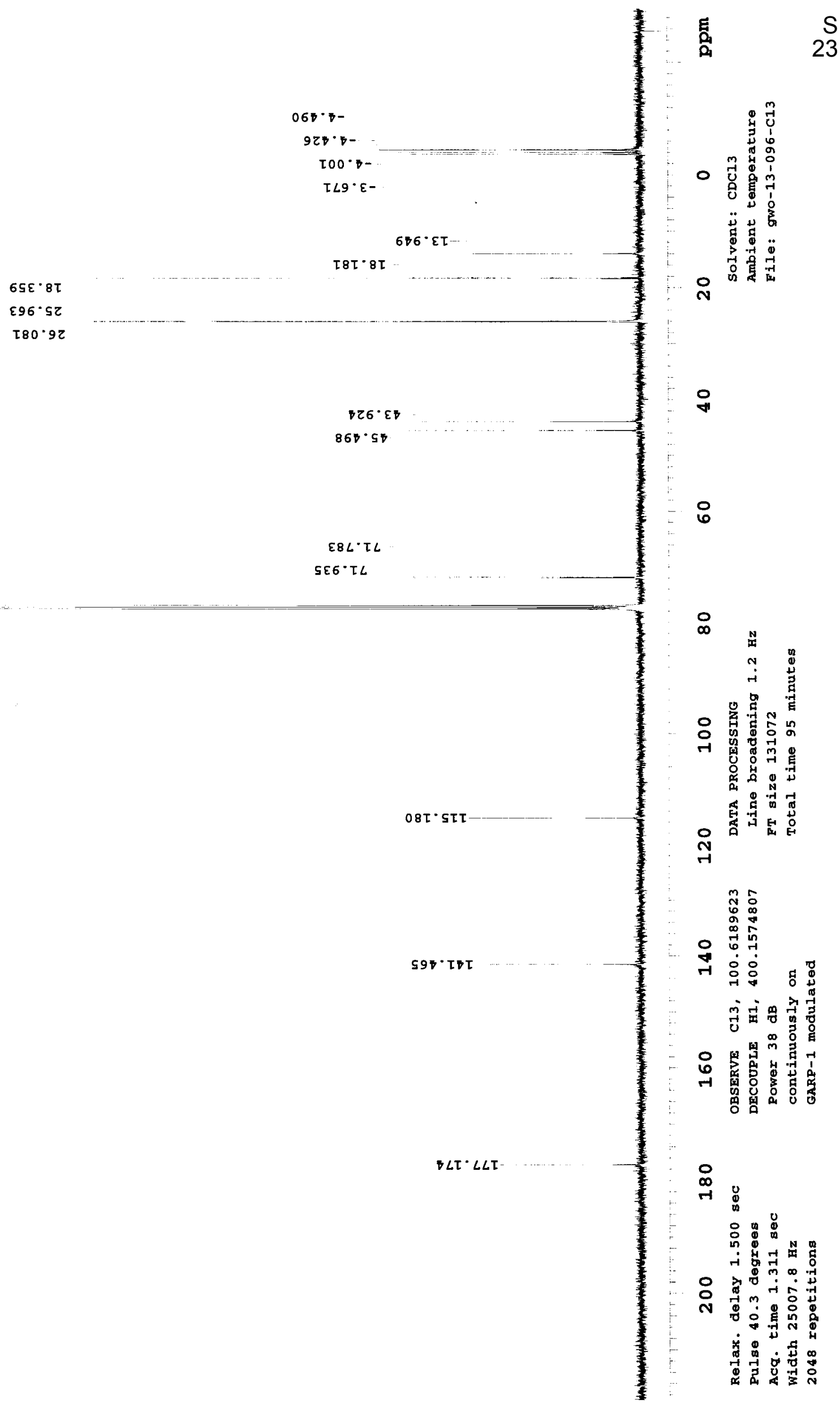




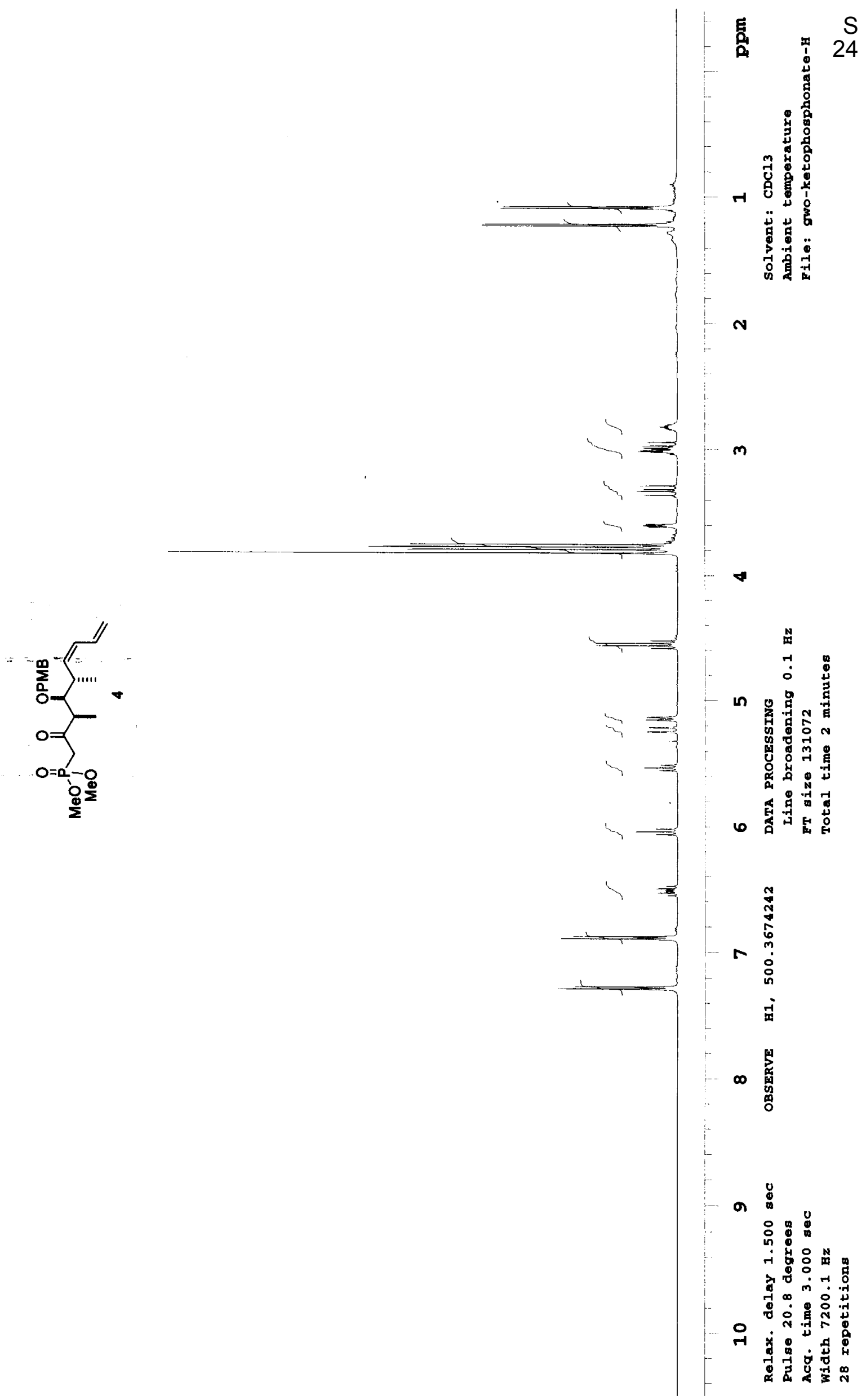




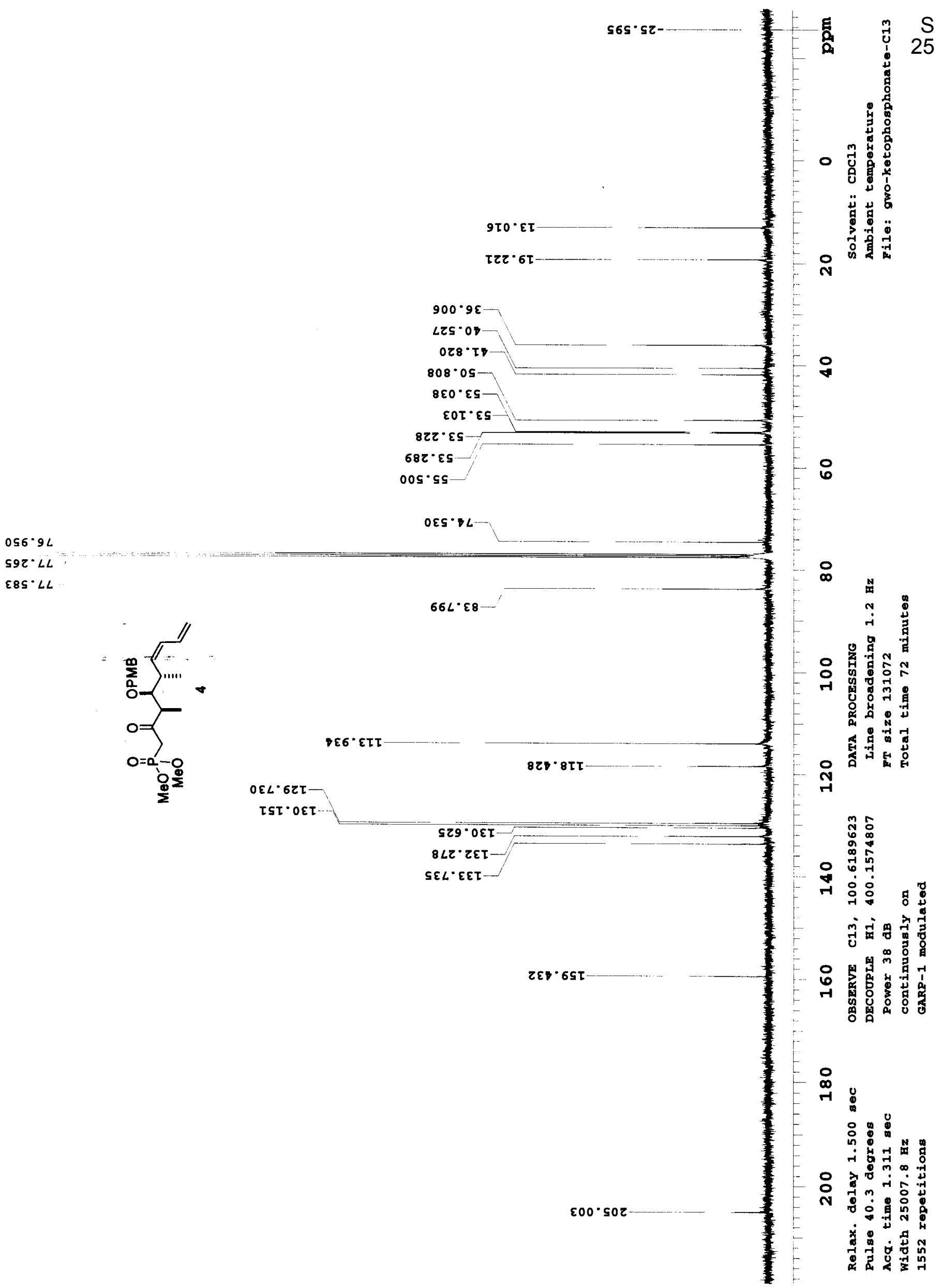




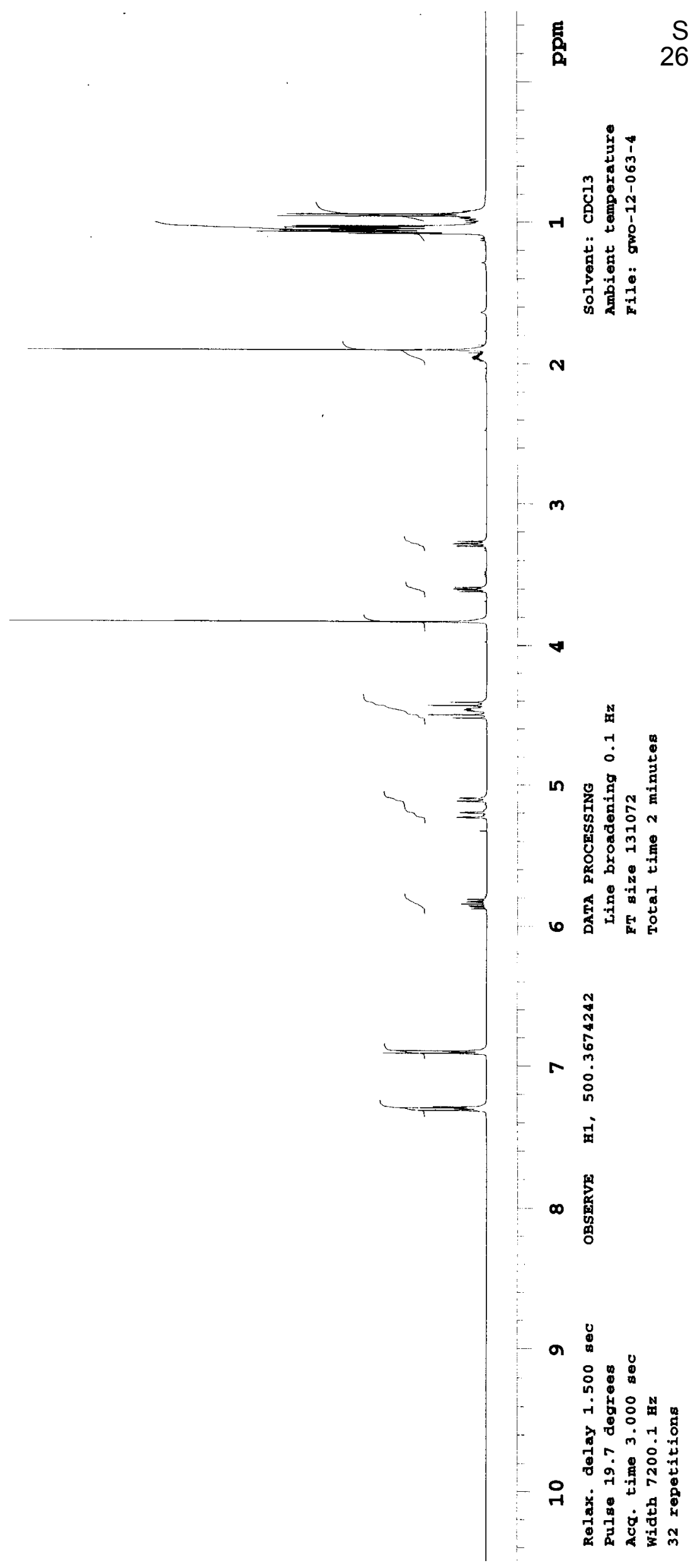



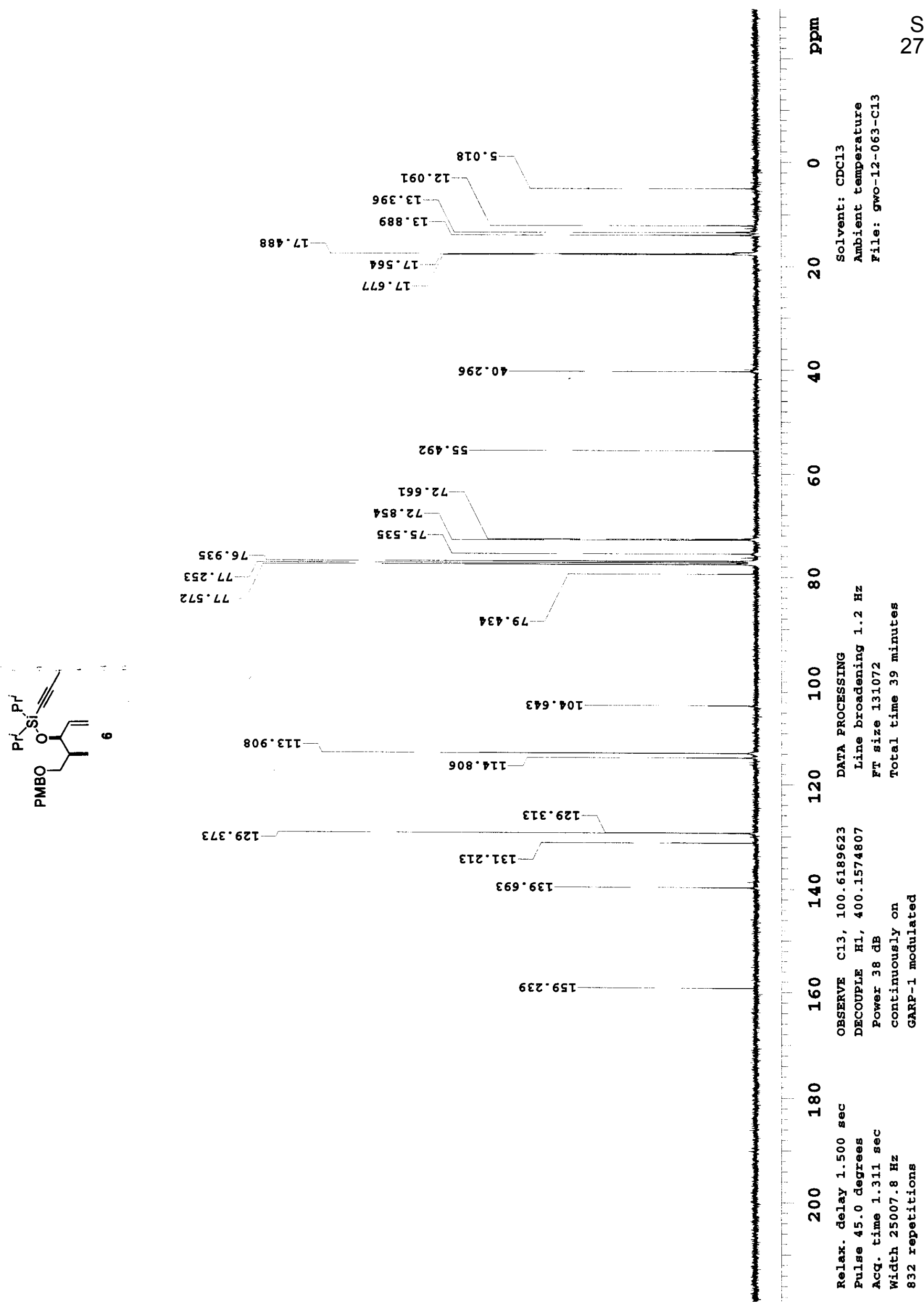


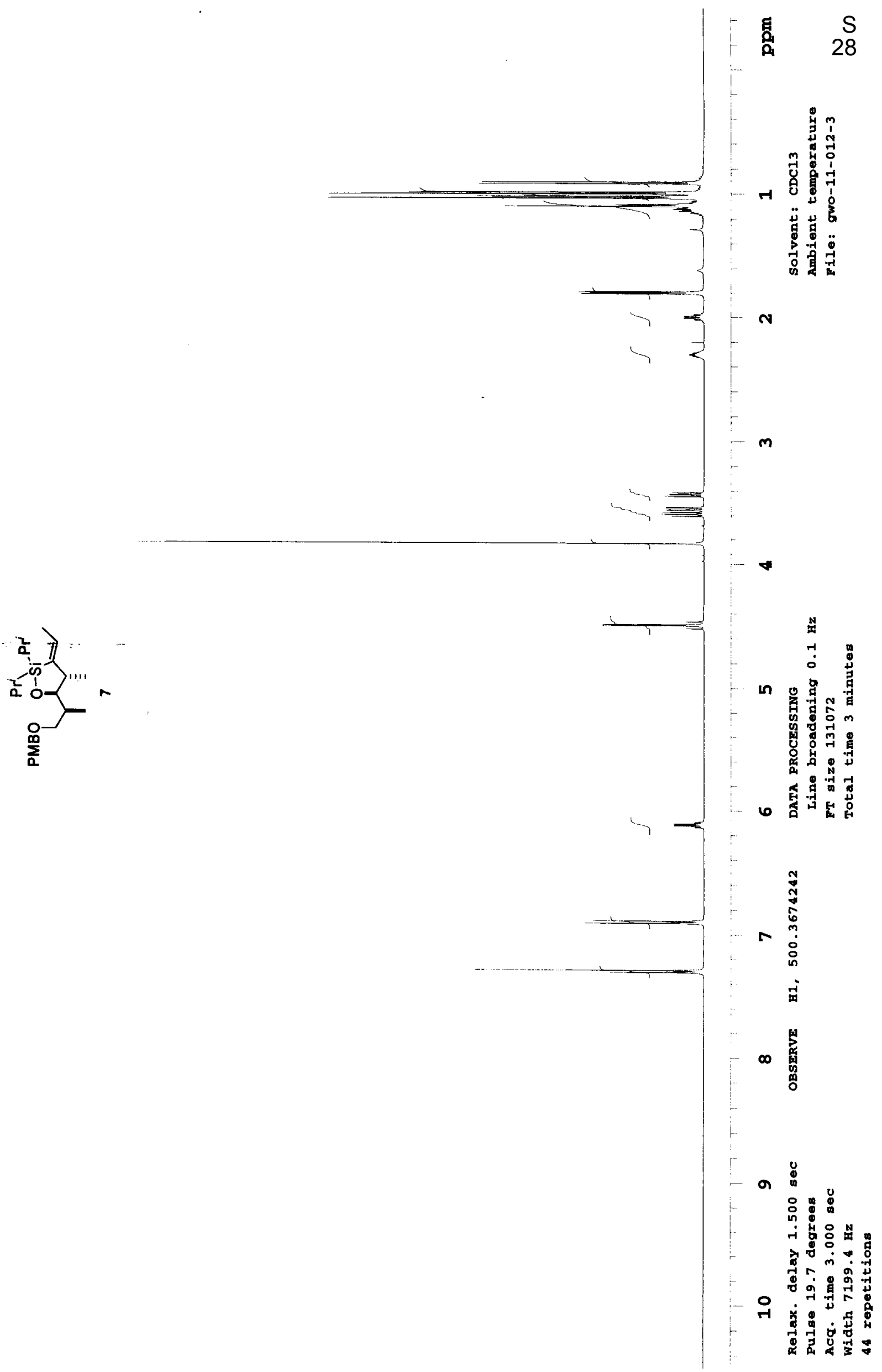




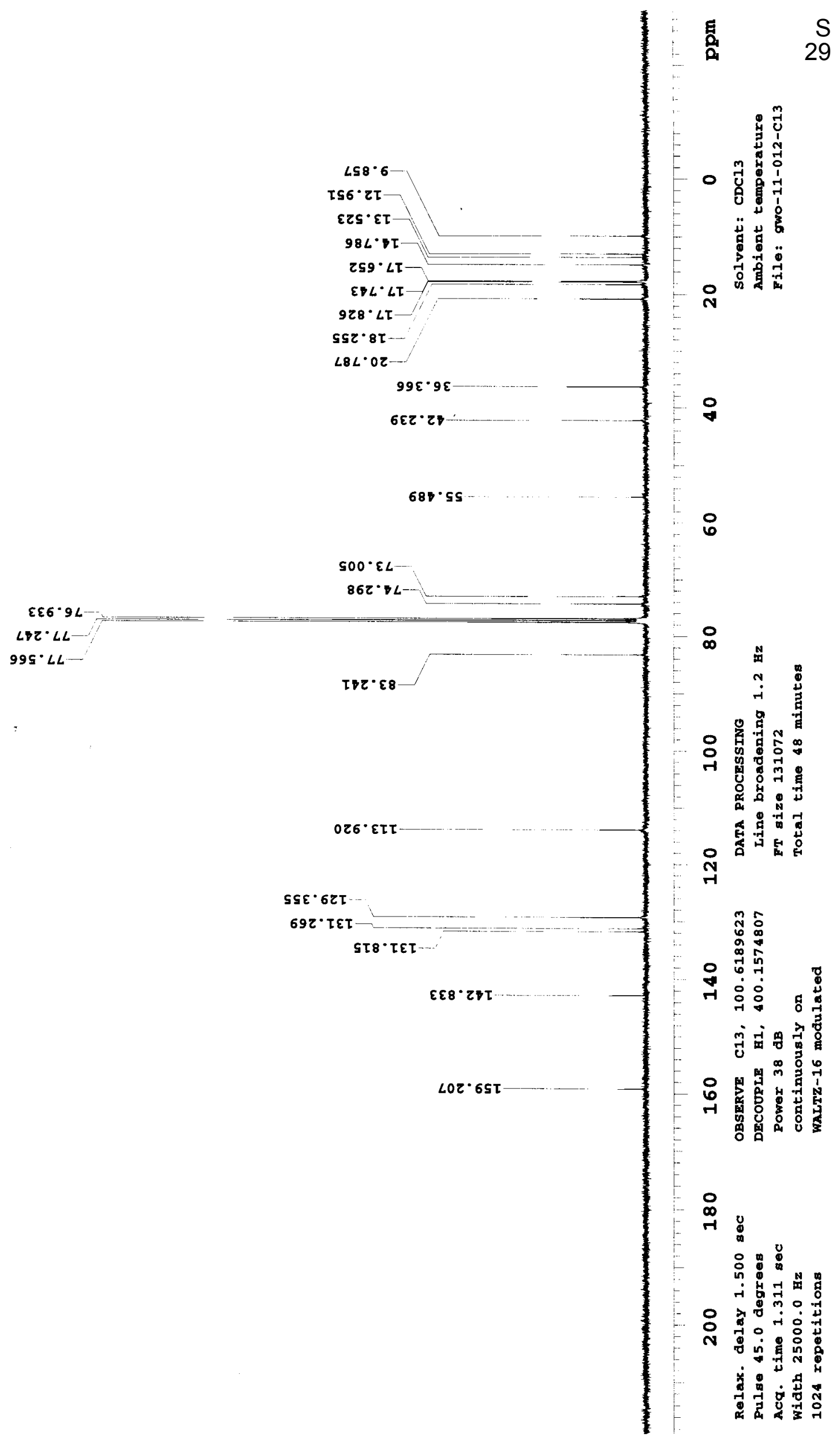




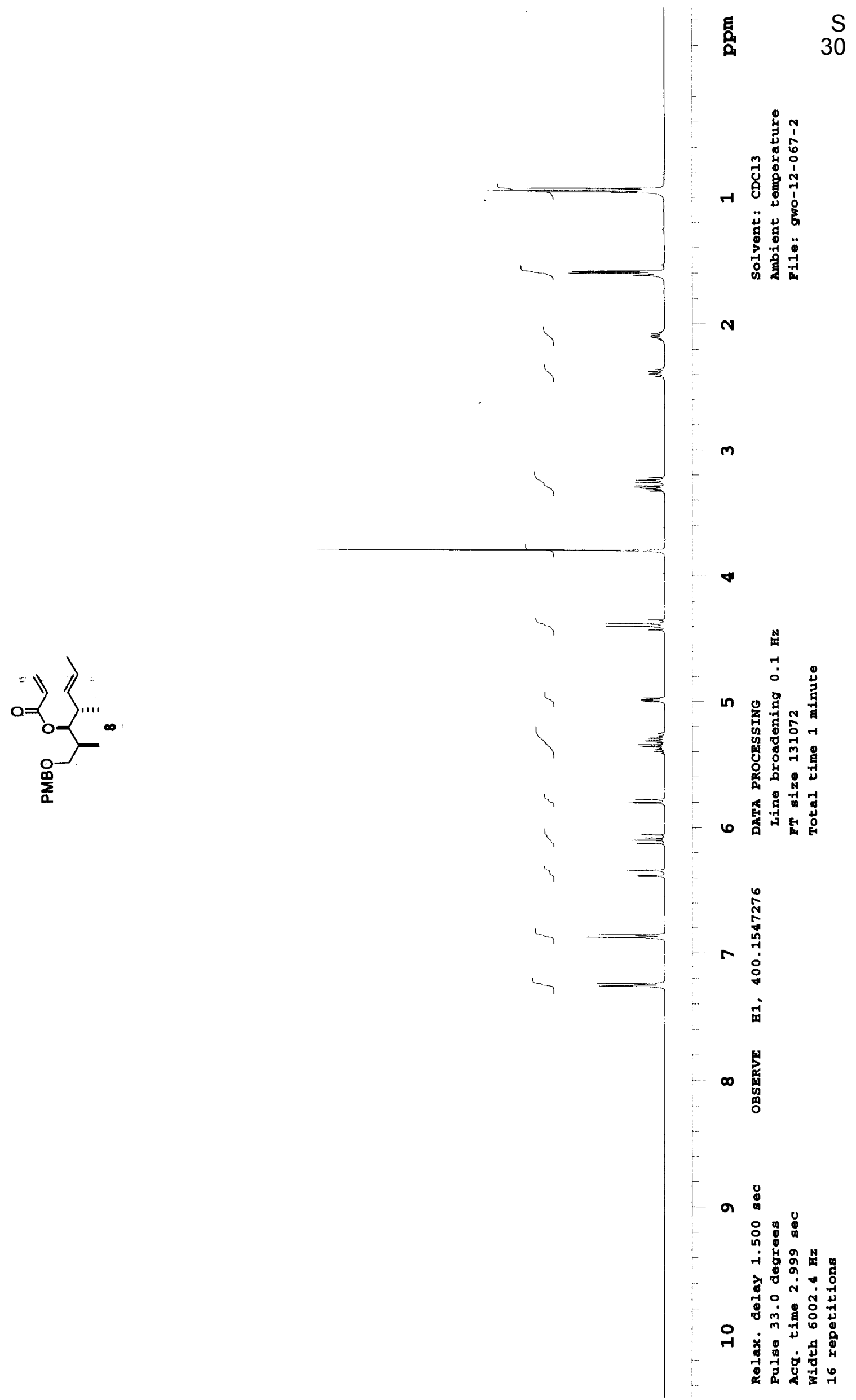




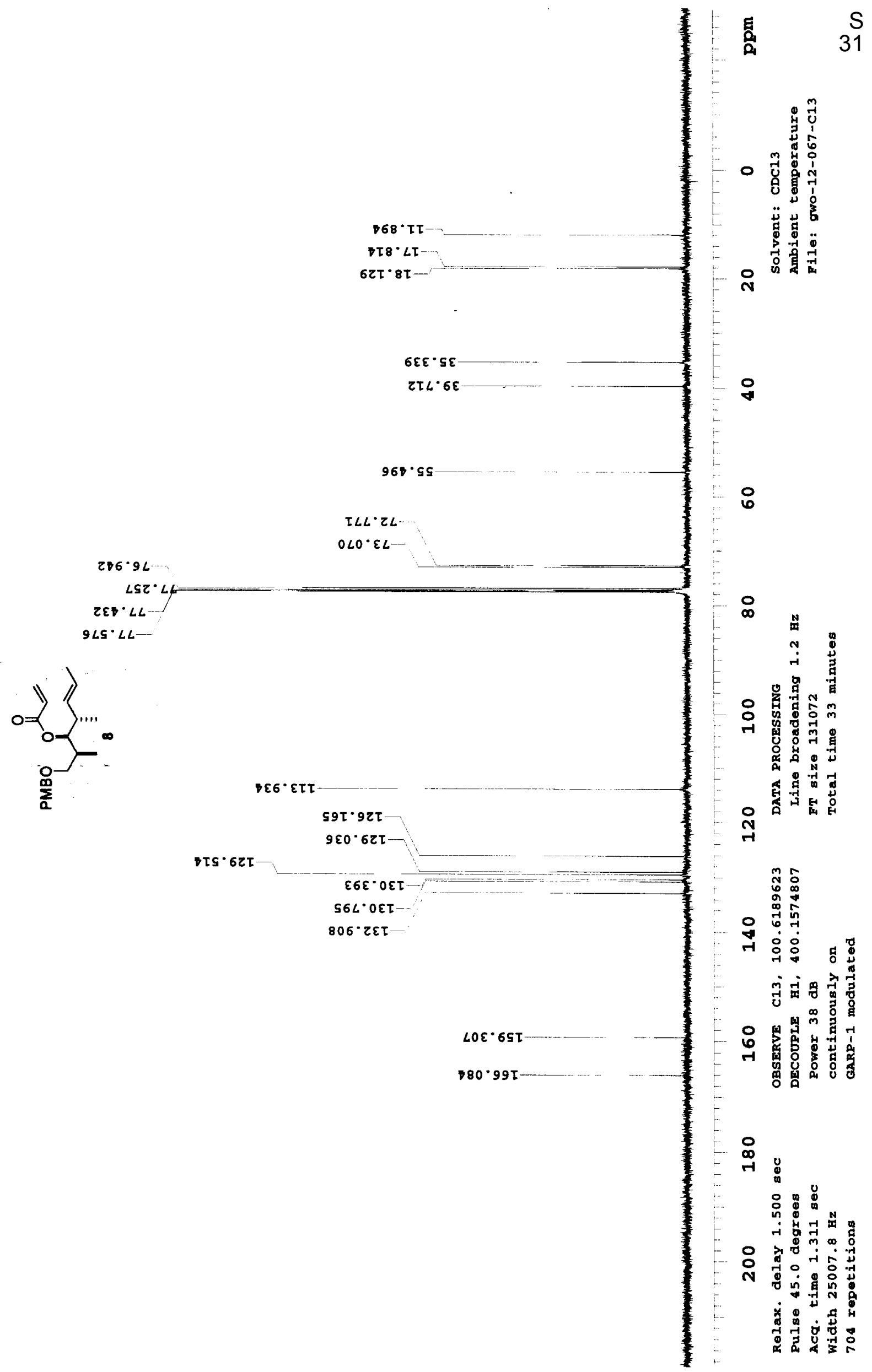




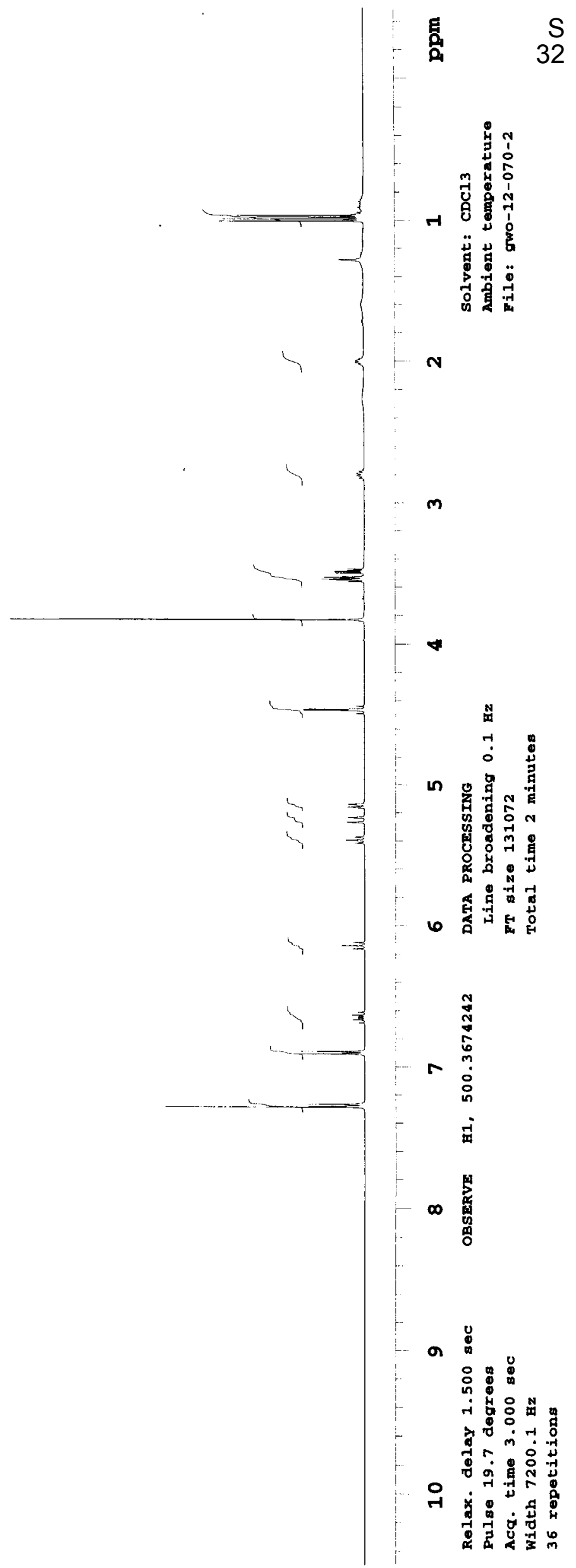




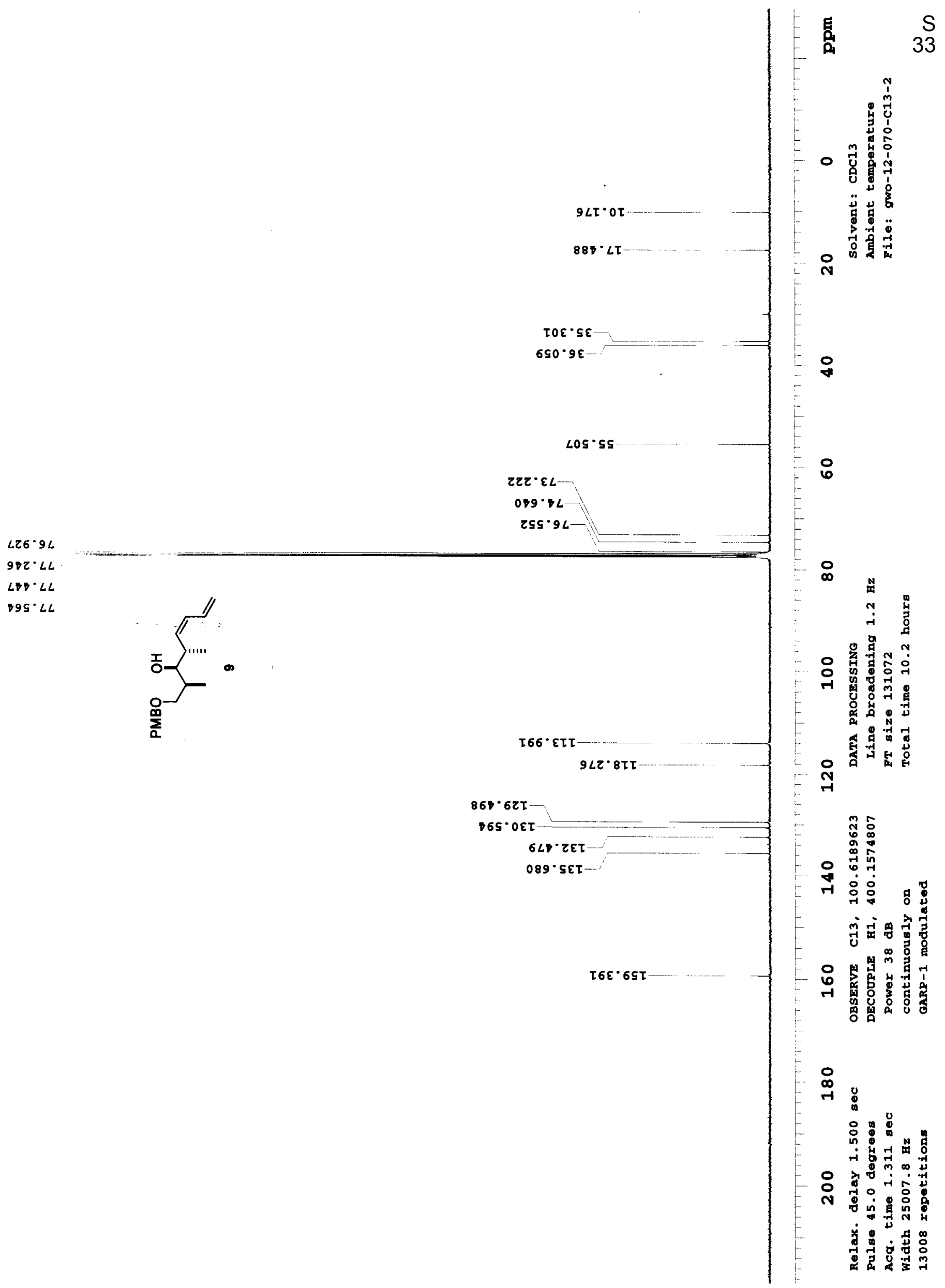



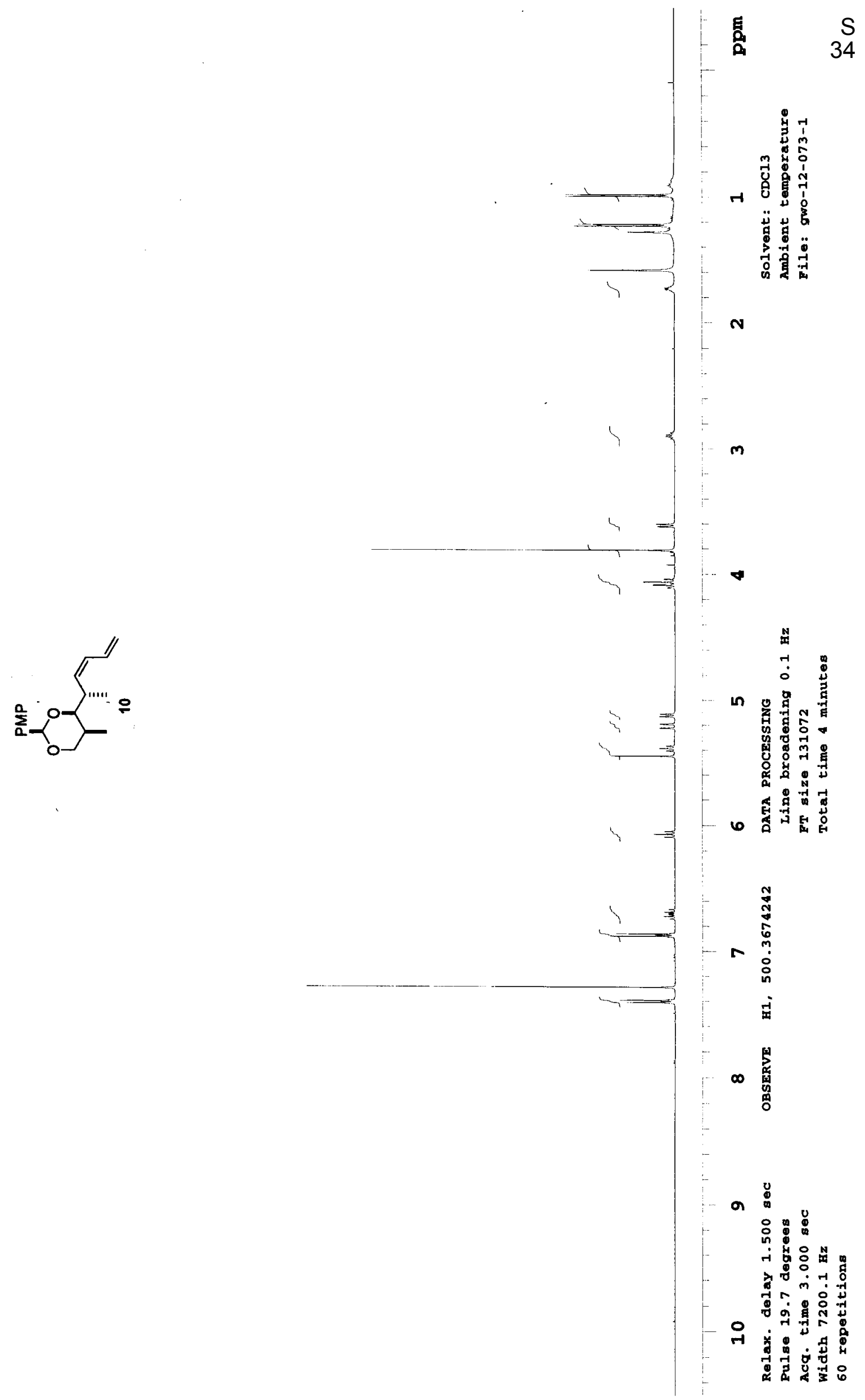


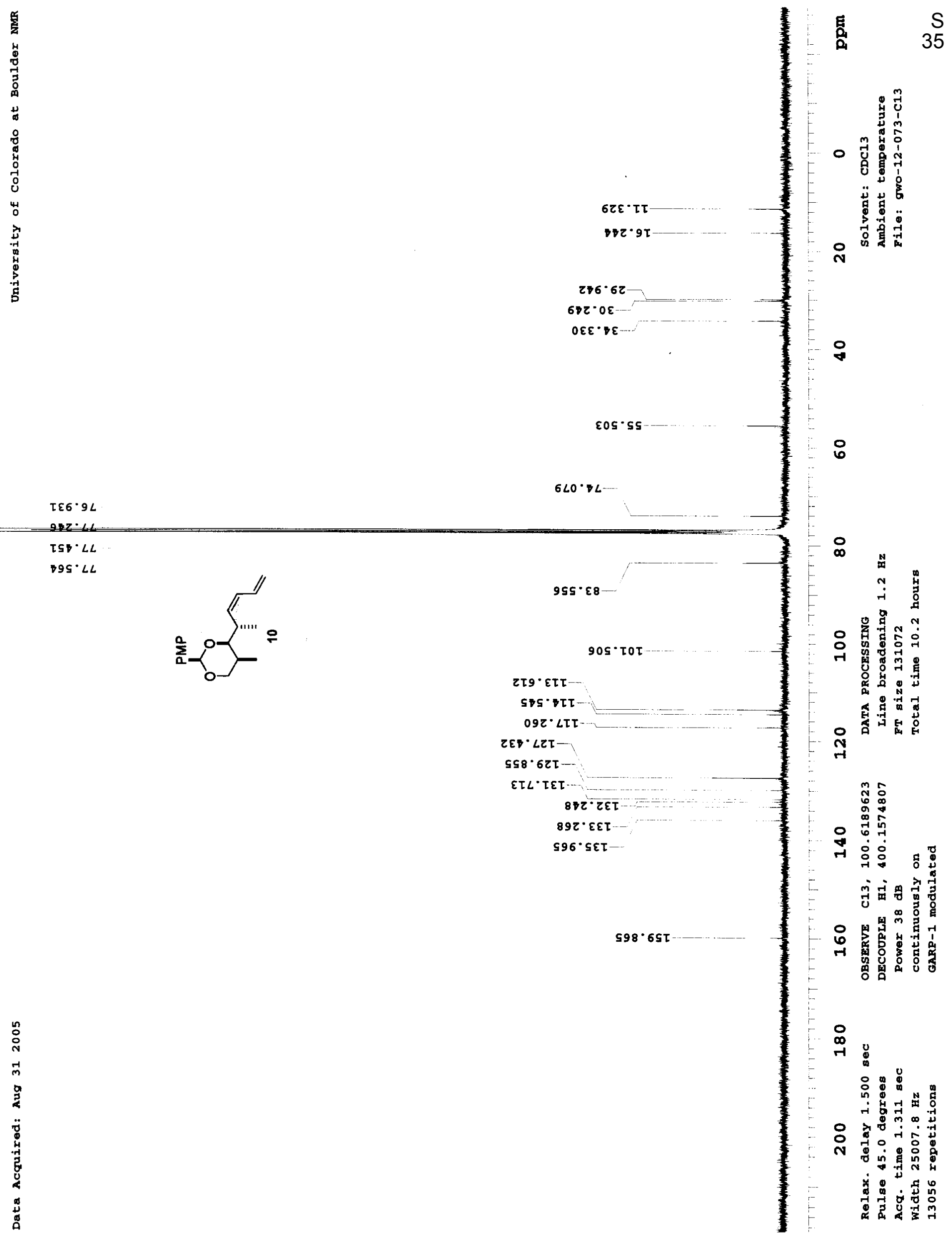




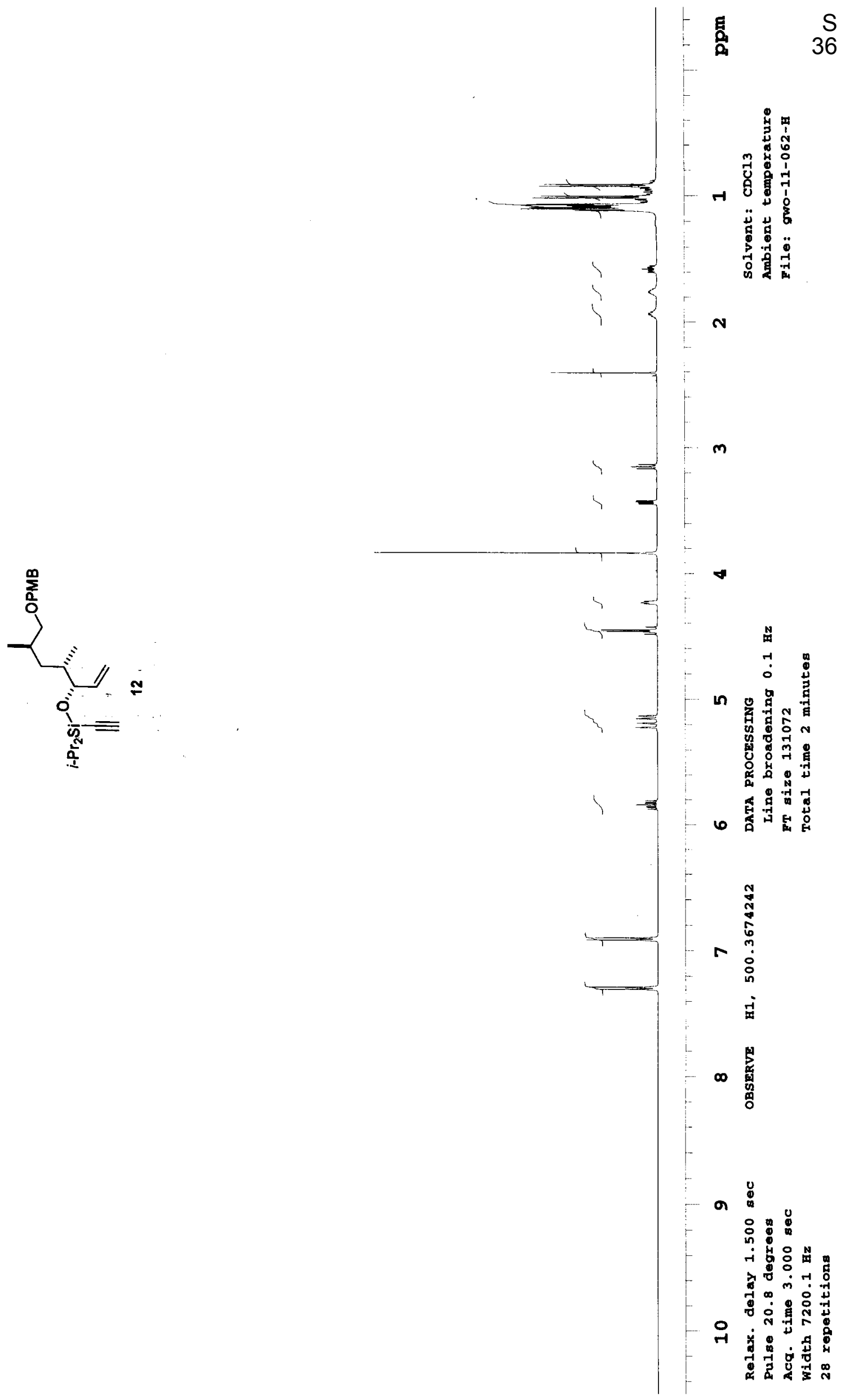




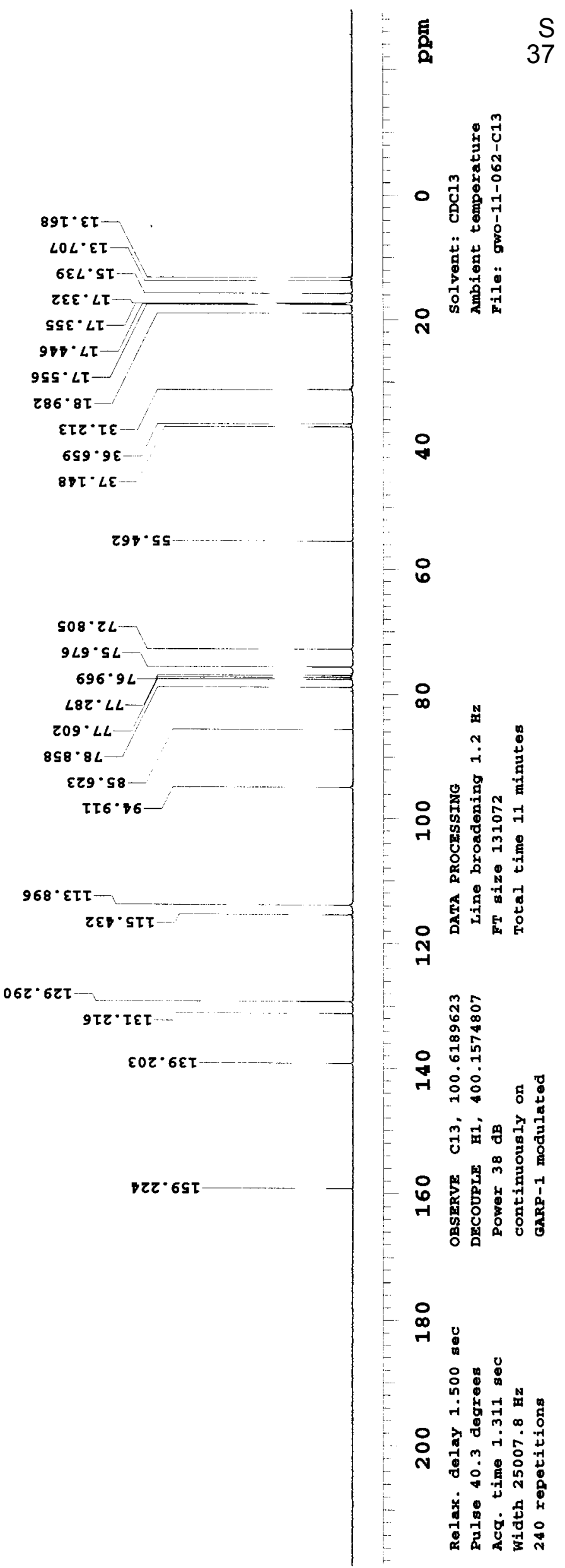




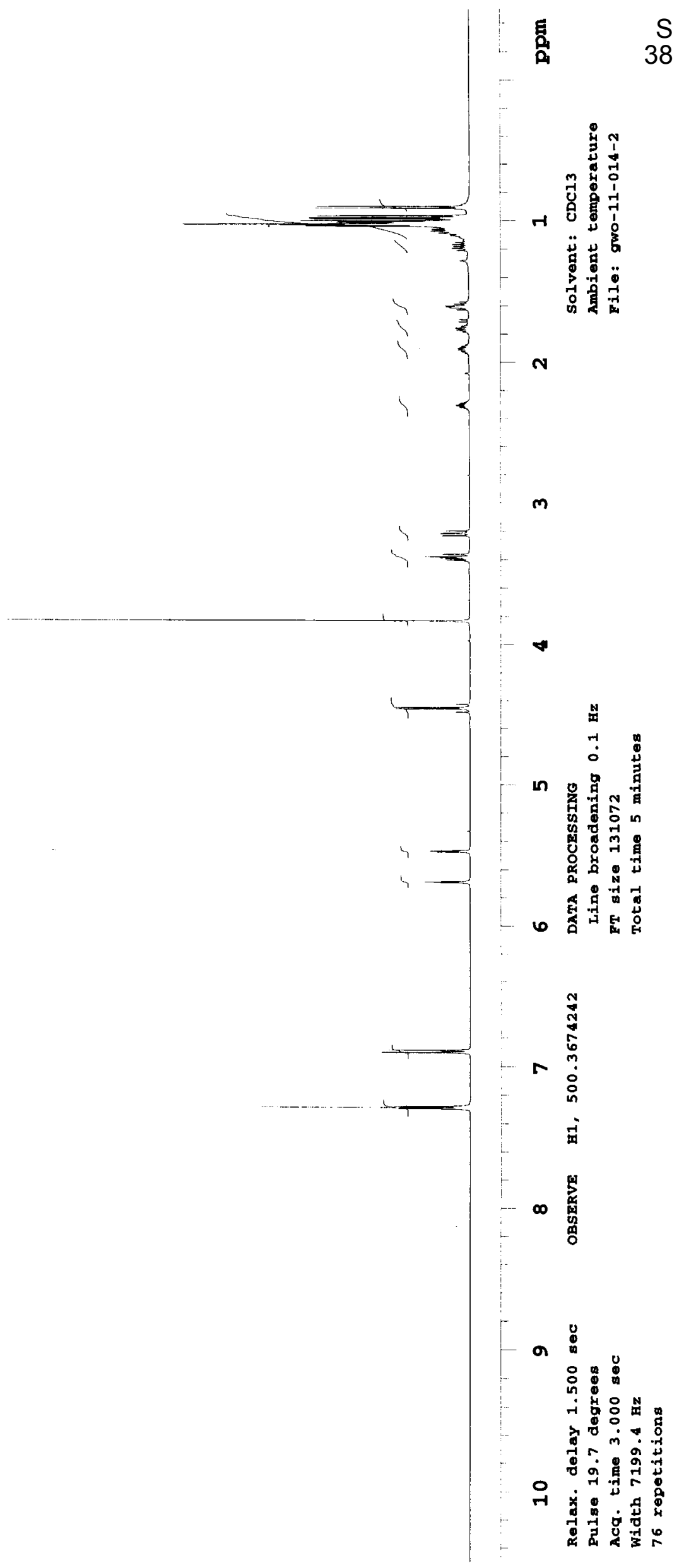




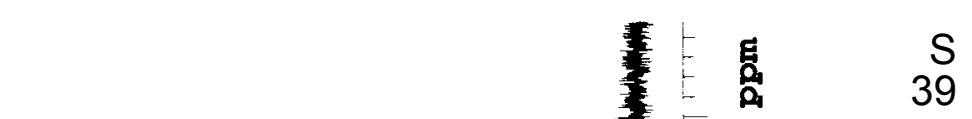

$626 \div 9 L=$

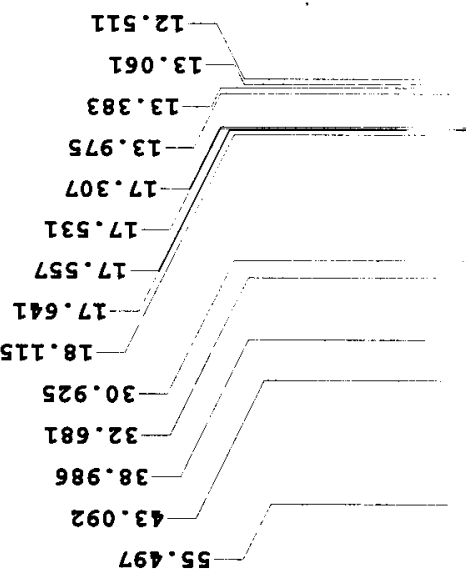

-

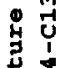

矛

\&

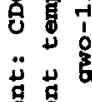

5.

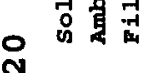

$\angle \nabla 2 \cdot \angle L$

$29 S^{\circ} L L$

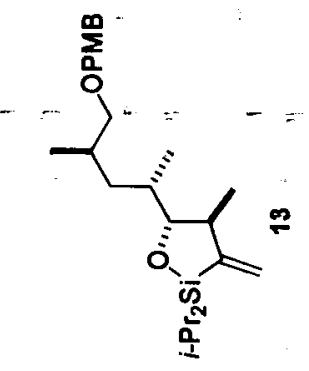

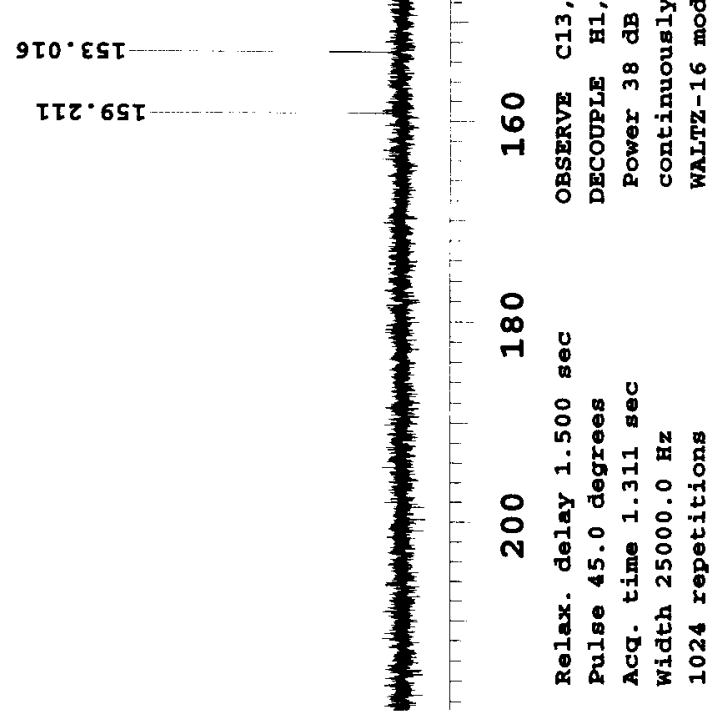




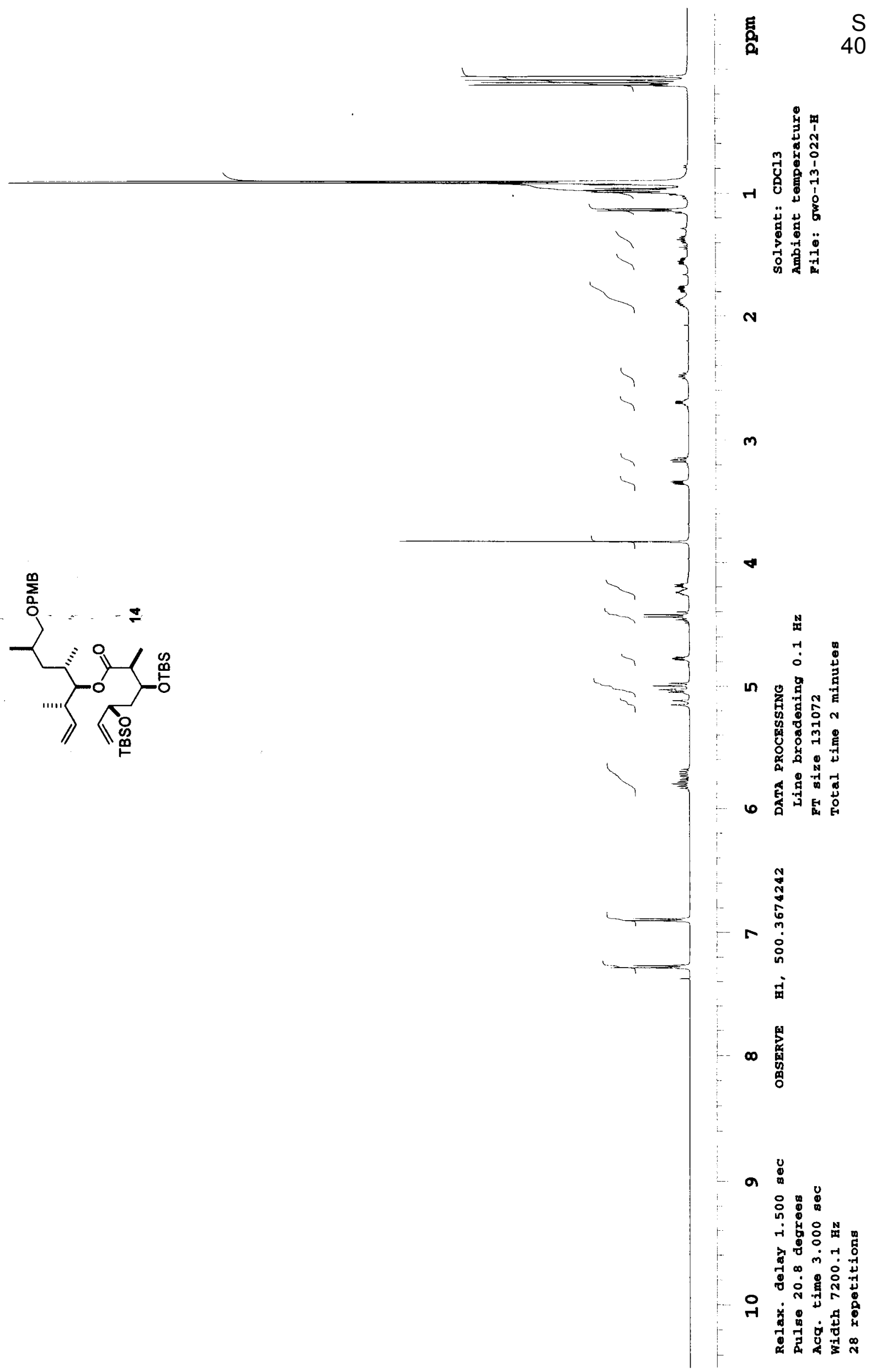




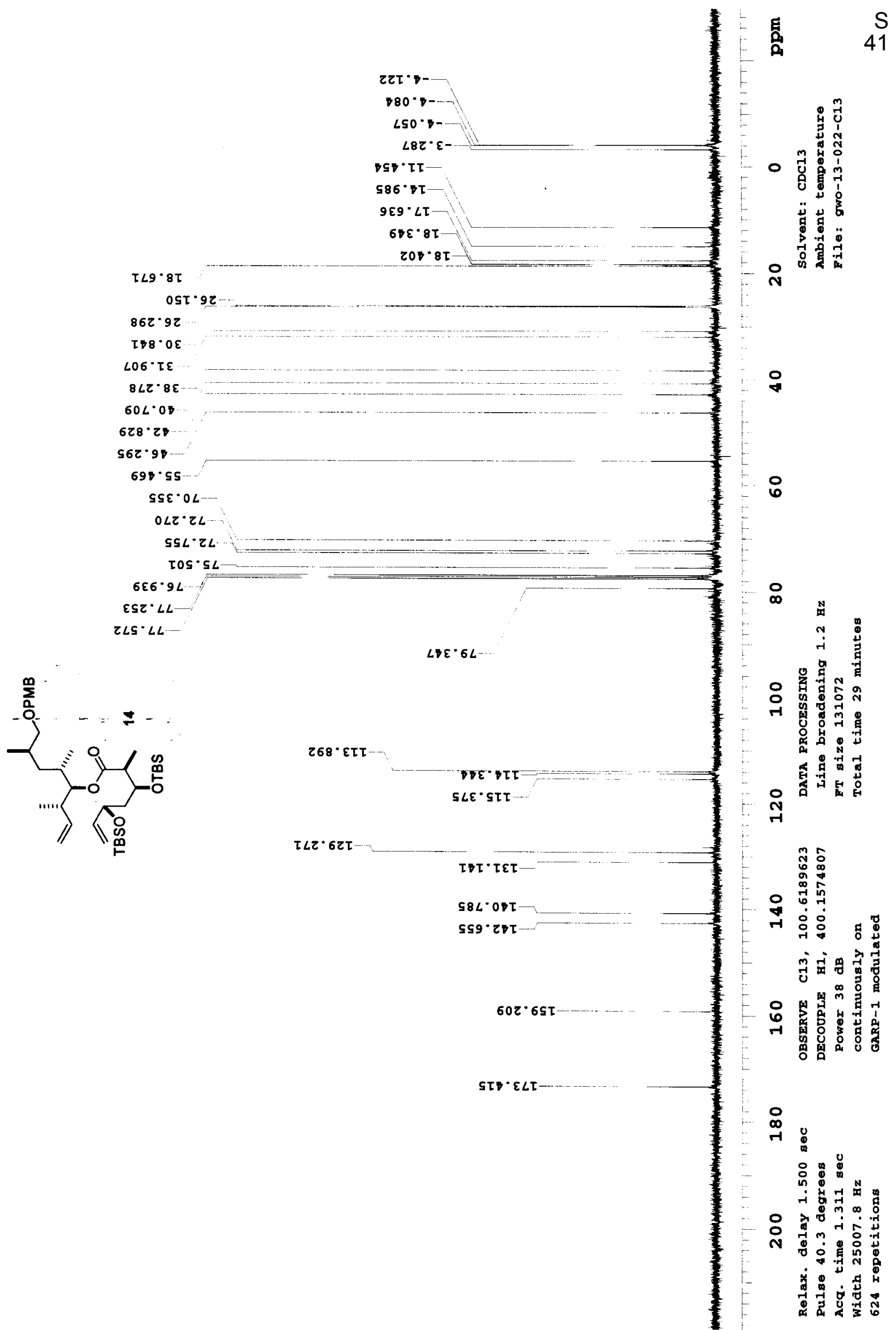

⿷匚⿱口口 


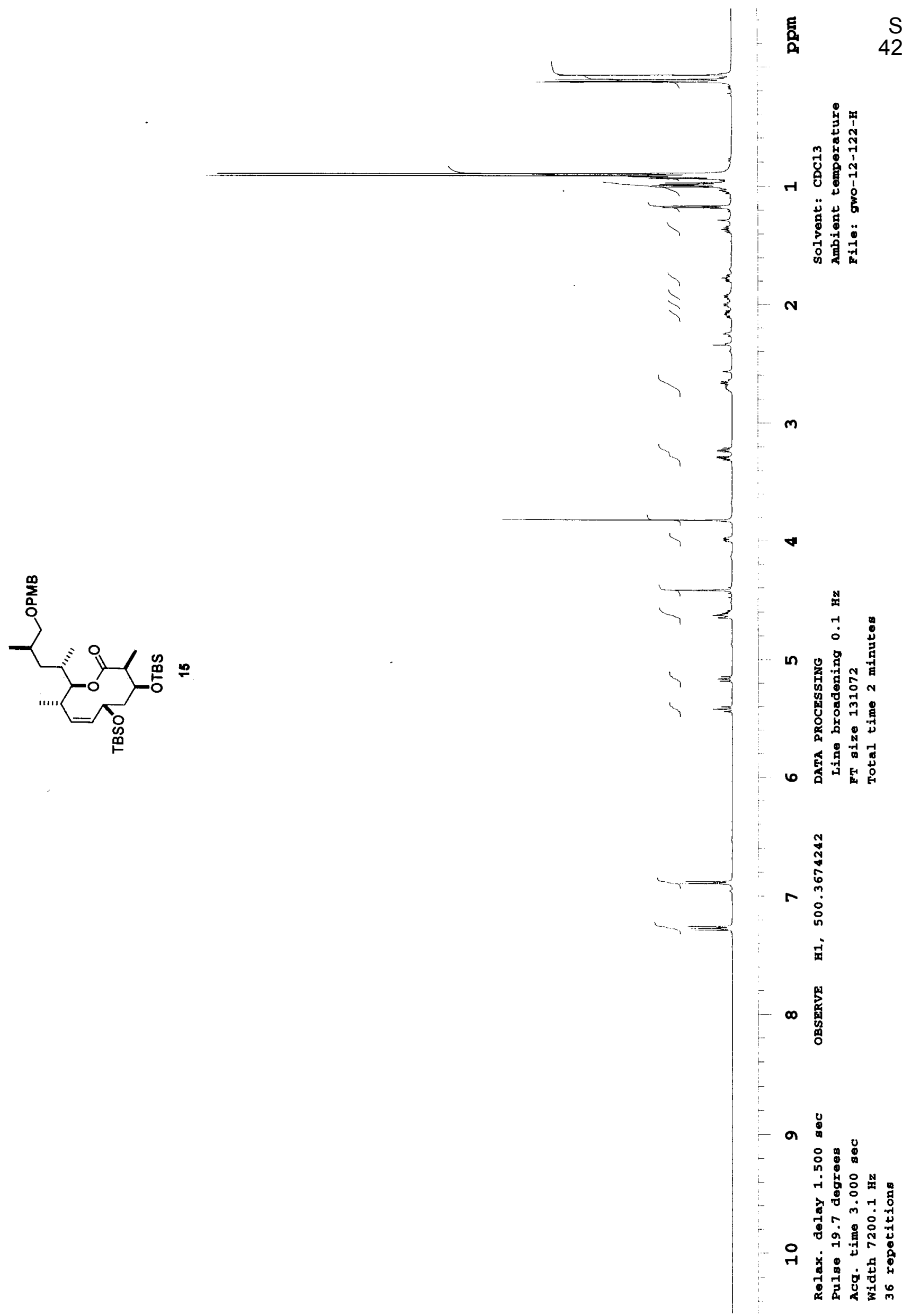




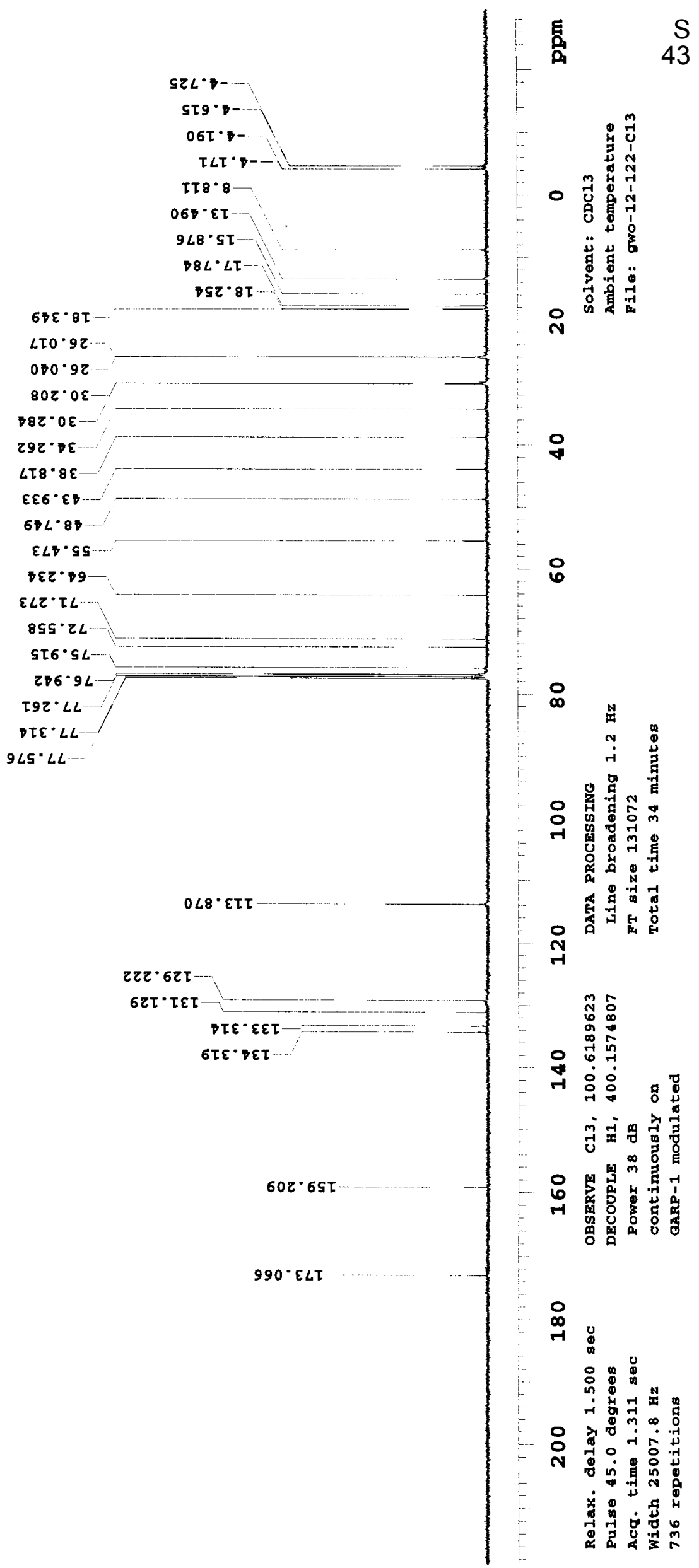




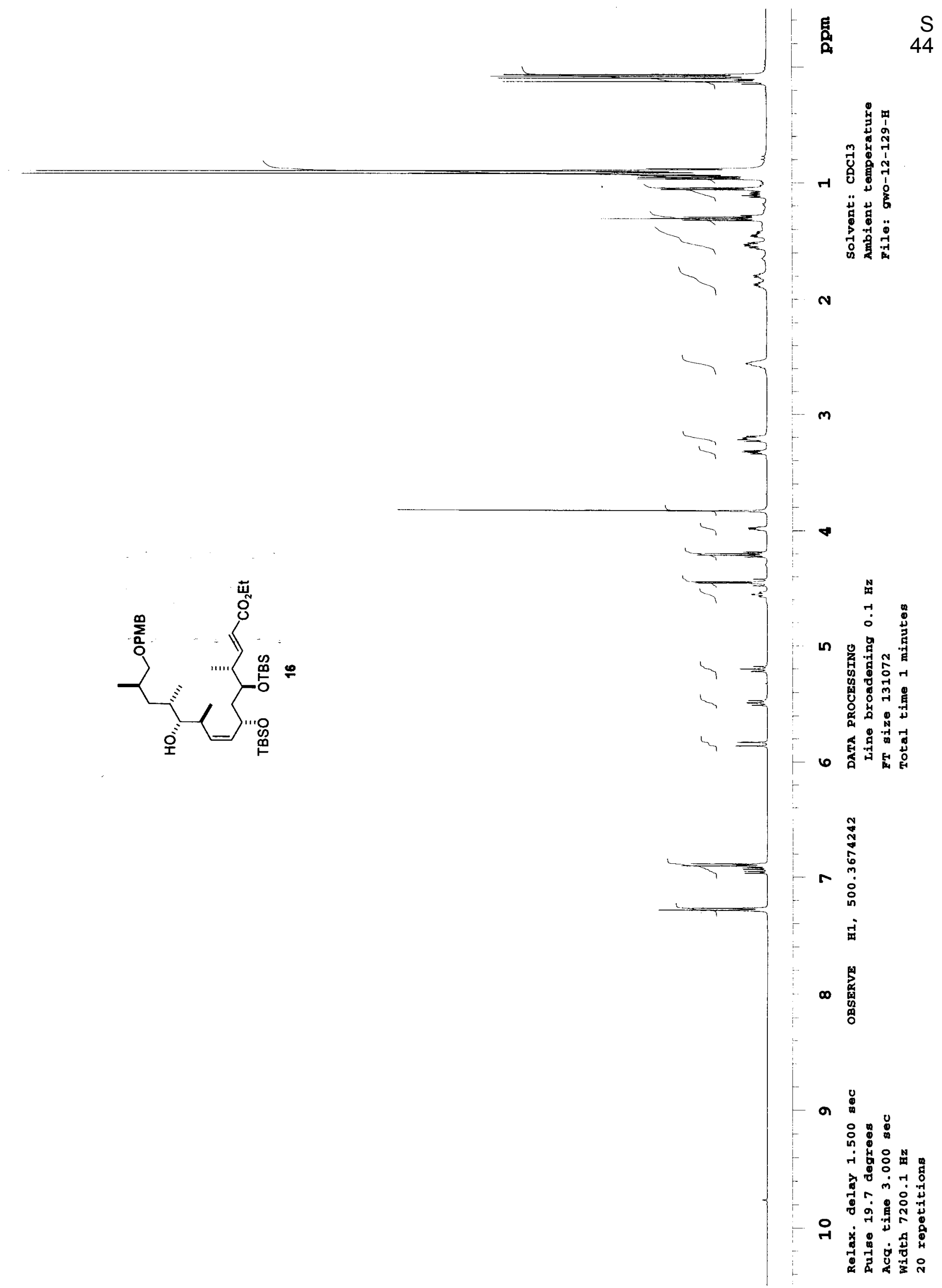


$\rightarrow T E \cdot 8 T$

SET. 92

Z58. OE

$\tau 8 \tau \cdot \tau \varepsilon$

โع $\angle \varepsilon$

โ99.8E

$0 \nabla 0^{\circ} 20$

$\varepsilon 00^{\circ} \varepsilon \nabla$

$880^{\circ} \mathrm{gS}$

$\varepsilon<\varepsilon \cdot 09$

$582 \cdot 99$

$9 \tau L^{\circ} \tau L$

$\$ 98^{\circ} \mathrm{ZL}$

$9 \varepsilon 0.9 L$

szs. $9 L$

$266^{\circ} 9 L$

OIE. LL

$629^{\circ} \angle L$
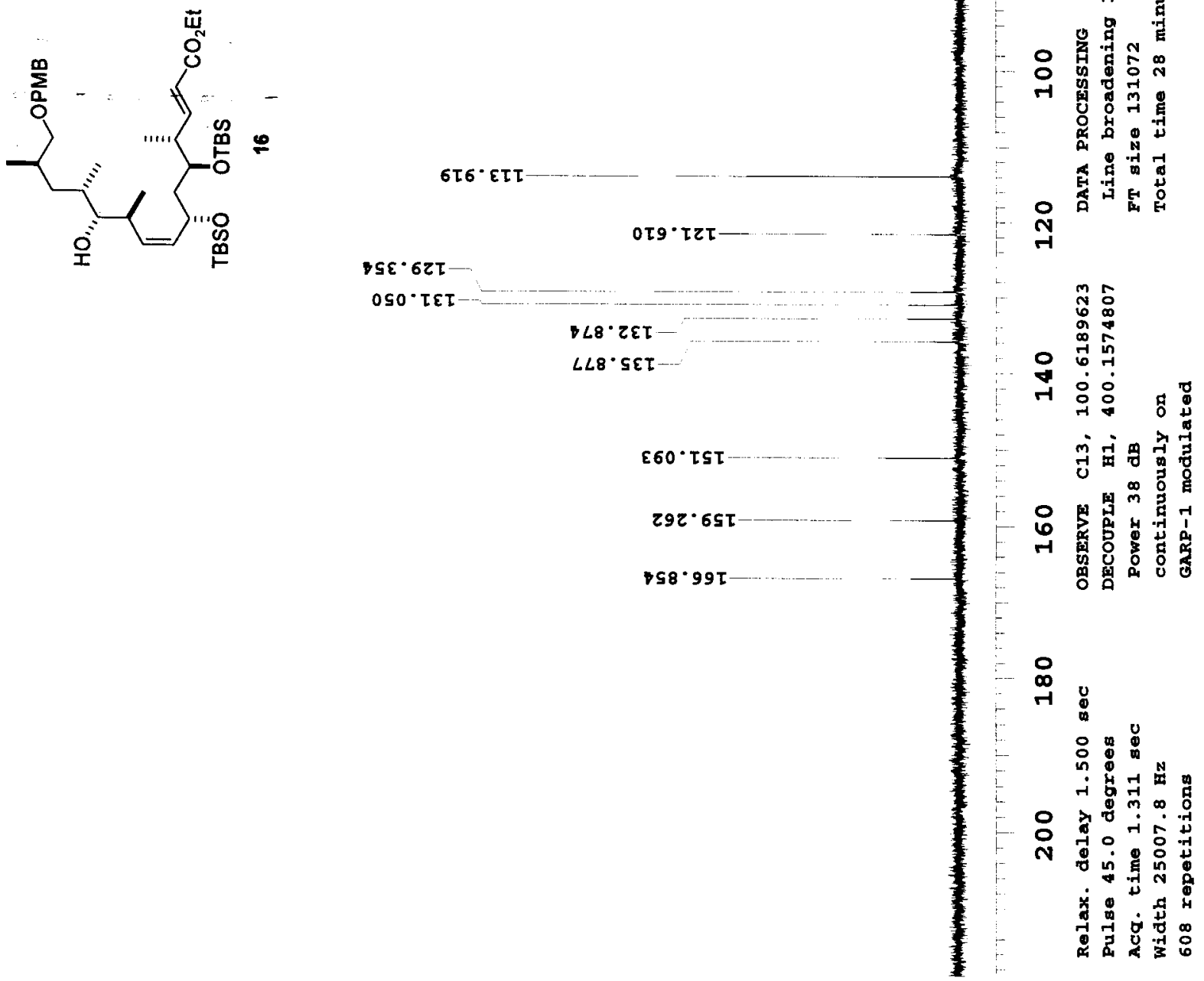


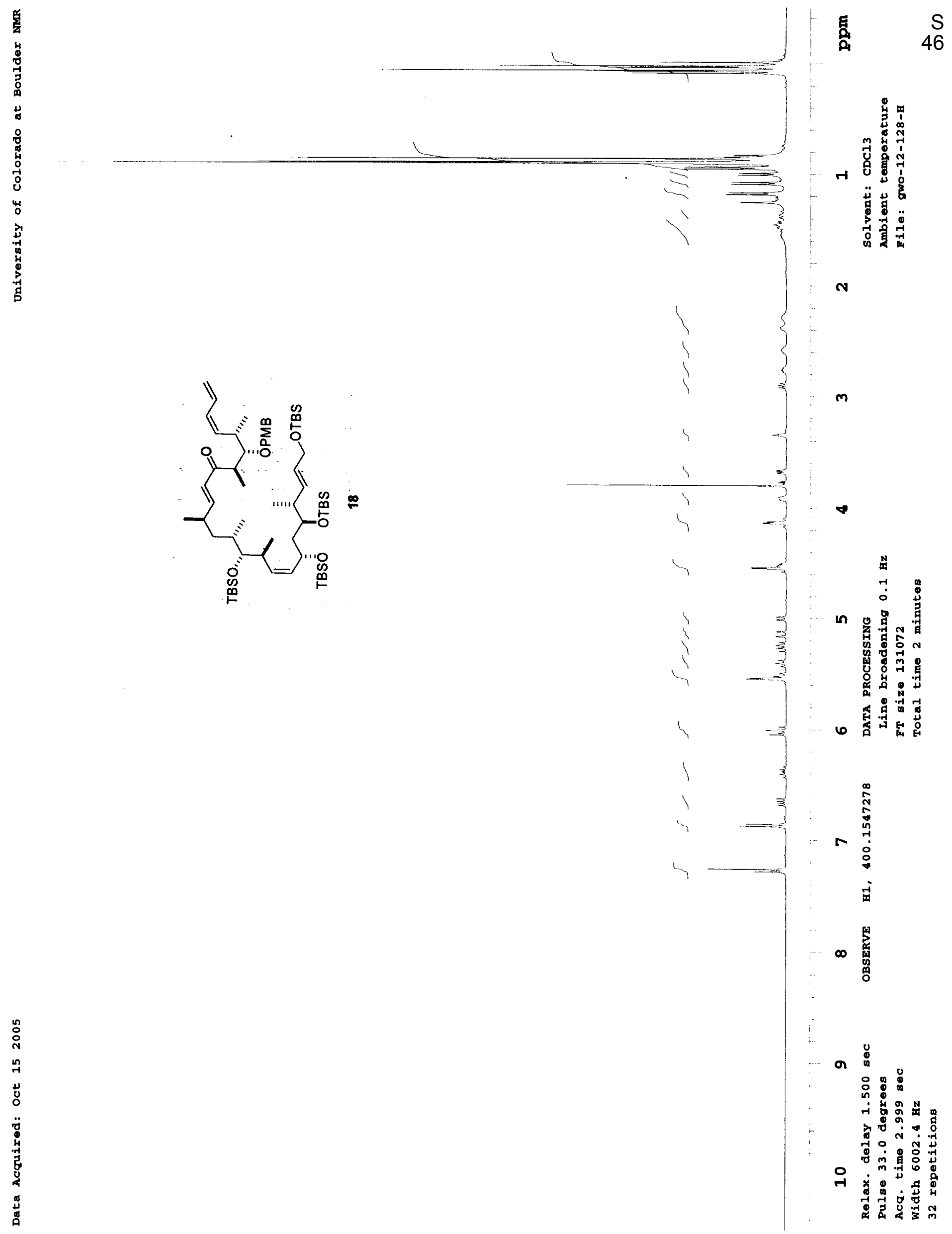




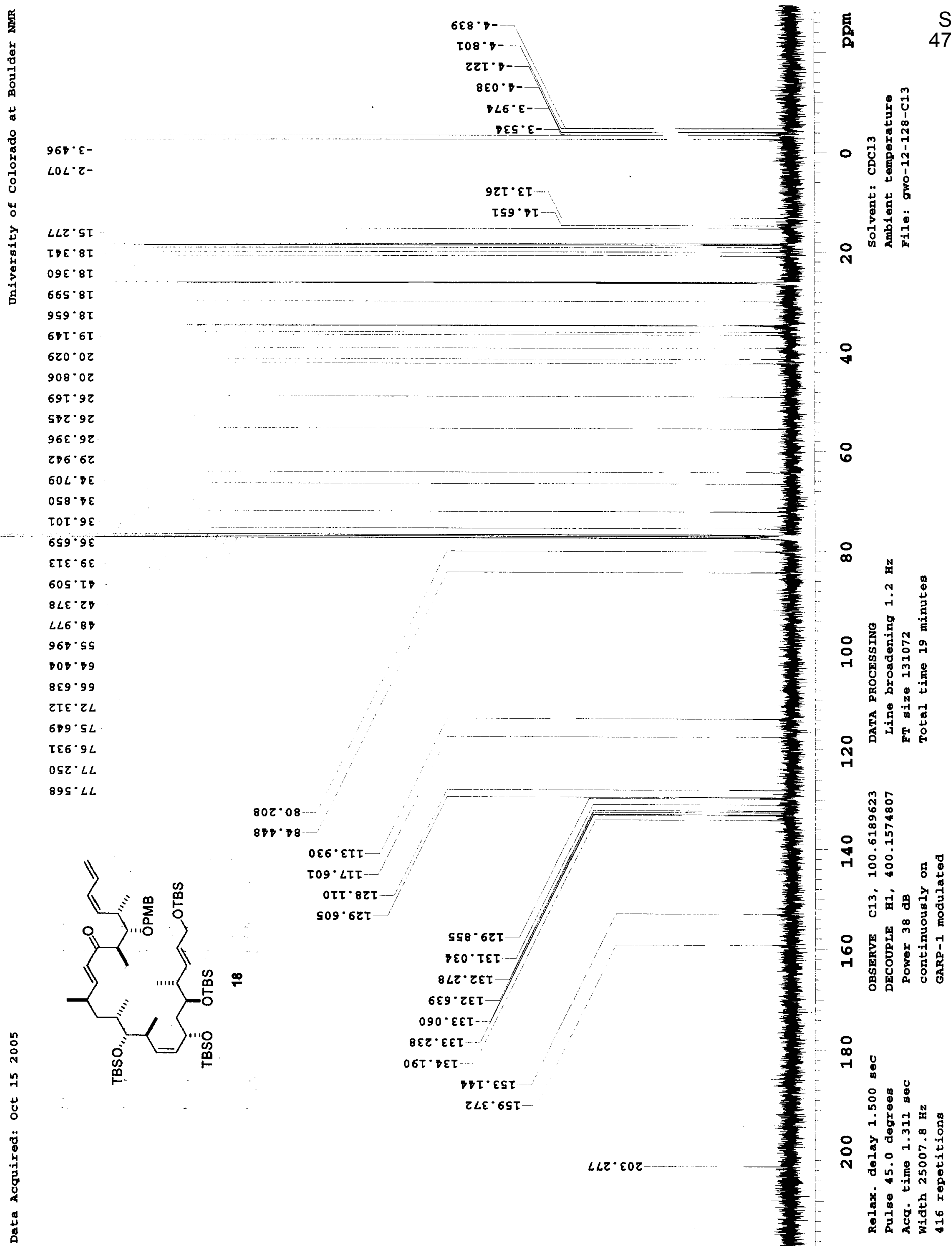




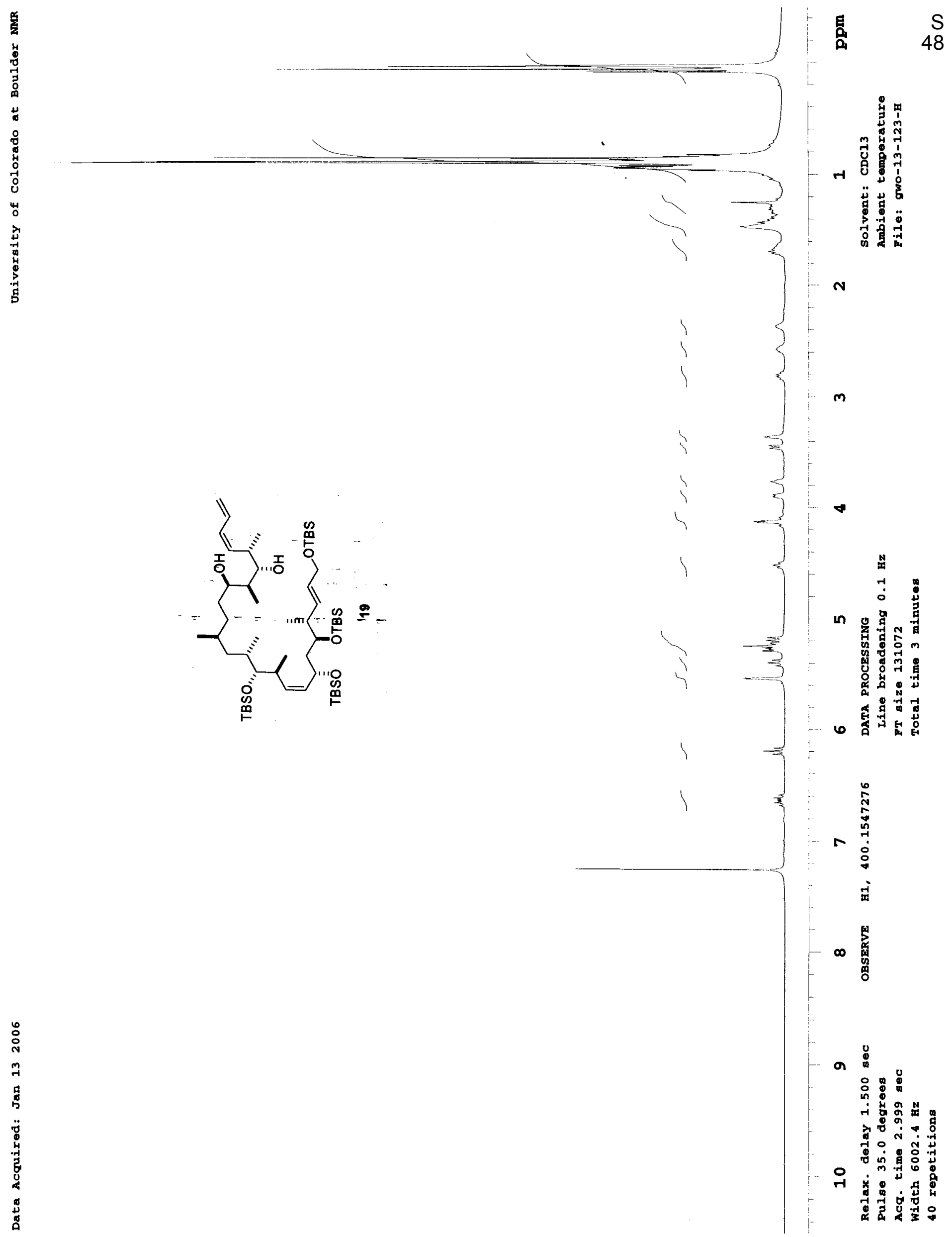




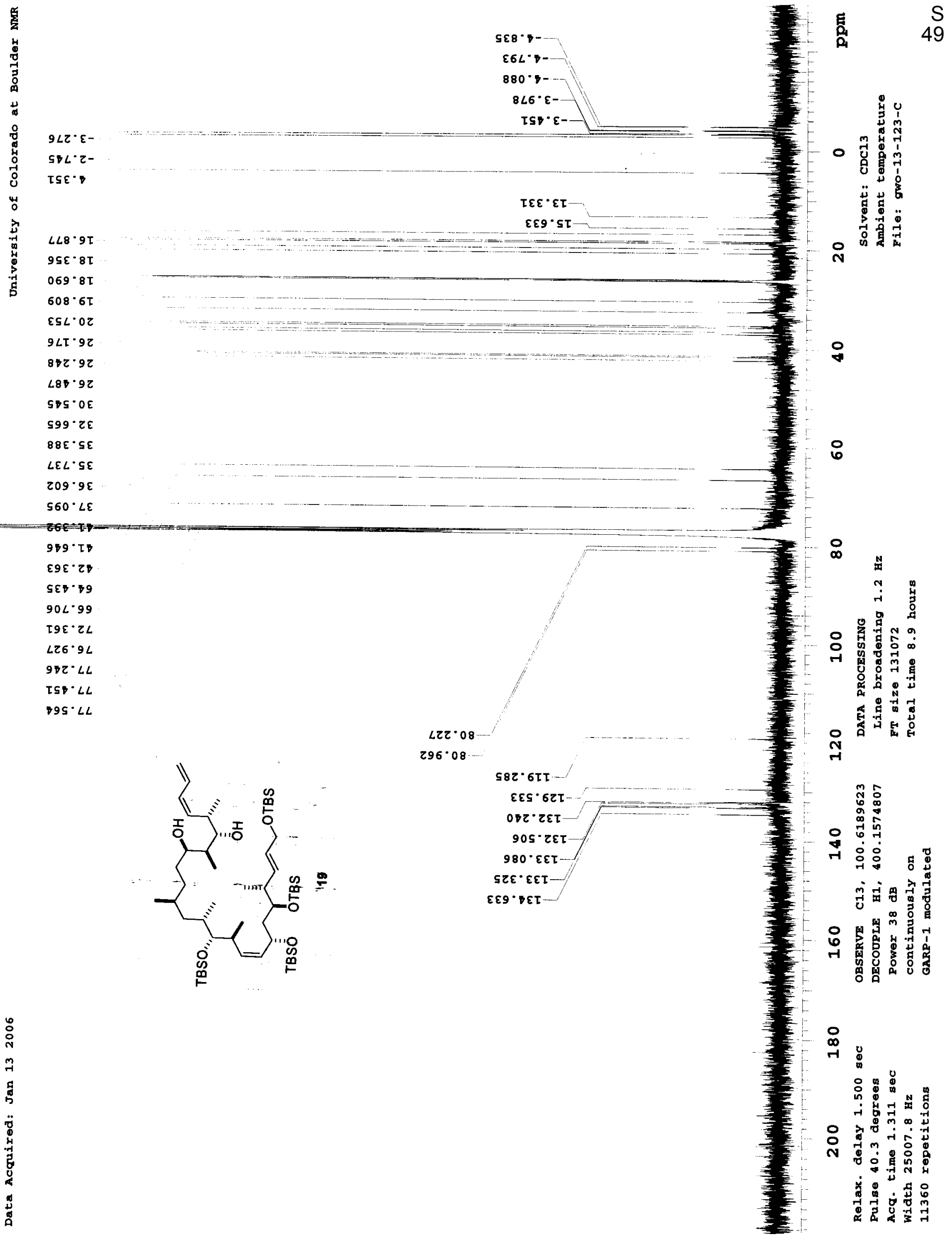




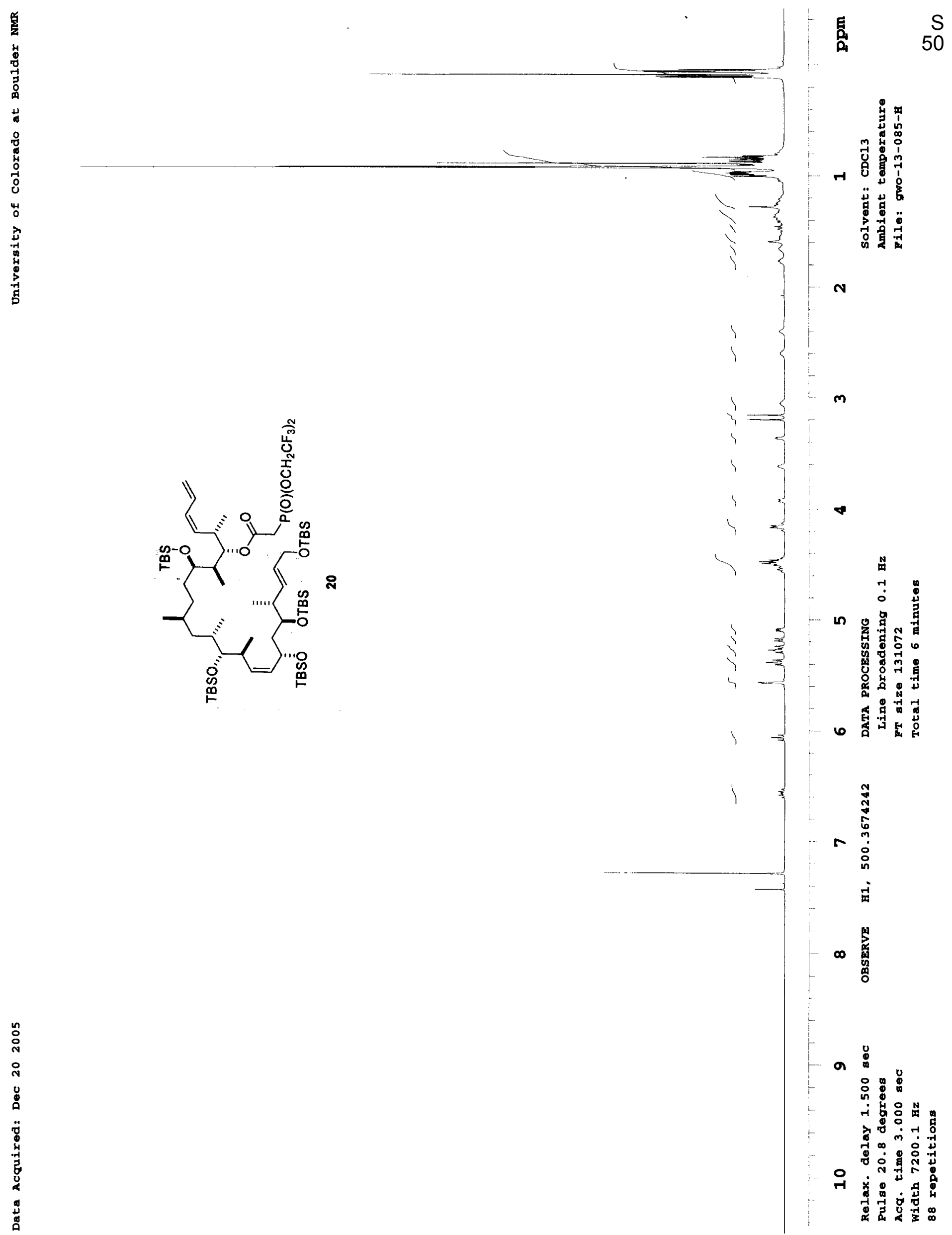




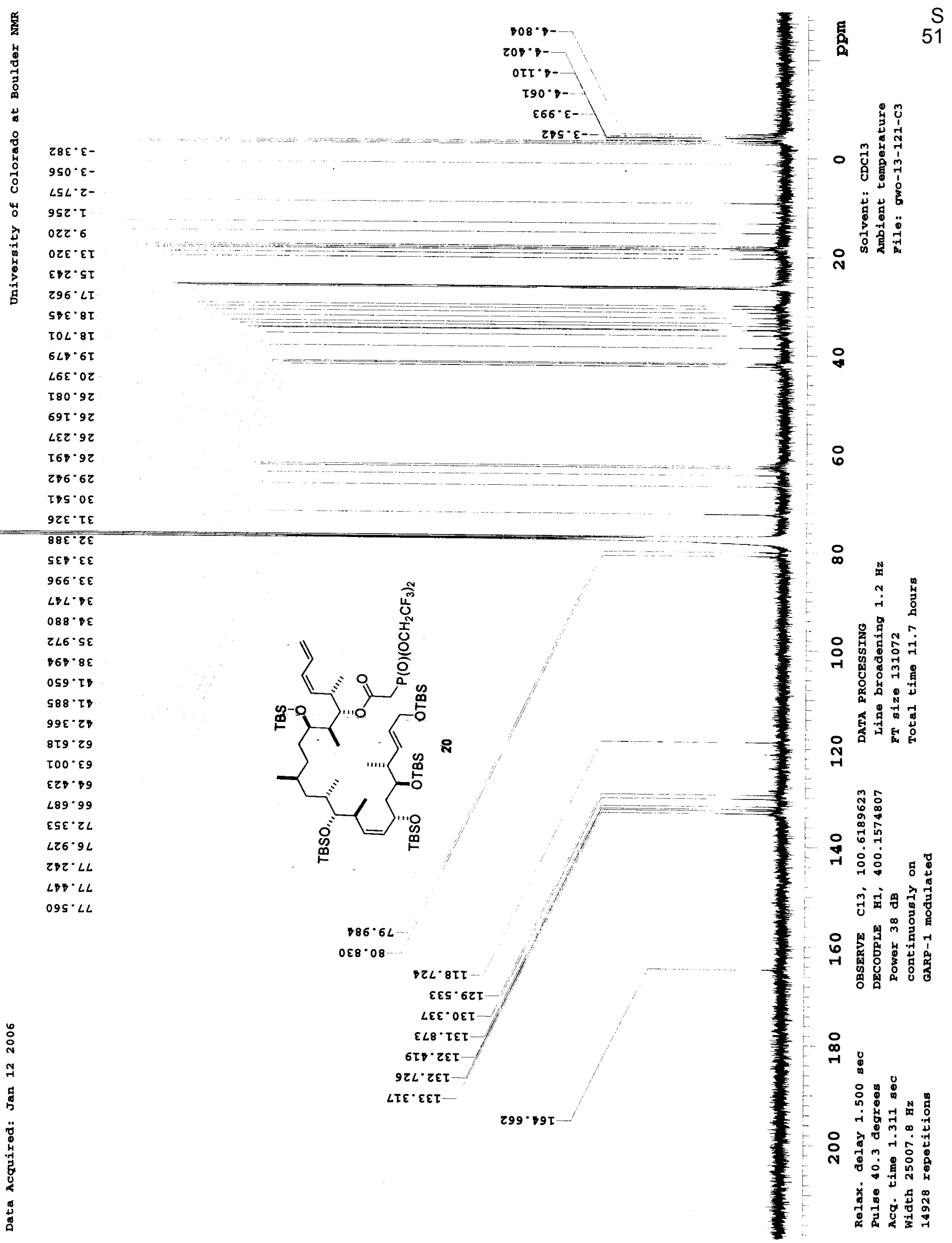




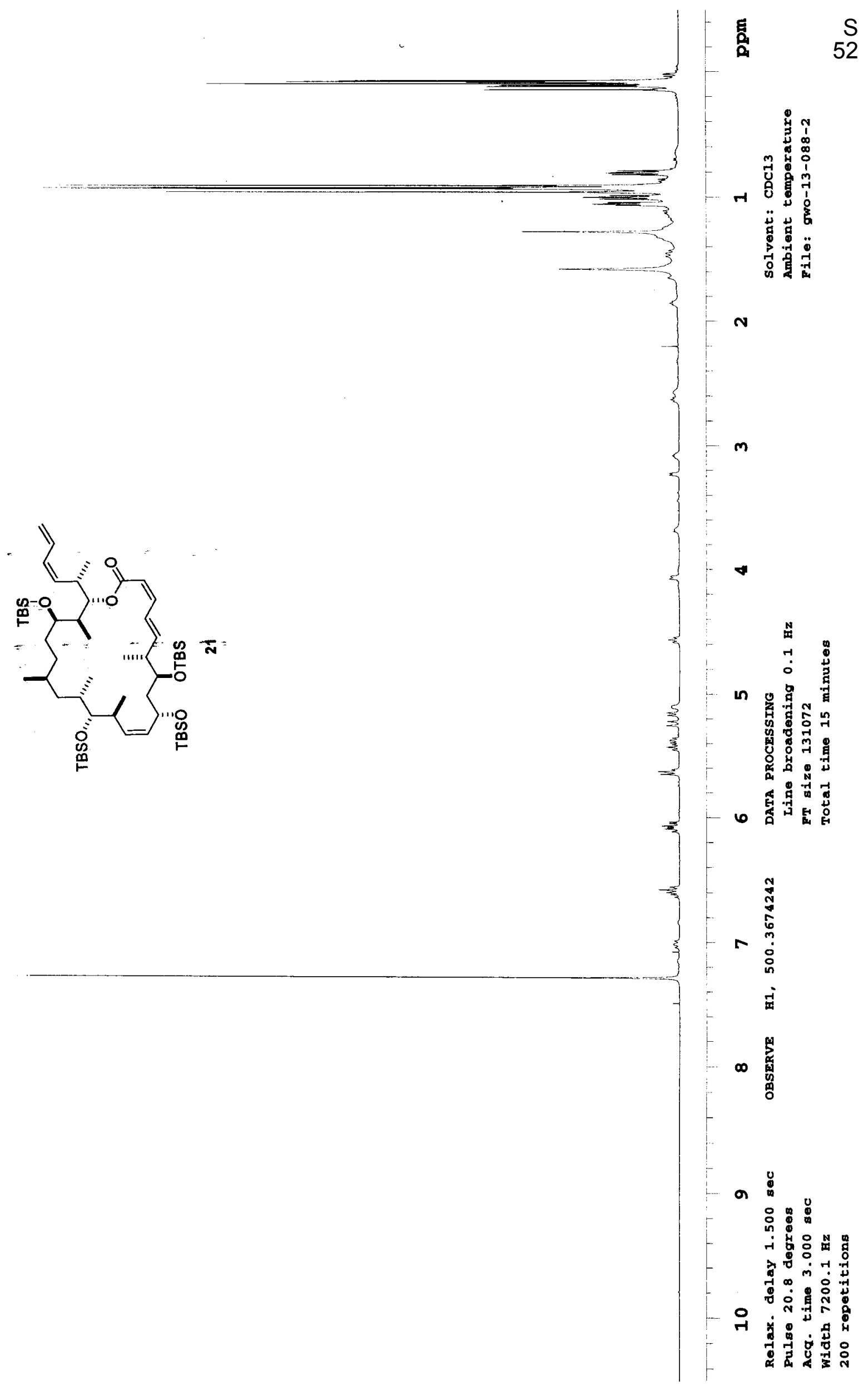




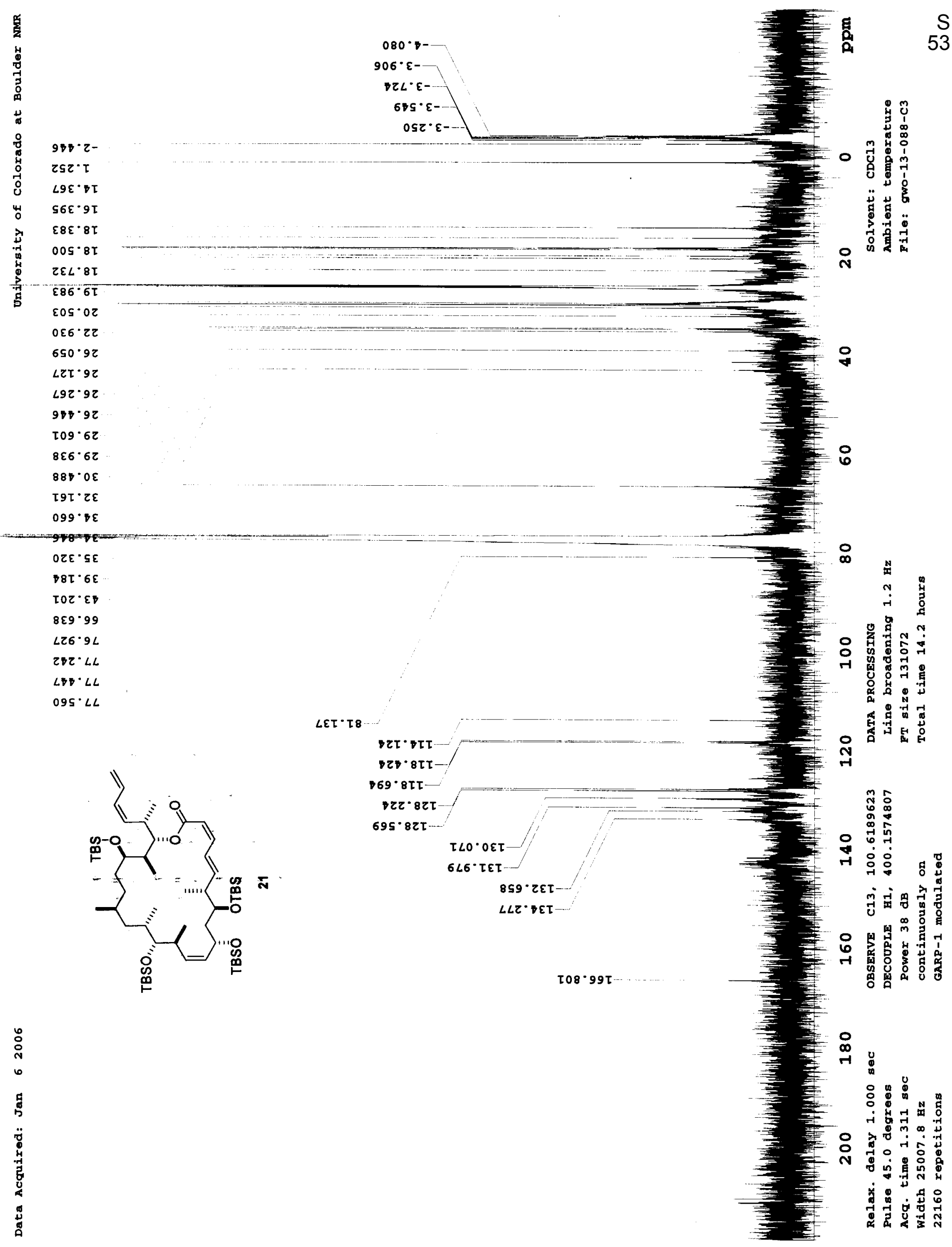




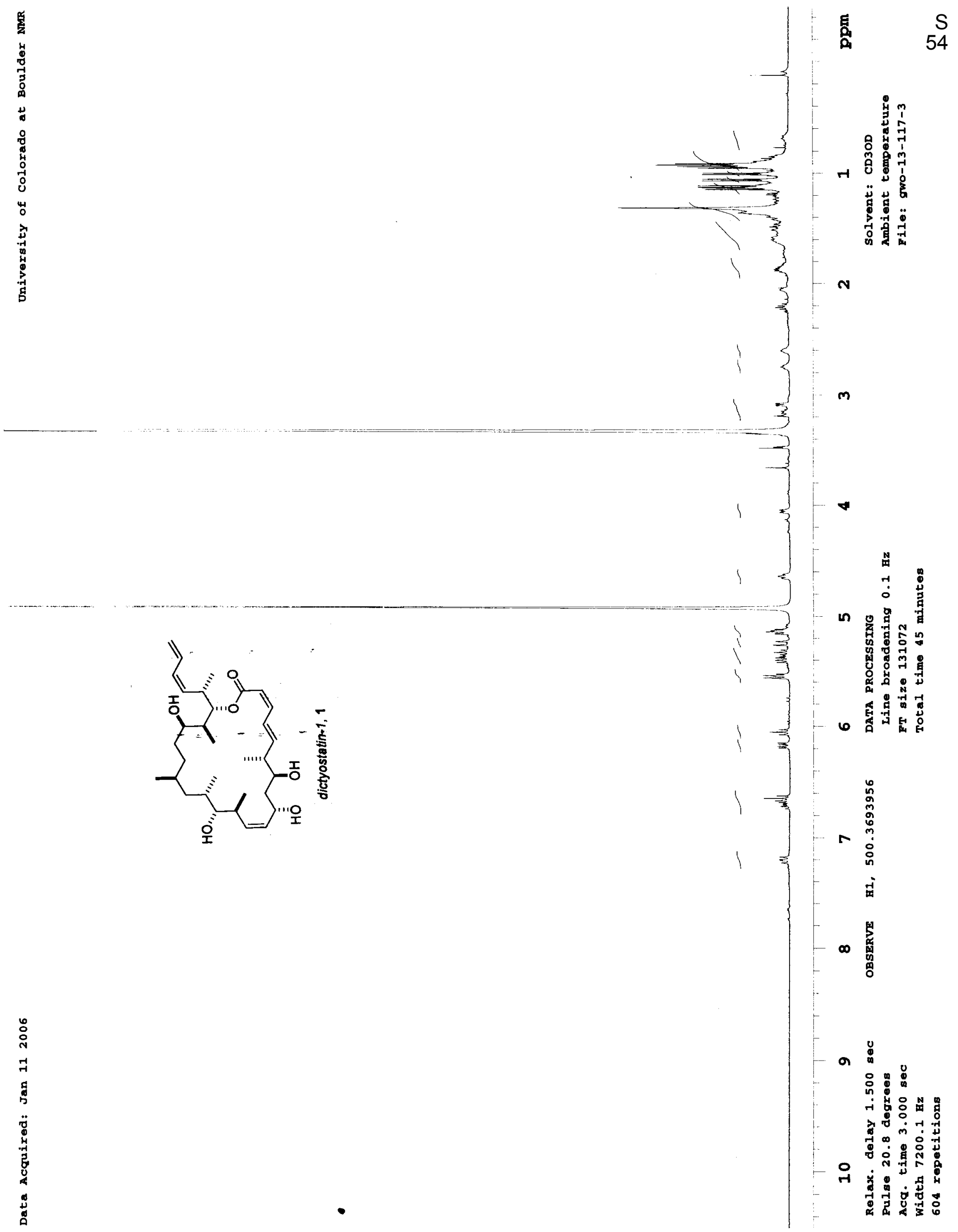

